\title{
Exploration of Work Zone Crash Causes and Implications for Safety Performance Measurement Programs
}

A Thesis
Presented to
The faculty of the School of Engineering and Applied Sciences
University of Virginia
In Partial Fulfillment
of the requirements for the Degree
Master of Science (Civil Engineering)
By
Jacquelyn Bray Clark
December 2014




\begin{abstract}
APPROVAL SHEET
This thesis is submitted in partial fulfillment of the requirements for the degree of

Masters of Science (Civil Engineering)

Jacquelyn Bray Clark
\end{abstract}

This thesis has been read and approved by the Examining Committee:

Dr. Michael D. Fontaine, Thesis Advisor

Dr. Brian Smith

Dr. John Miller

Accepted for the School of Engineering and Applied Sciences:

Dean, School of Engineering and Applied Sciences

December 2014 


\section{ACKNOWLEDGEMENTS}

I would like to use this opportunity to express my gratitude to everyone who supported me throughout the course of my M.S. degree. I am thankful for their aspiring guidance, invaluably constructive criticism, and friendly advice. I am sincerely grateful to them for sharing their truthful and illuminating views on a number of issues related to my course studies and research.

Foremost, I would like to express my sincere gratitude to my advisor Dr. Michael D. Fontaine for his continuous support, patience, motivation, enthusiasm, and immense knowledge throughout my M.S. study and research. I could not imagine having a better professor, advisor, and mentor. 


\begin{abstract}
Police crash reports are a fundamental data source for state work zone safety performance measurement programs. Past studies have often identified work zone crashes simply based on their location, and have not considered the causal role (if any) that the work zone played in the crash. This thesis identified crashes directly influenced by a work zone ("Directly Related" crashes) from a dataset of all crashes that were reported as occurring in a work zone ("Coded" crashes). This was done to assess the degree to which work zone activities appeared to actually influence the likelihood or severity of crashes within the work zone.
\end{abstract}

Data was obtained from Virginia crash reports as well as the National Highway Traffic Safety Administration's (NHTSA) National Motor Vehicle Crash Causation Survey (NMVCCS) and Large Truck Crash Causation Study (LTCCS). Work zone crash reports were examined individually, and crash causal trends were identified within each dataset. The process of extracting Directly Related crashes and determining work zone crash causality from typical DOT databases (including Virginia's) is time-consuming and imprecise. In contrast, data obtained from the NMVCCS and LTCCS is more precise due to the studies' high level of detail. However, extracting necessary crash information from a NMVCCS or LTCCS crash report takes approximately 15 times longer than a Virginia crash report.

The study found that there is a disparity between Coded crashes and Directly Related crashes. Only $23.0 \%, 53.8 \%$, and $73.8 \%$ of the Virginia, NMVCCS, and LTCCS Coded crashes, respectively, could be directly related to the work zone. Implications of 
the differences between Coded and Directly Related crashes on work zone safety performance measures are discussed.

Several work zone crash causes in each of the four primary crash types (rear-end, angle, sideswipe - same direction, and fixed object - off road) were common across all datasets. Analysis identified several potential avenues where work zone safety performance measures could be influenced by the Virginia Department of Transportation (VDOT), including improved work zone traffic management planning, ingress/egress design, and traffic control placement.

Datasets' analytical results were compared between the Virginia dataset and the NMVCCS and LTCCS datasets in order to determine if Virginia crash reports contained enough work zone related crash information in order to effectively and accurate develop crash trends and performance measures. This thesis found that Directly Related crash type proportions and crash cause proportions significantly varied between the Virginia dataset and the NMVCCS and LTCCS datasets. These differences are most likely the result of different levels of crash detail between the Virginia dataset and the NMVCCS/LTCCS datasets. Improvements to the Virginia crash forms are recommended in order to more accurately identify Directly Related crashes and their causes. 


\section{TABLE OF CONTENTS}

ACKNOWLEDGEMENTS iii

ABSTRACT

LIST OF TABLES $\quad$ ix

$\begin{array}{lc}\text { LIST OF FIGURES } & \text { x }\end{array}$

CHAPTER 1: INTRODUCTION 1

$\begin{array}{ll}\text { 1.1 Objectives and Scope } & 4\end{array}$

$\begin{array}{lr}\text { 1.2 Thesis Organization } & 5\end{array}$

CHAPTER 2: LITERATURE REVIEW 6

$\begin{array}{ll}\text { 2.1 Work Zone Crash Characteristics } & 7\end{array}$

$\begin{array}{ll}2.1 .1 \text { Crash Severity } & 8\end{array}$

\begin{tabular}{l} 
2.1.2 Crash Type \\
\hline
\end{tabular}

$\begin{array}{lr}\text { 2.1.3 Crash Location within Work Zone } & 10\end{array}$

$\begin{array}{lr}2.1 .4 \text { Vehicle Type } & 12\end{array}$

$\begin{array}{lr}2.1 .5 \text { Speeds } & 14\end{array}$

2.1.6 Roadway Characteristics and Geometry 14

$\begin{array}{ll}\text { 2.1.7 Lighting Condition and Time of Day } & 15\end{array}$

2.2 Work Zone Fatal Crash Causation $\quad 16$

2.2.1 Crashes Directly Influenced by the Work Zone 17

2.2.2 Crashes Indirectly Influenced by the Work Zone 17

2.2.3 Crashes Not Influenced by the Work Zone 17

$\begin{array}{lr}\text { 2.2.4 Study's Conclusions } & 18\end{array}$

$\begin{array}{lr}\text { 2.3 Work Zone Performance Measures } & 18\end{array}$

$\begin{array}{lr}\text { 2.3.1 Performance Measures and Exposure Rates } & 18\end{array}$

2.3.2 Performance Measures Targeted at Crash Causal Trends $\quad 19$

2.3.3 Crash Data Real-Time Availability and Accessibility 19

$\begin{array}{lr}\text { 2.4 Literature Review Summary } & 20\end{array}$

CHAPTER 3: METHODOLOGY 23

$\begin{array}{lr}\text { 3.1 Data Overview } & 23\end{array}$

$\begin{array}{ll}3.1 .1 \text { Virginia Dataset } & 24\end{array}$

3.1.2 National Motor Vehicle Crash Causation Survey (NMVCCS) Dataset 24

3.1.3 Large Truck Crash Causation Study (LTCCS) Dataset 25

3.2 Comparison of Available Data Elements within each Dataset 26

3.3 Analysis Methodology $\quad 29$

$\begin{array}{lr}3.3 .1 \text { Terminology } & 30\end{array}$

$\begin{array}{ll}\text { 3.3.2 Determination of Coded Crashes } & 31\end{array}$

3.3.3 Determination of Directly Related, Possibly Related, and Not Related Crashes 31

3.3.4 Determination of Crash Cause $\quad 33$ 
$\begin{array}{lr}\text { 3.4 Virginia Crash Examples } & 34\end{array}$

$\begin{array}{ll}\text { 3.4.1 Virginia Examples } & 34\end{array}$

3.4.1.1 Virginia Directly Related Example \#1 35

3.4.1.2 Virginia Unknown Relationship Example \#2 35

3.5 NMVCCS and LTCCS Crash Examples $\quad 36$

3.5.1 NMVCCS - Directly Related Example $\quad 37$

$\begin{array}{ll}\text { 3.5.2 LTCCS Directly Related Example } & 41\end{array}$

3.5.3 NMVCCS Not Related Example $\quad 45$

CHAPTER 4: VIRGINIA DATA ANALYSIS

4.1 Virginia High-Level Comparisons $\quad 52$

4.1.1 Virginia Crashes by Roadway and Crash Type $\quad 52$

$\begin{array}{ll}\text { 4.1.2 Virginia Work Zone Types } & 54\end{array}$

\begin{tabular}{l} 
4.2 Virginia Work Zone Causal Factors \\
\hline
\end{tabular}

$\begin{array}{lr}\text { 4.2.1 Virginia Rear-end Crashes } & 57\end{array}$

$\begin{array}{lr}\text { 4.2.2 Virginia Angle Crashes } & 59\end{array}$

$\begin{array}{ll}\text { 4.2.3 Virginia Sideswipe - Same Direction } & 60\end{array}$

4.2.4 Virginia Fixed Object Off Road Crashes $\quad 61$

4.2.4.1 Virginia Fixed Object - Off Road First Object Hit 63

4.2.5 Virginia Work Zone Vehicles $\quad 64$

$\begin{array}{lr}\text { 4.3 Virginia Data Summary } & 65\end{array}$

CHAPTER 5: NMVCCS AND LTCCS DATA ANALYSIS 67

5.1 NMVCCS \& LTCCS High-Level Comparisons $\quad \mathbf{6 8}$

5.1.1 NMVCCS and LTCCS Crashes by Roadway and Crash Type 68

5.1.2 NMVCCS and LTCCS Work Zone Type $\quad 71$

5.1.3 NMVCCS and LTCCS Crash Severity 73

\begin{tabular}{l} 
5.2 NMVCCS Work Zone Causal Factors \\
\hline 44
\end{tabular}

$\begin{array}{ll}\text { 5.2.1 NMVCCS Rear-end Crashes } & 75\end{array}$

$\begin{array}{ll}\text { 5.2.2 NMVCCS Angle Crashes } & 76\end{array}$

5.2.3 NMVCCS Sideswipe - Same Direction $\quad 77$

5.2.4 NMVCCS Fixed Object Off Road Crashes $\quad 77$

5.2.5 NMVCCS Fixed Object - Off Road First Object Hit 78

$\begin{array}{lr}\text { 5.3 LTCCS Work Zone Causal Factors } & 79\end{array}$

$\begin{array}{ll}\text { 5.3.1 LTCCS Rear-end Crashes } & 79\end{array}$

$\begin{array}{lr}\text { 5.3.2 LTCCS Angle Crashes } & 80\end{array}$

$\begin{array}{ll}\text { 5.3.3 LTCCS Sideswipe - Same Direction } & 80\end{array}$

5.3.4 LTCCS Fixed Object Off Road Crashes $\quad 81$

5.4 NMVCCS and LTCCS Work Zone Vehicles Crash Involvement 81

$\begin{array}{lr}\text { 5.5 NMVCCS Possibly Related Crashes } & 83\end{array}$ 


\section{CHAPTER 6: COMPARISON OF FINDINGS BETWEEN VIRGINIA DATA AND NMVCCS/LTCCS DATASETS

$\begin{array}{ll}\text { 6.1 High-Level Comparison of Findings } & \mathbf{8 7}\end{array}$

6.1.1 Distribution of Crash Types within KABC Coded Crashes 88

6.1.2 Distribution of Crash Types within KABC Directly Related Crashes 90

6.1.3 Distribution of KABC Coded Crashes Identified as KABC Directly Related Crashes 91

6.1.4 Distribution of KABC Cause of Crash 92

6.2 Similarities Among Datasets $\quad 94$

6.2.1 Work Zone Crash Causes for All Severity Levels 94

6.2.2 First Object Hit: Jersey Barriers for All Severity Levels 95

6.2.3 Work Zone Vehicles for All Severity Levels 95

6.3 Differences Among Datasets $\quad 96$

6.3.1 Work Zone Crash Causes for All Severity Levels 96

$\begin{array}{lr}\text { 6.4 Summary of Differences } & 98\end{array}$

CHAPTER 7: CONCLUSIONS AND RECOMMENDATIONS 100

$\begin{array}{ll}7.1 \text { Conclusions } & 100\end{array}$

7.2 Recommendations $\quad 103$

7.2.1 Major Work Zone Crash Causes and Possible VDOT Corrective Actions 103

7.2.2 Recommended Changes to the Virginia FR-300 Crash Report to Improve Work Zone Crash Analysis and Reporting $\quad 107$

$\begin{array}{ll}\text { 7.2.2.1 Work Zone's Influence Field } & 108\end{array}$

7.2.2.2. Identify "Work Zone Crash Causality" 111

7.2.3 Recommendations for Future Research 113

REFERENCES 116 


\section{LIST OF TABLES}

Table 3.1: Summary of Relevant Crash Report Data Fields by Dataset

Table 4.1: Summary of Crashes by Roadway and Crash Type, 2011-2012

Table 4.2: Crash Type vs. Work Zone Type (Directly Related Crashes)

Table 4.3: Summary of Crash Causes Directly Related to Work Zone Presence 56

Table 4.4 Location/Action of Work Zone Vehicles Involved in Crashes $\quad \mathbf{6 5}$

Table 5.1: NMVCCS \& LTCCS Summary of Crashes by Roadway and Crash Type, 2011-2012 70

Table 5.2: NMVCC \& LTCCS Work Zone Type (Directly Related Crashes) 72

Table 5.3: NMVCCS Work Zone Type Distributions (Directly Related Crashes)

Table 5.4: NMVCCS \& LTCCS Severity Level of Directly Related Crashes $\quad 74$

Table 5.5: NMVCCS Summary of Crash Causes Directly Related to Work Zone Presence 75

Table 5.6: NMVCCS \& LTCCS Location/Action of Work Zone Vehicles Involved in Crashes $\quad \mathbf{8 2}$

Table 6.1: Chi-Square Distribution Tests for KABC Crashes $\quad 89$

Table 6.2: Coded and Directly Related KABC Crash Type Distributions (Number of crashes shown in $\begin{array}{lr}\text { parentheses) } & 90\end{array}$

Table 6.3: Cause of Crash Distributions (number of crashes shown in parentheses) $\quad 93$

Table 6.4: Virginia and NMVCCS Crash Cause Distributions for All Severity levels 97

Table 7.1: Summary of Significant Crash Causes Across Crash Types $\quad 104$ 


\section{LIST OF FIGURES}

Figure 2.1: Work Zone Fatality Trends in the United States (FARS, 2014) 6

Figure 2.2: Component Areas of a Highway Work Zone (MUTCD, 2003, Figure 6C-1) 11

Figure 3.1: NMVCCS Directly Related Crash Diagram 39

Figure 3.2: NMVCCS Approach View of Vehicle Turning 4

Figure 3.3: NMVCCS Approach View of Vehicle Traveling Straight 4

Figure 3.4: LTCCS Directly Related Crash Diagram

Figure 3.5: Location of Crash at a Congested Time 43

Figure 3.6: Location of Crash at Non-Congestion Time 44

Figure 3.7: NMVCCS Not Related Crash Diagram $\quad 4 \mathbf{4 8}$

Figure 3.8: Picture of Intersection After Crash was Cleared 4

Figure 3.9: Picture of Intersection at Time of Crash 44

Figure 5.1: May Be Directly Related Angle Crash $\quad \mathbf{8 4}$ 


\section{CHAPTER 1: INTRODUCTION}

While transportation agencies have always been concerned about work zone safety, there has recently been an increased emphasis on the development of formal performance measurement and monitoring programs. The motor-vehicle infrastructure in the United States is growing older, and the number of active work zones is increasing to address growing maintenance and reconstruction needs. For example, there were between 6,500 and 7,200 work zones covering $20-27 \%$ of the National Highway System during the summers of 2002 and 2003 (FHWA, 2013A). In 2013, 547 fatal motor-vehicle crashes occurred within a work zone in the United States (FARS, 2014). As vehicle miles traveled (VMT) increases, motor-vehicle infrastructure ages, and the number of active work zones grows, it becomes increasingly imperative to identify common trends in work zone related crashes in order to develop appropriate counter measures to improve safety.

While all states and agencies agree on the importance of targeted performance measures, the performance measures used to assess safety within a work zone vary widely from state to state. The Federal Highway Administration (FHWA) (Ullman et al., $2011 \mathrm{~A}$ ) recently produced a primer that suggests several measures that could be used as work zone safety performance measures, including:

- Number of fatal crashes per year or per project broken down by fatal, injury, and property damage only (PDO) crashes.

- Percent crashes of certain types such as manner of collision (e.g., rear-end crashes), contributing factors (e.g., DUI crashes, speeding). 
- Percent change in crash rate or absolute change from the expected no-work zone crash rate; possibly stratified by roadway, work zone type, or severity.

- Percent of projects that exceed an acceptable (pre-defined) crash rate in the work zone.

- Percent change in work zone crash costs from the expected no-work zone crash costs, using monetized crashes based on severity level

- Number of highway worker injuries or worker injury rate per hours worked.

- Work zone inspection scores.

- Number of work zone inspections performed.

- Frequency or change in frequency of service patrol or fire department dispatches to a work zone.

While FHWA recommends several options, most states' work zone performance measures are limited to monitoring crash frequency and/or number of fatal crashes within a work zone (Ullman et al., 2011A). A FHWA scan (Bourne et al., 2010) of 15 state departments of transportation (DOTs) found that the most common performance measure used by agencies is crash frequency, while few agencies measure specific crash severities or crash types. Even so, many of these agencies felt that without normalizing information (e.g. number of work zone hours or work zone traffic volumes), year-to-year changes in crash frequency are not very meaningful and are difficult to use when diagnosing safety problems (Ullman et al., 2011B; Bourne et al., 2010). Further, delays in crash data entry make real time assessments of work zone safety difficult (Bourne et al., 2010).

While it is preferable to base work zone safety assessments on performance 
measures that are not subject to inherent random year-to-year fluctuations (e.g., crash frequency), the integrity of any work zone crash performance measure may be compromised when work zone crashes are not clearly and accurately defined and recorded. Each state's DOT classifies a work zone crash differently. Some states' DOTs, including Massachusetts (Swansen et al., 2012) and Kentucky (Pigman, 1990), empower the responding police officer to determine the relationship between the crash and the work zone. However, many states, including Virginia $(D M V, 2014)$, define any crash occurring within a work zone temporary traffic control area as being related to the work zone. The Manual on Uniform Traffic Control Devices (MUTCD) defines a work zone area as stretching "from the first warning sign or high-intensity rotating, flashing, oscillating, or strobe lights on a vehicle to the END ROAD WORK sign or the last [Temporary Traffic Control] TTC device" (Federal Highway Administration, 2003). Thus, these states' DOTs define a work zone crash based on its physical location, not the role that the work zone played in the crash.

This definition's major flaw is that not all crashes occurring in a work zone are actually influenced by the work zone. For example, a deer crash that occurs within the work zone limits may be categorized as a work zone crash even if the work zone did not play a significant causal role in the crash. Thus, the basic definition of a work zone crash has the potential to skew any crash-based analysis or performance measures that are developed. Identification of crashes directly influenced by the work zone is needed in order to develop useful performance measures and identify methods to improve work zone safety. 


\subsection{Objectives and Scope}

The objectives of this study are to:

1. Review Virginia crash report narratives in order to identify if the work zone influenced the likelihood or severity of a crash,

2. Identify the major factors that contributed to crashes influenced by the work zone and the chain of events that led to the crash in Virginia,

3. Contrast the causal factors using Virginia data with other more detailed crash datasets

4. Using this information, identify areas where DOTs should invest greater resources in work zone planning and safety, and

5. Determine if current Virginia crash reports provide sufficient work zone related information to develop effective countermeasures and reliable performance measures, and recommend possible improvements to work zone crash data collection processes.

This paper will focus on crash causes that a DOT could potentially address, since these causal factors would be the most relevant to a performance measurement program. This information will allow DOTs to more effectively invest their resources in work zone planning and safety, as well as help illuminate the degree to which the work zone influences crashes within the temporary traffic control area.

The scope of this research is limited to examination of crash data. Data on work zone frequency, vehicle miles of travel, and other exposure measures are not explicitly considered. 


\subsection{Thesis Organization}

This thesis begins by discussing previous work zone safety literature in Chapter 2 . Previous studies' findings and potential shortcomings are discussed in this chapter. The need for additional research is also identified. Chapter 3 outlines the methodology used to conduct this thesis' data collection and analysis. This is followed by Chapter 4, which discusses the analytical results obtained using Virginia crash reports. Chapter 5 continues by performing similar data analysis, but for data obtained from the National Motor Vehicle Crash Causation Survey (NMVCCS) dataset (NASS, 2014A) and the Large Truck Crash Causation Study (LTCCS) dataset (NASS, 2014B). Both of these datasets are collect by the National Highway Traffic Safety Administration's (NHTSA) National Automotive Sampling System (NASS). Chapter 6 compares the analytical results obtained from the Virginia crash reports to those obtained from the NMVCCS and LTCCS. Finally, Chapter 7 highlights the major conclusions drawn from conducting and comparing each datasets' analysis. The chapter also recommends areas where a DOT should focus efforts to improve work zone safety. The chapter concludes by recommending changes to the current Virginia crash report in order to improve data collection accuracy and reduce processing/analysis time. 


\section{CHAPTER 2: LITERATURE REVIEW}

Numerous studies have characterized the risk factors associated with roadway crashes and safety. Regulatory and advisory documents such as the Manual on Uniform Traffic Control Devices (MUTCD) (Federal Highway Administration, 2003), and the American Association of State Highway and Transportation Officials (AASHTO) Green Book (2011) provide guidance for engineers to develop safer roadways. A constant area of concern in roadway safety is work zone related crashes. The chart below illustrates the number of fatal crashes per year within work zones in the United States. This information was obtained from the Fatality Analysis Reporting System (FARS) (2014). Comparing the number of yearly work zone fatal crashes to the total number of fatal crashes per year indicates that approximately $2.1 \%$ of fatal crashes in the United States are work zone related.

Figure 2.1: Work Zone Fatality Trends in the United States (FARS, 2014)

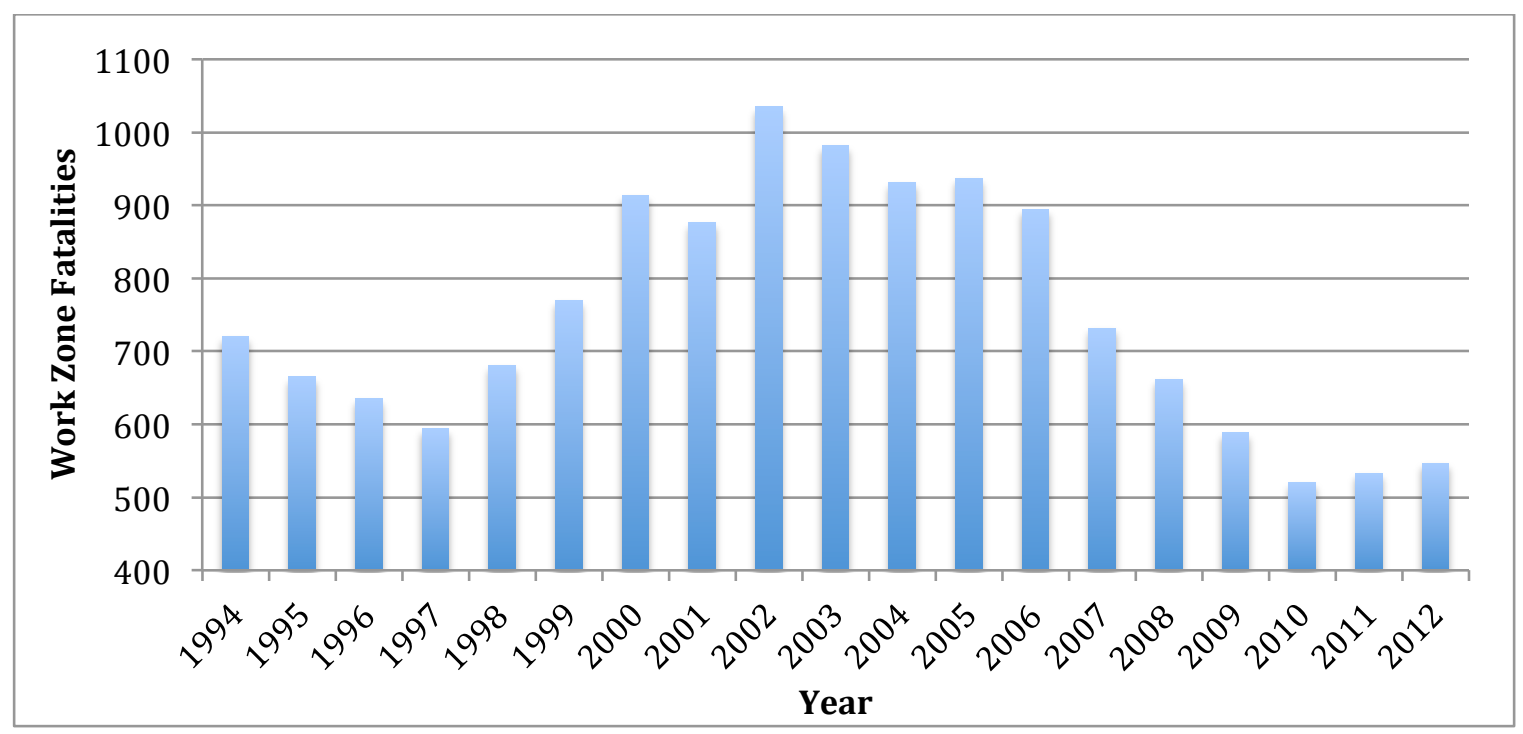


Walker et al. (1999), found similar results in Arizona for work zone accidents occurring between 1992-1996. Work zone accidents comprised approximately $2.9 \%$ of total accidents. Studies performed by Khattak et al. (2002) and Ullman et al. (1991) in California and Texas, respectively, concluded that crash frequencies increased significantly when a work zone was implemented. Crash rates on California limitedaccess highways increased $21.5 \%$ during work zone periods (Khattak et al., 2002) while crash rates in Texas for work zones erected between 1984-1988 experienced a 28.7\% increase (Ullman et al., 1991).

Ullman et al.'s (2008) study went a step further and developed crash modification factors (CMFs) using an empirical Bayes analysis for the effect on crash frequency due to the work zone's presence. The study developed CMFs for different scenarios including: active and inactive, and lane and no lane closure work zones. The all severity level CMFs developed for daytime freeway crashes were:

- $\mathrm{CMF}=1.13$ - Work Zone present but not active, No Lane Closure,

- $\mathrm{CMF}=1.31$ - Active Work Zone, No Lane Closure, and

- $\mathrm{CMF}=1.66-$ Active Work Zone, Lane Closure.

\subsection{Work Zone Crash Characteristics}

All of the studies mentioned so far indicate that work zones increase the total number of crashes experienced at a site relative to non-work zone conditions. In an effort to determine how and why work zones cause an increase in crash rates, characteristics of work zone crashes have been studied over the last several decades. The more recent studies available utilize a variety of analysis methods. In order to better understand the 
causes behind increases in crashes, this chapter examines work zones' effect on several aspects of crash occurrence. Severity level, vehicle type, crash type, crash location in work zone, influence of speeds, effect of lighting condition and time of day, and influence of roadway characteristics and geometry are reviewed. It is important to note that all of these studies used crash reports that indicated that the crash occurred in a work zone during analysis. They did not identify and extract crashes influenced by the work zone from those that were unrelated to the work zone's presence.

\subsubsection{Crash Severity}

There are contradictory findings about a work zone's effect on crash severity. Pigman et al. (1990) concluded that for work zones in Kentucky between 1983-1986, the proportion of injury and fatal accidents increases when a work zone is implemented by $6.1 \%$ of the total number of crashes while the proportion of property damage only (PDO) crashes decreases by the same proportion. On the other hand, Swansen et al. (2012) found that work zones in Massachusetts between 2007-2009 experienced very little change in severity proportions. Studies conducted in California, Arizona, Alabama, Michigan, Tennessee, Texas, and Wisconsin studying crash data from between 1984-2004 concluded that the proportion of severe (injury and fatal) accidents decreases when a work zone is implemented by between $1-6 \%$ of the total number of crashes while the proportion of PDO crashes increases by the same amount (Khattak et al., 2002; Ullman et al., 1991; Lindly et al., 2000).

These contradictory findings may be the result each studies' data collection methods. Pigman et al. (1990) took data from 20 case studies in Arizona. The study collected crash rates and trends during work activity and compared it to crash rates and 
trends before the work zones were implemented. Swansen et al. (2012) only considered work zone crashes involving an issued citation. Khattak et al. (2002) examined crashes occurring in 36 California freeway work zone projects in 1993. Their study obtained information about each work zone's length and duration and used this information to normalize their crash analysis. Ullman et al. (1991) study only considered 5 long-term work zone projects in Texas. Lindly et al. (2000) examined all work zone crash occurring across a 1-4 year period (depending on availability in each state) in Alabama, Michigan, and Tennessee. Therefore, the variability between studies' data collection methods is most likely the reason for the contradictory findings between studies.

\subsubsection{Crash Type}

While results vary from study to study, most studies agree that rear-end crashes increase during the work zone as compared to non-work zone conditions (Rouphail et al., 1988; Swansen et al., 2012; Pigman et al., 1990; Antonucci et al., 2005; Daniel et al., 2000). The increase in the proportion of rear-end crashes ranges from $40.2 \%$ (Swansen et al., 2012) to 169\% (Antonucci et al., 2005) in these studies. Further, two studies (Rouphail et al.,1988; Antonucci et al., 2005) found that non-rear-end crash proportions decreased due to the large increase in rear-end crashes. Daniel et al. (2000) concluded that the proportion of head-on and rear-end collisions both increased. Pigman et al. (1990) observed an increase in the proportion of same direction sideswipe crashes.

Lindly et al. (2002) attributed the increase in rear-end collisions to a decrease in mean time headway. This study used data from five work zones in Alabama and found that for all work zones considered, mean vehicle speed decreased, level of service (LOS) of the roadway decreased, speed standard deviations entering the work zone increased, 
and density increased. Further, the percentage of vehicles below an unsafe time headway (2.5 seconds) ranged from $43 \%$ - 64\% for work zones while non-work zones exhibited a range of $30.5 \%-44 \%$. Two of the five work zones considered in this study reduced the number of lanes from two lanes to one lane. For these two work zones, decreased speeds and shorter headways were most likely the result of congestion caused by roadway capacity reduction. The other three work zones considered in the study narrowed the adjacent lane but did not reduce the number of lanes. Narrowed lane widths can also reduce roadway capacity by causing traffic to slow. Therefore, this study links the increase in rear-ends to reduced speeds, reduced headways, and increased congestion.

Conversely, a 2008 study by Ullman et al. found that all crash type distributions stayed approximately the same during work zone conditions (+/- 6\%) as compared to non-work zone conditions. This study's dataset was the most robust of the studies considered and included 64 work zone projects, more than 17,000 crashes, 465 centerline-mi of roadway, and over 82 years of combined work.

\subsubsection{Crash Location within Work Zone}

Most work zones, or temporary traffic control (TTC) zones, are divided into four areas: the advance warning area, the transition area, the activity area, and the termination area. The MUTCD (2003) contains official definitions of these zones and illustrates them in a Figure 6C-1 re-represented in this paper as Figure 2. These four work zone areas are defined in Sections 6C.04 through 6C.07 in the MUTCD (2003). 
Figure 2.2: Component Areas of a Highway Work Zone (MUTCD, 2003, Figure 6C-1)

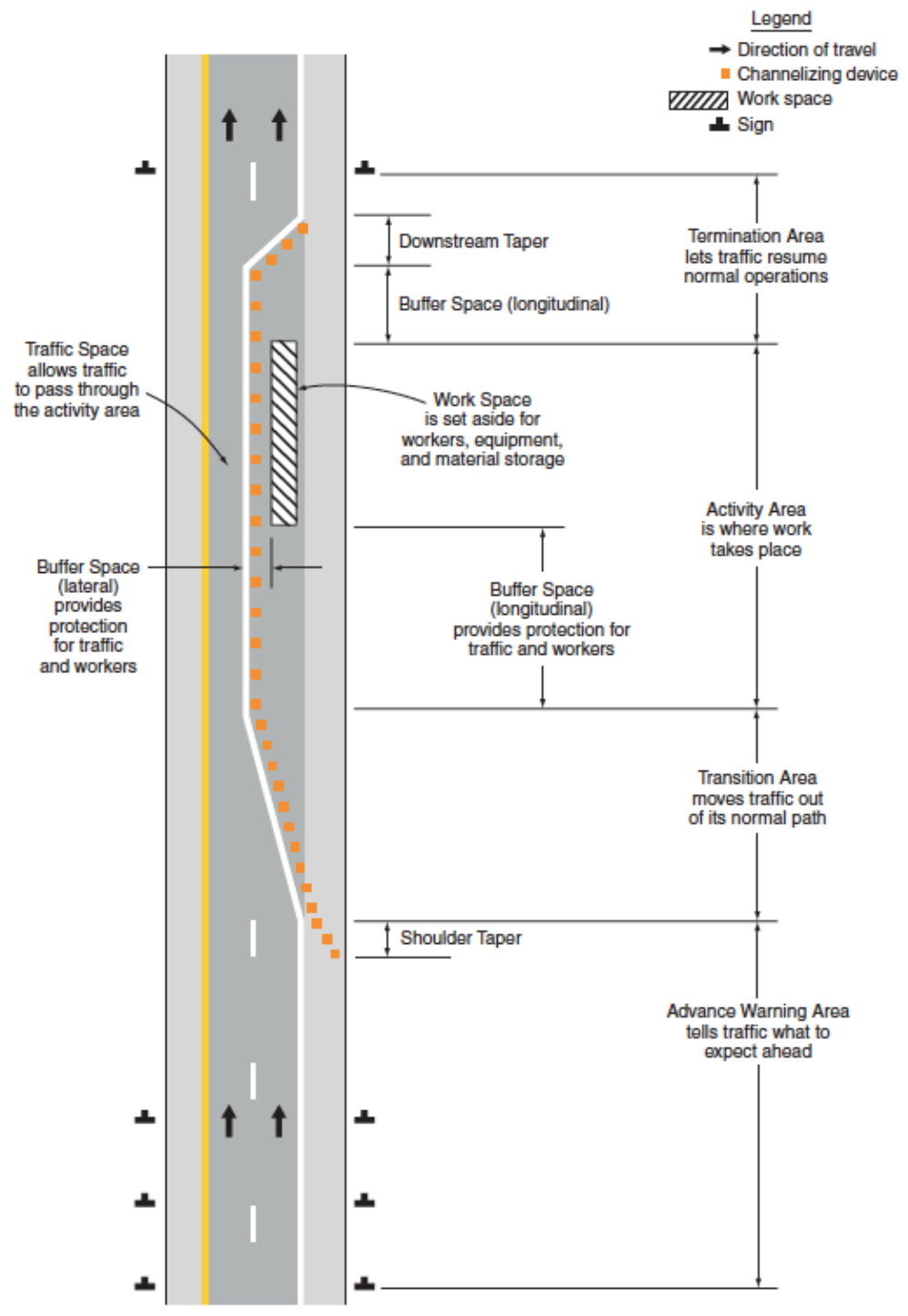

Several studies determined that the largest proportion of crashes take place in the activity area (Pigman et al., 1990; Akepati et al., 2011; Garber et al., 2002; Schrock et al., 2004; Qin et al., 2007). Pigman et al. (1990), Akepati et al. (2011), Garber et al. (2002), and Schrock et al. (2004) also found that the transition area experienced the second largest proportion of crashes while Qin et al. (2007) found that the advanced warning area experienced the second largest proportion. The studies cannot agree which area experiences the lowest number of crashes. While these studies produce general 
trends, they do not target the factors that cause activity area to experience the largest number of crashes and the termination area to experience the lowest level of crashes. Further, the number of crashes is most likely dependent on the layout of the work zone, which differs from work zone to work zone. It is important to note that the lengths associated with each area of the work zone vary. Activity areas could be a couple hundred feet or 20 miles long. Conversely, transition areas are typically much shorter, ranging from 50 to 1000 feet. Therefore, unless normalized by length, activity area crashes are probably overrepresented in many studies' analyses.

\subsubsection{Vehicle Type}

Hughes et al. (1999), Harb et al. (2008), and Lindly et al. (2000), found differing results while examining work zones' influence on truck crash frequency. Hughes et al. (1999) found that work zone crashes involving trucks comprised $1-4 \%$ of total truck crashes in North Carolina during 1993-1997. The most prominent type of collision was a rear end collision ( $37 \%$ of the time) followed by a head-on collision ( $21 \%$ of the time). Further, while Interstates account for only 20-21 percent of the total number of fatal large truck involved crashes, two thirds of all fatal truck-involved crashes, which occurred in work zones, occurred on Interstates.

Harb et al. (2008) studied work zone related crashes in Florida between 20022004 and concluded that trucks and large trucks are $44.6 \%$ more likely to be involved in a work-zone single-vehicle crash compared to non-work-zone locations. Lindly et al. (2000) examined the types of vehicle crashes involved in work zone crashes across Alabama, Michigan, and Tennessee from 1994-1997 and found that in each state the proportion of crashes in work zones involving trucks increased for all types of trucks as 
compared to the proportion of crashes in non-work zones. However, for both studies (Harb et al., 2008; Lindly et al., 2000), work zone related crashes for passenger cars and light trucks composed the largest majority (64\%-93\%) of all crashes while truck related crashes ranged from $8 \%-14 \%$ for work zones and $4 \%-7 \%$ for non-work zones.

Daniel et al. (2000) examined the effect of work zones on truck crash severity levels. The study concluded that trucks were responsible for a significantly higher proportion of work zone fatal crashes in Georgia between 1995-1997 than at non-work zone locations. The study found that 13 percent of the fatal crashes at non-work zone locations involved trucks as compared with 20 percent in work zones.

Khattak et al. (2004) investigated the relationship between severity level and speed for work zone crashes involving trucks. Their study compared crash frequency between work zones with differing characteristics. They did not compare work zone crash frequency to non-work zone crash conditions. The study found that as posted speed limit increased, the probability of a fatal or injury crash caused by a truck at the work site increased. Logically, this makes sense because at higher speeds the amount damage caused by a truck during a crash increases. The authors did not extrapolate this result to other types of vehicle crashes.

Thus, these studies indicate that large truck crashes tend to be overrepresented in work zones. This may imply that work zones affect truck crash frequency more than other vehicle types, particularly on interstates. Further, these crashes are more severe as compared with crashes in non-work zone conditions. 


\subsubsection{Speeds}

So far, a nationwide standard speed limit for work zones has not been set. Further, cost effective methods for forcing driver compliance with the reduced speed limit are still being studied. Maze et al. (2000) conducted surveys across multiple states' departments of transportations (DOTs) from July 1999 - July 2000 and found that during an active work zone, most reporting DOTs mandated a 10 mph reduced speed limit. In addition, $70 \%$ of these DOTs considered police presence as the most effective means of enforcing the reduction in speed limit. Lindly et al.'s (2002) study supports this by also concluding police presence as the most effective method of reducing vehicle speeds in work zones. Further, the study found that the standard deviation of the speed of vehicles increases as they enter the work zone. Increased standard deviation is often linked to increased crash frequency.

Finally, it is important to note that speed limits are often set as a function of roadway geometry and/or traffic conditions at the site. Therefore, there may be confounding issue when trying to correlate speed with crash frequency.

\subsubsection{Roadway Characteristics and Geometry}

Articles studying the effect of work zone roadway geometry on crash frequency tend to overrepresent the number of crashes experienced on straight and level segments. Both Harb et al. (2008) and Bai and Li (2006; 2007) found that the largest proportion of work zone crashes occurred on straight and level roadway segments. The second largest crash proportion was experienced on straight upgrade/downgrade segments while curved segments experienced the smallest proportion of crashes. Rather than indicating that straight and level segments are the most dangerous roadway geometry, these results most 
likely reflect that the majority of roadways are composed of straight and level segments (as opposed to curved segments). Further, agencies are more likely to erect a work zone on a straight and level segment than a curved or sloped segment because setup and construction is easier.

\subsubsection{Lighting Condition and Time of Day}

Studies examining the effect which lighting and time of day has on crashes in work zones have yielded contradictory results with different varying degrees of accuracy. Harb et al. (2008) found that for work zones in Florida between 2002-2004, the proportion of daytime crashes relative to all other times of day increased when a work zone was implemented while the proportion of nighttime crashes decreased. However, it is possible that these trends are highly correlated with the studies' selected sample population of work zones. It is very possible that the work zones did not cause this increase. Instead, a significant majority of the work zones considered by the paper happened to be daytime work zones, therefore skewing the number of crashes observed during the daytime as compared with the nighttime work zone crash numbers.

Arditi et al. (2007) developed an adjustment factor in order to compensate for crash rate overrepresentation, differences in work zone time span, and variations in traffic volume for fatal crashes occurring in daytime work zones and non-daytime work zones. The study included 121 fatal accidents in Illinois occurring between 1996-2000 and found that non-daytime work zones experience three times the adjusted crash rate as daytime work zones. This study concluded that nighttime work zones are more likely to cause a crash due to poor site visibility than daytime work zones. However, more crashes 
are experienced during the daytime because annual average daily traffic (AADT) volumes are higher.

Finally, Ullman et al. (2008) considered the changes in crash severity level due to the time of day for New York work zones between 2000-2005. The study found that proportion of fatal and injury crashes increased relative to PDO crashes for nighttime work zone crashes. These studies suggest that nighttime work zones may experience less crashes than daytime work zones, however the probability of a crash increases at nighttime as well as the level of severity of the crash.

\subsection{Work Zone Fatal Crash Causation}

All of the previously discussed studies categorize a work zone crash as any crash occurring in a work zone, regardless of whether it was influenced by the work zone's presence. A study by Schrock et al. (2004) delves deeper and tries to identify to what degree fatal crashes occurring in a work zone are influenced by the work zone. The study categorized fatal crashes as either directly influenced by the work zone, indirectly influenced by the work zone, or not influenced by the work zone. This study used 77 fatal work zone crashes in Texas from February 2003 through April 2004. Crash causes within each category were identified, however the study did not report crash numbers or proportional statistics for the crash causes. Therefore, more prominent crash causes could not be distinguished from less prominent causes. The study's work zone influence levels are discussed individually with example crash causes. 


\subsubsection{Crashes Directly Influenced by the Work Zone}

The study found that a work zone directly influenced only $8 \%$ of investigated fatal crashes. Directly influenced crashes were defined as crashes where the work zone was partially at fault. Crashes in this category that were similar to those found within this thesis include:

- Worker killed in activity area by construction equipment, and

- Work zone traffic control was not installed according to standards.

\subsubsection{Crashes Indirectly Influenced by the Work Zone}

The study found that an additional $39 \%$ of the investigated crashes were indirectly influenced by a work zone. Indirectly influenced crashes were defined as crashes that were influenced by the work zone but were most likely not the fault of the work zone. Crashes in this category that were similar to those found within this thesis include:

- Shoulder removal prevented disabled vehicle from leaving roadway

- Vehicle struck back of queue at work zone transition area

- Vehicle entered activity area and struck worker

- Driver confused and went in wrong direction on two-lane two-way operation

\subsubsection{Crashes Not Influenced by the Work Zone}

The study found that a work zone did not influence $45 \%$ of the investigated fatal crashes. This category included crashes such as:

- Drove too fast for conditions or with excessive speed

- Turning driver seemingly misjudged speed/location of oncoming traffic 
- Vehicle ran red light or stop sign

- Aggressive or inexperienced driver caused crash (criminal activity)

- Driver inattention unrelated to work zone

\subsubsection{Study's Conclusions}

While the study identifies multiple countermeasures addressable by a DOT that would help mitigate some of the directly and indirectly influenced crashes, it does not identify which countermeasures will most greatly improve work zone safety and reduce fatal crash frequency. This is most likely the byproduct the study's small sample size (77 crashes) causing specific crash statistics to be excluded from the report because they contain a large error. Even so, this research indicates that there are significant differences between crashes occurring in the work zone and crashes influenced (both directly and indirectly) by the work zone.

\subsection{Work Zone Performance Measures}

Performance measures typically used to assess work zone safety were briefly discussed in the introduction. This section focuses on issues with some of the commonly used performance measures.

\subsubsection{Performance Measures and Exposure Rates}

At a programmatic level, differences in the magnitude of a construction program from year to year can influence how many work zones are present on a DOT system. Work zones with higher exposure rates (i.e., located on higher VMT roadways or erected for 
longer durations) will typically have higher crash counts, cash rates, and inspection counts $(F H W A, 2013 B)$. As a result, if a DOT wants to track safety performance over time, it would be desirable to normalize data by some measure of exposure. However, it is difficult to obtain work zone exposure measures. Currently, a comprehensive set of data on work zone exposure characteristics does not exist at the national level (Ullman, 2004). Therefore, most DOTs do not normalize their crash data (Ullman et al., 2011B).

\subsubsection{Performance Measures Targeted at Crash Causal Trends}

Even if work zone crashes can be normalized, monitoring changes in crash frequency only identifies potential problematic work zones. It does not provide enough information to take corrective steps. For example, Lindley et al.'s (2002) study concluded rear-end crashes increased during a work zone by using high-level crash type trend analysis. However, the study could not conclude the reason work zones tend to increase rear-end crashes solely from the high-level data. The study gathered more investigative data (i.e. time headways and speeds) and determine that increased work zone rear-end crashes are linked to decreased headways and increased speed variability. Therefore, without a team dedicated to further investigation, performance measures based on high-level crash trends do not provide enough information to identify the crash cause and develop effective countermeasures. More information about crash causal trends is needed in order to develop effective countermeasures.

\subsubsection{Crash Data Real-Time Availability and Accessibility}

Most DOTs do not possess the manpower to enter crash data into an electronic database in near real-time (Bourne et al., 2010). Therefore, DOTs typically analyze programmatic 
performance measures long after the work zone has been removed. A very small number of DOTs allocate the manpower necessary to rapidly upload police crash reports to an electronic format for use in assessing project level performance measures (useful for assess the safety of currently ongoing work zones). The Ohio DOT (ODOT) is one of the more proactive states in terms of rapid work zone crash collecting and processing. ODOT gathers hard copies of police crash reports at major project areas every two weeks and manually codes this data into a database so that crash statistics on current projects can be monitored. A team trained to identify underlying crash causes investigates major crash "hotspots" identified through a monitoring process so that the agency can make improvements to work zones as soon as possible (Bourne et al., 2010). Since many DOTs do not have the manpower to enter crash data and assess performance measures in this manner, they most likely do not have enough manpower to manually diagnose crashes directly influenced by the work zone from those that occurred in a work zone. A method for quickly targeting work zone causal trends is needed in order to expedite project level work zone performance measure analysis and countermeasure implementation.

\subsection{Literature Review Summary}

The studies summarized within this literature review mainly identified work zone crash trends, which often disagreed with one another. Some of the differences in the results of these studies may be partially attributable to the characteristics of the analyzed datasets. Two studies (Antonucci et al., 2005; Daniel et al., 2000) focused only on fatal work zone crashes, while other studies utilized all crash severity levels (Rouphail et al., 1988;

Swansen et al., 2012; Pigman et al.; Ullman et al., 2008). Four of these studies were 
conducted statewide or nationwide and included all roadway types (1988; Swansen et al., 2012; Pigman et al.; Antonucci et al., 2005; Daniel et al., 2000), while two others (Rouphail et al., 1988; Ullman et al., 2008) focused on freeway work zone crashes. This variability in the crash data and analysis methods makes it difficult to directly compare study results or collect statistical information useful for performance measure analysis and countermeasure development.

Further, most studies assumed crashes coded as occurring in the work zone limits were influenced by the work zone. More detailed investigation of crash causes in work zones has been limited by the crash report data elements (usually numeric codes corresponding to specific crash characteristics) typically available in work zone crash databases. More detailed crash diagrams or crash report narratives have not been available electronically until relatively recently. Without this information, it is difficult to identify major work zone crash contributors or establish successful countermeasures.

Additionally, there are always aspects of performance measures that a DOT cannot control such as economic trends, changes in vehicle design, or abnormally severe weather conditions. However, a more direct tie between crashes that occur within the physical bounds of the work zone and crashes that were actually influenced by the work zone allows DOTs to better develop plans and strategies to continuously improve their work zone safety program.

The one study (Schrock, 2004) that does target crashes influenced by the work zone focuses on fatal crashes and their casual trends. Further, the study's sample size is too small to report reliable crash cause statistics. Therefore, the study does not guide DOTs toward countermeasures that deserve priority and immediate attention. 
This thesis' goal is to go beyond the high-level work zone crash trends discussed in this literature review and delve into the chain of events that led to the work zone crash. Unlike most previous studies, this thesis' analysis will focus exclusively on crashes that are determined to been influenced by the work zone. It will examine crash trends (similar to those considered in the previously discussed studies) for crashes determine to have been influenced by the work zone. It will also determine major crash cause factors that contributed to these crashes and the chain of events that led to the crash, similar to Schrock's (2004) study. However, this thesis' sample size will be nearly 20 times larger than Schrock's and will hopefully produce reliable crash cause statistics. This thesis will identify work zone planning and safety areas where DOTs should invest greater resources while the work zone crash causal statistics will direct DOTs towards countermeasures that deserve priority and immediate attention. 


\section{CHAPTER 3: METHODOLOGY}

This thesis uses data from the Virginia Department of Transportation (VDOT) as well as National Highway Traffic Safety Administration's (NHTSA) National Motor Vehicle Crash Causation Survey (NMVCCS) and Large Truck Crash Causation Study (LTCCS). Each source differs in their data collection methods and criteria. This chapter begins by identifying each datasets' origin and broad characteristics. Then, the information available in each dataset is compared and contrasted. Next, it describes the process and criteria used to determine which crashes are influenced by a work zone from those occurring in a work zone. This is followed by a description of the process and criteria used to determine and assign crash causes. Finally, the chapter ends by presenting examples from each dataset.

\subsection{Data Overview}

Work zone crash causes were examined using three datasets that had very different sample sizes and levels of detail. The Virginia crash dataset represents a database of work zone crashes where a large number of crashes were available for investigation, but the level of detail captured on each crash was relatively coarse. Two federally collected databases are also investigated. In these studies, detailed crash investigation information was collected on smaller numbers of crashes. Descriptions of the data elements present in each dataset are discussed below. 


\subsubsection{Virginia Dataset}

The Virginia dataset utilized crash data from the Virginia Roadway Network System (RNS) Crash Database. The dataset consists of work zone crashes occurring in Virginia between January $1^{\text {st }}, 2011$ and December $31^{\text {st }}, 2012$. This date range was selected since electronic report narratives were available for all crashes during this time period. Virginia crash reports define a work zone crashes as any crash occurring within the MUTCD (2003) defined work zone area $(D M V, 2014)$. In total, 6,774 work zone crashes were coded during this time period. The total number of crashes occurring in Virginia during this time period is 122,204 , so work zone crashes represent $5.5 \%$ of all crashes in Virginia during these two years. The Virginia DOT is responsible for operating and maintaining all roadways outside of incorporated cities, so these work zone crashes included all roadway types.

The Virginia crash report contains over 50 multiple-choice fields as well as a crash description field where police officers can record specific information about the crash that is not addressed in one of the multiple-choice fields. The crash descriptions are short, often vague, and sometimes missing. No photographs are included with the crash reports. Examples of several Virginia crashes are provided in section 3.4 towards the end of this chapter.

\subsubsection{National Motor Vehicle Crash Causation Survey (NMVCCS) Dataset}

The National Highway Traffic Safety Administration's (NHTSA) National Automotive Sampling System (NASS) collected the National Motor Vehicle Crash Causation Survey (NMVCCS) dataset (NASS, 2014A). The NMVCCS dataset was gathered as a result of a 
Congressionally required nationwide survey of crashes involving light passenger vehicles, with a focus on the factors related to pre-crash events (NHTSA, 2008A). Each investigated crash involved at least one light passenger vehicle that was towed due to damage. Data was collected over a three-year period from January 2005 to December 2007, at 24 different geographic areas in 18 States. Virginia was not one of the states in which data was collected. All facility types were included (Bellis et al., 2008)(NHTSA, 2008B).

The NMVCCS dataset consists of 6949 crashes, of which 161 were coded as possessing a relationship with a work zone. The study's crash reports contain a detailed crash description; crash diagrams, pictures of the crash scene and damaged vehicles as well as approximately 600 data element fields. Work zone location information is not explicitly provided due to the study's efforts to keep the crashes anonymous. Examples of two NMVCCS crashes are provided in section 3.5 towards the end of this chapter.

\subsubsection{Large Truck Crash Causation Study (LTCCS) Dataset}

The National Highway Traffic Safety Administration (NHTSA) and the Federal Motor Carrier Safety Administration (FMCSA) of the United States Department of Transportation (USDOT) sponsored the collection of the Large Truck Crash Causation Study (LTCCS) dataset (NASS, 2014B). The LTCCS was developed by NHTSA's National Center for Statistics and Analysis (NCSA) and FMCSA. It was conducted within the National Automotive Sampling System (NASS) that NCSA operates. An attempt was made to ensure that each crash involved at least one large truck with a gross vehicle weight rating of more than 10,000 pounds, and resulted in at least one fatality or one incapacitating or non-incapacitating but evident injury. The study collected data at 24 
different geographic areas in 17 States, during 2001 through 2003. Virginia was not one of the states in which data was collected. All facility types were included (Starnes, 2006)(Toth et al., 2003)(U.S.DOT FMCSA, 2005).

The LTCCS dataset consists of 1070 crashes, of which 70 were coded as possessing a relationship with the work zone area. The LTCCS crash report contains a detailed crash description, crash diagrams, pictures of the crash scene and damaged vehicles, as well as approximately 1000 data element fields. Specific work zone location information is not provided due to the studies efforts to keep the crashes anonymous. An example of an LTCCS crash is provided in section 3.5 towards the end of this chapter.

\subsection{Comparison of Available Data Elements within each Dataset}

Data collection methods differed greatly between the Virginia dataset and the NMVCCS and LTCCS datasets. The Virginia crash reports standardize data collection by including specific fields and check boxes. While this can lead to consistent record keeping, it restricts the information gathered to the fields within the report. Further, the crash narrative length averages 30-40 words, with 8.2\% (527 crashes) of all Virginia Coded crashes containing no description. The crash's cause and relationship to the work zone must be obtained from the crash description because this information is not directly addressed by one of the fields. Typically, a different police officer responds to each crash. Therefore, the results obtained from crash descriptions can be inconsistent due to nonstandard narrative recording procedures as pertaining to work zones.

Conversely, a designated team of researchers collected NMVCCS and LTCCS crash information. Since the same researchers worked on multiple reports, there is likely 
a greater degree of internal consistency in these datasets. Each researcher arrived on the scene of the crash, collected 600-1000 variables, and conducted interviews with all parties involved. While standardized fields are used to collect some of the information, much of the information used to determine work zone crash causality cannot be obtained from the predefined fields recorded by the researcher. Each crash report contains a very detailed narrative (200-700 words in length) and pictures from which most of the information for the NMVCCS and LTCCS data analysis was taken. While the narratives tried to be consistent, sometimes information was missing (e.g. work zone type, location of crash within work zone, work zone role in the crash).

Table 3.1 lists Virginia, NMVCCS and LTCCS crash report fields used to help determine the work zone's influence in the crash. Each dataset contained an explicit field linking the crash to the work zone. This field is referred to as "Coded work zone crash" in the Table 3.1. The Virginia dataset contained a specific entry field for each of the informational items listed in Table 3.1 (except for the crash cause). For the NMVCCS and LTCCS datasets, crash type, work zone type, facility type, first object hit during a fixed object - off road crash, and crash cause were not pre-defined fields within the crash report. This information was gathered manually from the crash description, diagram, and pictures (although, LTCCS reports did contain a field for crash type). As a result, sometimes this information was missing or could not be determined. The location of the crash in the work zone and the lateral/longitudinal coordinates of the NMVCCS and LTCCS crashes were not captured in pre-defined fields and could not be determined from the crash descriptions. 
Table 3.1: Summary of Relevant Crash Report Data Fields by Dataset

\begin{tabular}{|l|l|l|l|}
\hline $\begin{array}{l}\text { Field/ } \\
\text { Dataset }\end{array}$ & $\begin{array}{l}\text { Virginia } \\
\text { Crash Report }\end{array}$ & $\begin{array}{l}\text { NMVCCS } \\
\text { Crash Report }\end{array}$ & $\begin{array}{l}\text { LTCCS } \\
\text { Crash Report }\end{array}$ \\
\hline Coded work zone crash & Crash Report Field & Crash Report Field & Crash Report Field \\
\hline Injury level & Crash Report Field & Crash Report Field & Crash Report Field \\
\hline Speeding & Crash Report Field & Crash Report Field & Crash Report Field \\
\hline Crash Type & Crash Report Field & $\begin{array}{l}\text { Narrative, Diagram, } \\
\text { Pictures }\end{array}$ & Crash Report Field \\
\hline Work Zone Type & Crash Report Field & $\begin{array}{l}\text { Narrative, Diagram, } \\
\text { Pictures }\end{array}$ & $\begin{array}{l}\text { Narrative, Diagram, } \\
\text { Pictures }\end{array}$ \\
\hline Facility Type & Crash Report Field & $\begin{array}{l}\text { Narrative, Diagram, } \\
\text { Pictures }\end{array}$ & $\begin{array}{l}\text { Narrative, Diagram, } \\
\text { Pictures }\end{array}$ \\
\hline $\begin{array}{l}\text { First Object Hit: Fixed } \\
\text { Object - Off Road }\end{array}$ & Crash Report Field & $\begin{array}{l}\text { Narrative, Diagram, } \\
\text { Pictures } \\
\text { Crash lat/long }\end{array}$ & Crash Report Field \\
Not Provided & $\begin{array}{l}\text { Narrative, Diagram, } \\
\text { Pictures }\end{array}$ \\
\hline $\begin{array}{l}\text { Crash location in work } \\
\text { zone }\end{array}$ & Crash Report Field & $\begin{array}{l}\text { Narrative, Diagram, } \\
\text { Pictures }\end{array}$ & $\begin{array}{l}\text { Not Provided } \\
\text { Pictures }\end{array}$ \\
\hline $\begin{array}{l}\text { Crash Cause } \\
\text { Carrative, Diagram, Diagram, }\end{array}$ & $\begin{array}{l}\text { Narrative, Diagram, } \\
\text { Pictures }\end{array}$ & $\begin{array}{l}\text { Narrative, Diagram, } \\
\text { Pictures }\end{array}$ \\
\hline
\end{tabular}

Both Virginia's and NMVCCS/LTCCS's data collection methods contain strengths and weaknesses. Virginia's dataset has the advantage of a larger sample size. Additionally, Virginia's crash report check box fields ensure consistency but limit the detail and type of data collected. Conversely, NMVCCS/LTCCS's detailed crash descriptions contain a depth and breadth of information that provides a richer view of crash circumstances. However, the descriptions' contents can vary, causing some narratives to leave out information important to this specific study. Further, there are a limited number of crash reports available for analysis. The NMVCCS/LTCCS crash reports that are available take approximately 15 times longer to extract information from than the Virginia crash reports due to their length and level of detail.

Additionally, it is important to note that some Virginia crash causes are easier to identify than others. For example, the crash cause stopping/slowing due to the work zone does not need to be mentioned explicitly in the crash description. It can be concluded from a combination of an indication of a lane closure in the "Work Zone Type" field, 
deduction of off peak time of day in the "Time" field, and mention of congestion in the crash description. A crash that resulted from a more subtle crash cause (e.g. uneven pavement, confusion, or limited sight distance due to the work zone) is harder to identify because this information must be explicitly stated in the crash description in order to be identified. As a result, some of these subtler crash causes are probably being grouped in with more general crash causes. Thus, easier to identify crash causes may be overrepresented in the Virginia dataset while subtler crash causes are underrepresented. Instances of this can be seen in the examples in section 3.5 towards the end of this chapter.

\subsection{Analysis Methodology}

The crashes were analyzed by crash type since crash causes are likely to vary significantly among crash types. Only those crash types that comprised at least $10 \%$ of work zone crashes were used in the analysis in order to ensure that sample sizes were large enough to be meaningful. This resulted in the consideration of only rear-end, angle, sideswipe - same direction, and fixed object - off road crashes. These crash types represent $94.8 \%, 88.8 \%$, and $92.9 \%$ of all Virginia, NMVCCS, and LTCCS crashes, respectively, and are assumed to be a good representation of the majority of the work zone crash population. 


\subsubsection{Terminology}

During analysis, crashes were subdivided into a maximum of four crash categories. For consistency, all crash categories only consider rear-end, angle, sideswipe - same direction, and fixed object - off road crashes. The four crash categories are:

- Work Zone Coded crashes. All rear-end, angle, sideswipe - same direction, and fixed object - off road crashes coded in crash reports as possessing a relationship to the work zone. This terminology is used for all datasets.

- Directly Related crashes. All rear-end, angle, sideswipe - same direction, and fixed object - off road crashes determined to have been influenced (either directly or indirectly) by the work zone. This terminology is used for all datasets.

- Possibly Related crashes. All rear-end, angle, sideswipe - same direction, and fixed object - off road crashes that may have been influenced by the work zone. In this case, the work zone may have played a role in the crash occurrence or severity, but the relationship is unclear. This terminology is only used for the NMVCCS and LTCCS datasets. These crashes could not be determined in the Virginia dataset due to insufficient information.

- Not Related crashes. All rear-end, angle, sideswipe - same direction, and fixed object - off road crashes determined to have not been influenced by the work zone. This terminology is only used for the NMVCCS and LTCCS datasets. These crashes could not be determined in the Virginia dataset due to insufficient information.

- Unknown Relation crashes. All rear-end, angle, sideswipe - same direction, and fixed object - off road crashes with an undeterminable level of influence by the 
work zone. This terminology is only used for the VDOT datasets. The work zone's level of influence for all NMVCCS and LTCCS crashes could be determined and categorized into one of the above definitions.

\subsubsection{Determination of Coded Crashes}

In the Virginia dataset, Coded crashes were all crashes within the study period that contained a "Yes" entry in the "Work Zone Related?" field. In the NMVCCS, Coded crashes were identified by a "1-Present" in the "Traffic Flow Interruption Factors: Construction Work Zone" field and/or the "Trafficway Flow Restriction: Work Zone" field. In the LTCCS, Coded crashes were identified by the presence of "Construction Work Zone" in the field "Traffic Flow Related Factors: Traffic Factor Element" and/or by the presence of "Work Zone" in the field "Trafficway relation to: Restrictions".

\subsubsection{Determination of Directly Related, Possibly Related, and Not Related Crashes}

The Directly Related, Possibly Related, and Not Related crashes are a subset of the Coded crash datasets. For the Virginia dataset, Directly Related crashes were determined by examining each crash report's description in tandem with various crash report fields such as first harmful event (e.g. jersey wall), lighting condition, work zone type (e.g., lane closure), work zone location (i.e., latitude and longitude coordinates), work zone area (e.g. transition area), route, date, and time. For the NMVCCS and LTCCS datasets, Directly Related crashes were determined by examining each crash report's description, diagram, and pictures. Factors considered when determining if a crash fell into the Directly Related Category included whether: 
- a work zone vehicle or piece of equipment was struck,

- the crash description directly referenced a work zone feature,

- the crash description directly indicated that the work zone created changes in traffic flow or speed,

- the description indicated a specific driver response to the work zone, or

- the outcome of the crash (i.e., severity level, crash type, crash location, additional vehicles hit, etc.) was affected by the work zone's presence.

For many cases in the Virginia dataset, the crash report contained insufficient information to make a determination as to the role, if any, that the work zone played in the crash. Therefore, crashes not influenced by the work zone could not be identified. For the NMVCCS and LTCCS datasets, crashes were designated as Not Related if all of the following criteria were met:

- an explanation for the cause of the crash could be determined

- that explanation did not involve the work zone in any way

- the outcome (severity) of the crash was not affected by the work zone.

Crashes were designated as Possibly Related if the crash report provided insufficient information to determine that the crash was either Directly Related or Not Related.

Crashes not determined to be Directly Related in the Virginia dataset as well as crashes designated as Possibly Related in the NMVCCS and LTCCS datasets could still have been influenced by the work zone. They were not categorized as Directly Related because the police officer or researcher may have failed to capture this influence in the crash report. It is important to note that crashes determined to be Directly Related in each 
dataset were not necessarily caused by the work zone and may have been only slightly or indirectly influenced by the work zone's presence.

\subsubsection{Determination of Crash Cause}

Next, crashes were categorized based on their crash cause. The crash causal categories were based on trends observed within the data while determining the crash's relationship to the work zone. For instance, crashes which involved stopping or slowing due to congestion created by the work zone were broken out as a category within the Directly Related data. The same crash cause categories were used across all three datasets. Common crash categories were:

- Stopping/ slowing due to work zone (including congestion and merging);

- Stopping/ slowing due to flagman, police officer, or work zone sign;

- Changing lanes due to work zone lane closure or congestion;

- Confusion due to work zone traffic control;

- $\quad$ Limited sight distance due to work zone activities;

- Work zone vehicle entering/exiting work zone;

- Unauthorized work zone entry;

- Avoiding crash with another vehicle or object;

- Lost control, struck work zone device/barrier;

- Lost control due to uneven pavement, and

- Unknown, but work zone device/barrier was struck. 
These crash categories are further defined and discussed within each dataset's data analysis chapter (Chapters 4 and 5). Other crash cause categories that were identified but did not represent a significant percentage of the work zone crashes included: backing up, falling asleep/fatigued, driver inattention, misjudged gap while turning or merging, improper work zone instruction or conduct (such as improper flagger operations or improper work zone set up), and reckless driving.

\subsection{Virginia Crash Examples}

This section contains five examples of crashes taken from the Virginia dataset. These examples demonstrate the processes of determining a work zone's level of influence on a crash and the crashes primary cause. They also illustrate the level of detail present in the dataset. All crashes are Coded crashes, (i.e., they were indicated in the crash reports occurring in the work zone). The first three examples are of crashes determined to be Directly Related. For the last two examples, the relationship of the crash to the work zone could not be determined.

\subsubsection{Virginia Examples}

The following examples are taken from the Virginia Directly Related crash dataset. Crash fields typically used to help diagnose the work zone relationship to the crash are recorded below along with an exact quotation of the contents of the crash report's officer-provided crash narrative. The reasoning for designating the crash as Directly Related (or not) and the crash cause are explained. Full definitions of the primary crash causes are displayed in Chapter 4. 


\subsubsection{Virginia Directly Related Example \#1}

Document Number: 122585135

Work zone type: Lane Closure

Work zone area: Transition Area

Crash Type: Rear-end

Weather: No Adverse Condition (Clear/Cloudy)

Time: 8:40am

Day: Friday

Date: $9 / 14 / 12$

Route/Street Name: I-495 North

Crash Description: "Vehicle \#2 and Vehicle \#3 were slowing to lane change for lane closure. Vehicle \#1 hit Vehicle \#2 causing Vehicle \#2 to hit Vehicle \#3.”

Reasoning: The crash description mentions slowing for a lane change made necessary by a lane closure. Therefore, this crash is categorized as a Directly Related crash because the slowing is connected to the lane closure. The crash is categorized into the broad crash category of "Stopping/slowing due to the work zone" and then into the subcategory "Stopping/slowing due to congestion" (discussed in the Chapter 4).

3.4.1.2 Virginia Unknown Relationship Example \#2

Document Number: 121990082

Work zone type: Lane Closure

Work zone area: Advance Warning Area

Crash Type: Rear-end

Weather: No Adverse Condition (Clear/Cloudy)

Time: 11:05am 


\section{Day: Monday}

Date: $6 / 11 / 12$

Route/Street Name: $21^{\text {st }} \mathrm{ST}$

Crash Description: "Veh 1 ran into the rear of Veh 2."

Reasoning: The crash description is purely redundant of the information in the crash type

field. It does not provide any information that links the crash to the work zone or indicates the cause of the crash. Therefore, there is not enough information available to conclude the work zone's level of influence on the crash.

Many crash report descriptions in the Virginia dataset are equally ambiguous. Therefore, a large proportion of the crashes in the Virginia dataset have an unknown relationship to work zone.

\subsection{NMVCCS and LTCCS Crash Examples}

This section contains three examples of crashes taken from the NMVCCS and LTCCS dataset. These examples demonstrate the processes of determining a work zone's level of influence on a crash and the crashes primary cause. They also illustrate the level of detail present in the dataset. All crashes are Coded crashes, (i.e., they were indicated in the crash reports as possessing a connection to the work zone). The first two examples are of crashes determined to be Directly Related. The last example is of a crash determined to be Not Related. 


\subsubsection{NMVCCS - Directly Related Example}

The following is an example of a NMVCCS Directly Related crash taken from the NASS NMVCCS Case Viewer. Crash fields typically used to help diagnose Directly Related crashes are recorded below along with an exact quotation of the contents of the crash report's description. The crash diagram and the two most descriptive pictures in the crash report are also provided, although additional pictures are also present in the crash report. Facility type, work zone type, and crash type are not provided as a specific field. These are concluded from the crash description, diagram, and pictures. The reasoning for designating the crash as Directly Related and the crash cause are explained. Full definitions of the primary crash causes are displayed in Chapter 5.

Case Number: 2005-074-048

Case ID: 2005074433742

Date: $06 / 2005$

Day of Week: Wednesday

Time: $12: 37 \mathrm{pm}$

Severity: C - Possible injury

Crash Description:

"This two vehicle crash occurred just past noon during daylight hours at a four leg intersection, with five lanes north/south and two lanes east/west. East/west traffic controlled by stop signs. The road surface is dry, level asphalt. South traffic limited to curb lane, lanes two and three closed due to construction. Posted speed limit $56 \mathrm{kph}$ (35 mph). 
Vehicle one (V1) a 2005 Chrysler PT Cruiser driven by a 52 year-old male with two passengers was traveling north making a left turn at intersection. Vehicle two (V2) a 1979 Buick Park Avenue Coupe driven by a 31 year-old female with four passengers was traveling south in the curb lane. As V1 was making a left turn the front of V2 contacted the right side of V1, after impact V1 rotated clockwise coming to final rest north, V2 continued south coming to final rest in lane to facing south. Both vehicles were towed from the scene.

The pre-event movement for V1 coded stopped in traffic lane, category this vehicle traveling turning left at intersection. Critical reason for the critical event coded driver related factor "inadequate surveillance".

The pre-event movement for V2 coded going straight, category this vehicle traveling crossing over passing through intersection. Critical reason for the critical event not coded to this vehicle.

Additional factor for V1, possible view obstruction from construction equipment.” 
Figure 3.1: NMVCCS Directly Related Crash Diagram

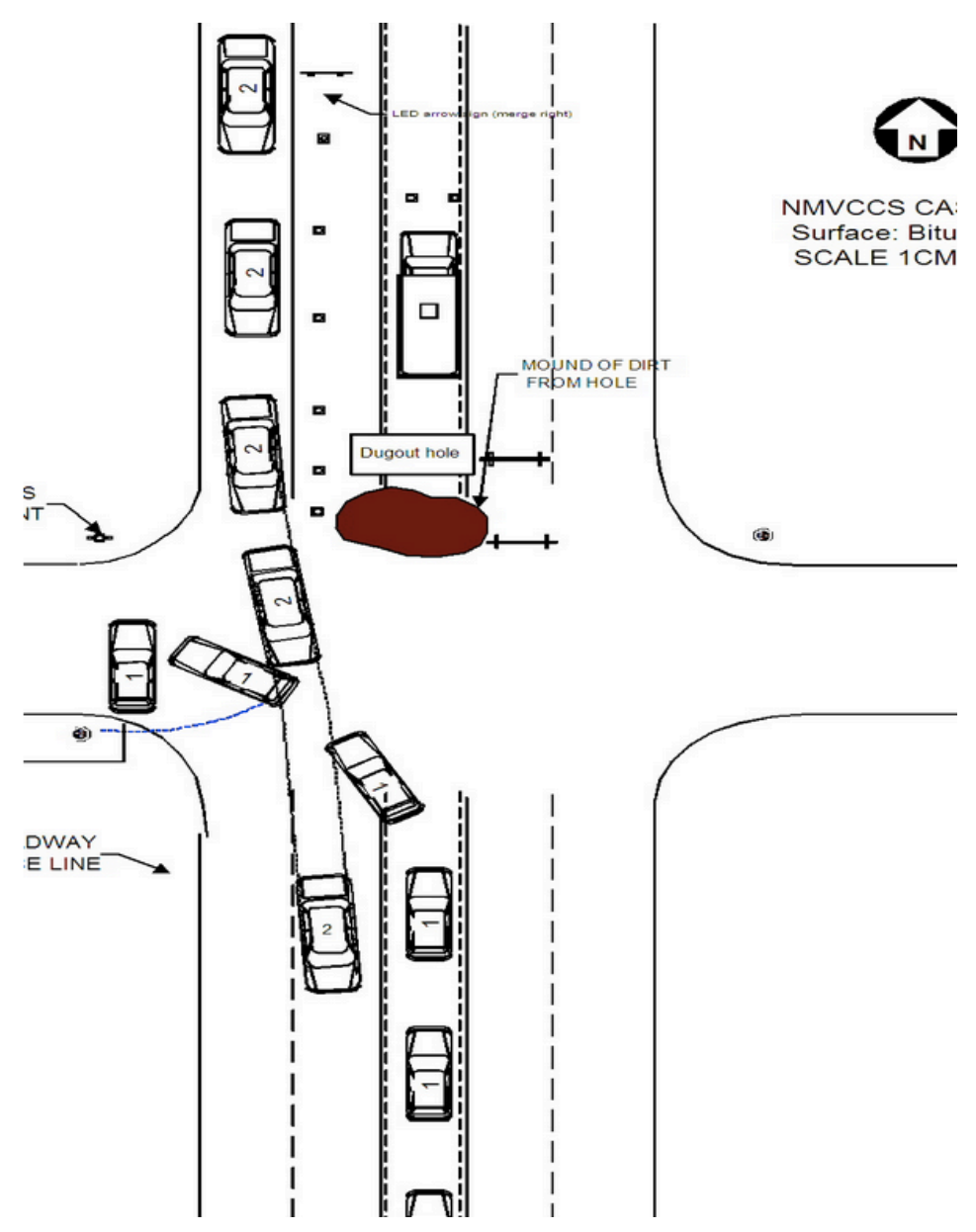


Figure 3.2: NMVCCS Approach View of Vehicle Turning

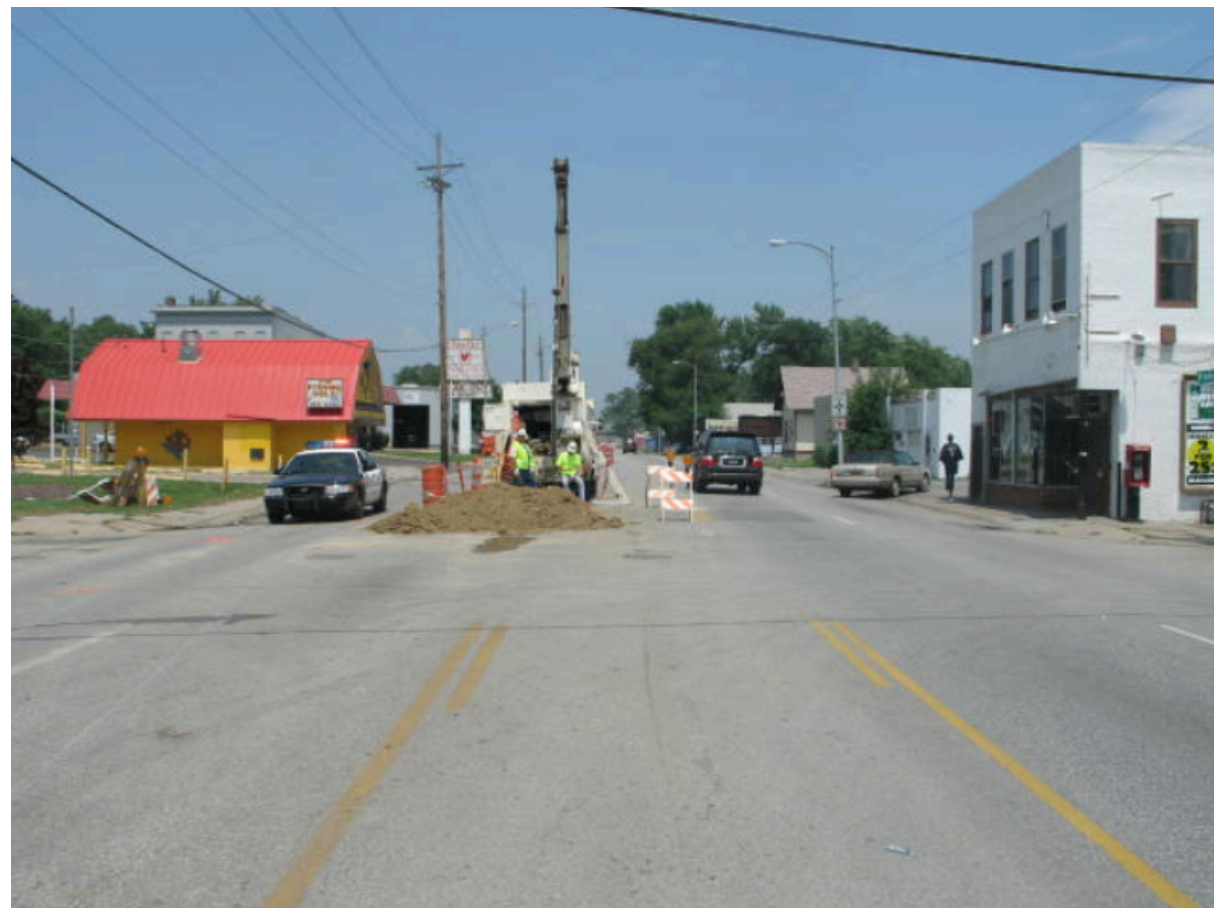

Figure 3.3: NMVCCS Approach View of Vehicle Traveling Straight

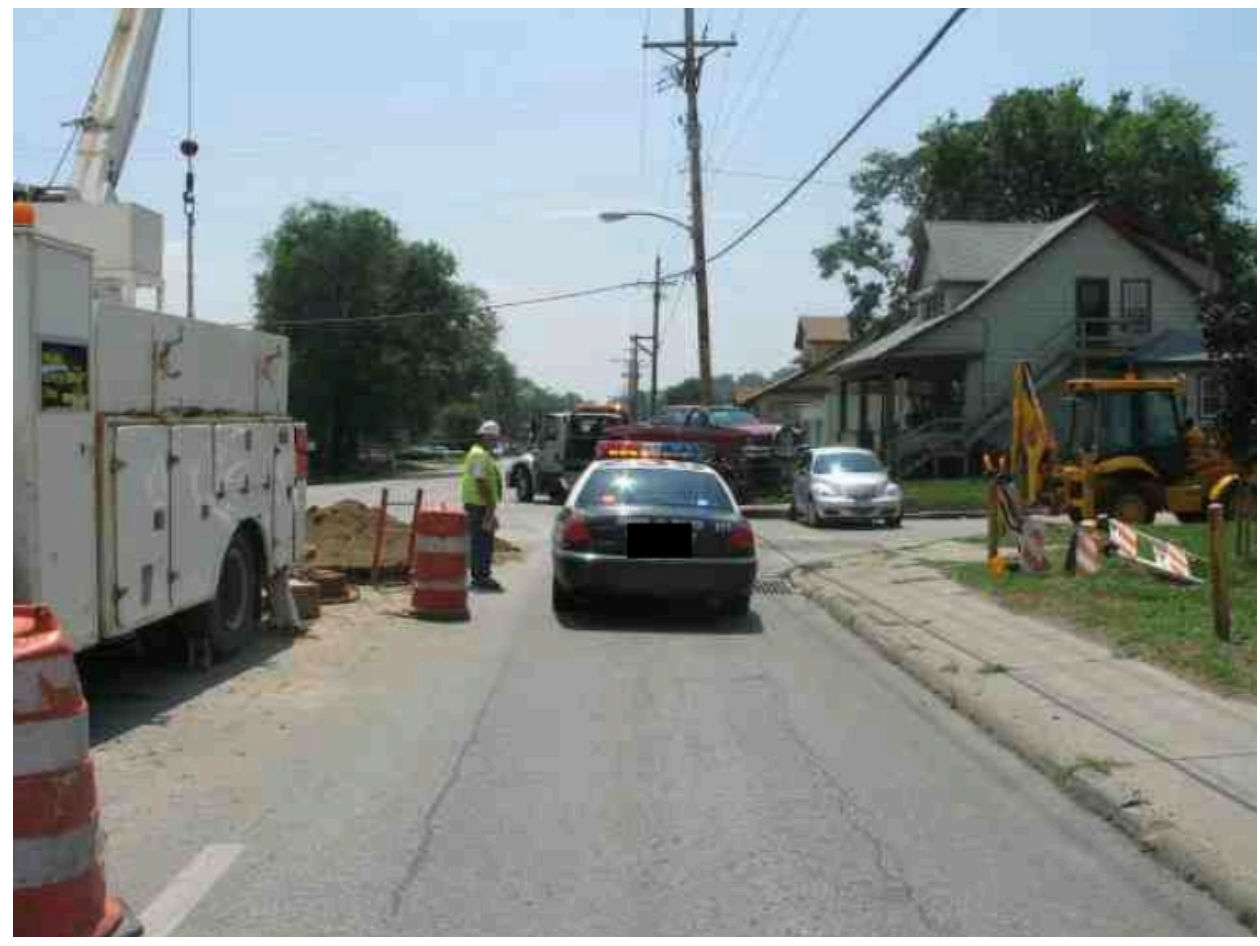


Additional Information: Facility type, crash type, and work zone type are not specific fields in the NMVCCS crash reports like they were in the Virginia crash reports. Therefore, they were determined from the crash description, diagram, and pictures. The crash diagram illustrates that this was an angle crash. The crash description, diagram, and pictures indicate the crash occurred at an intersection. Therefore, the facility type is classified as "Non-Freeway". The crash description describes the work zone layout as "lanes two and three closed due to construction". Therefore, the work zone type is classified as "Lane Closure".

Reasoning: The crash description cites "inadequate surveillance" and "possible view obstruction from construction equipment" as influencing factors. Alone, the crash description is not enough to confirm that the work zone influenced the crash. However, by examining the diagram and the pictures (Figures 3.1, 3.2, and 3.3), it is apparent that the construction equipment blocked the line of sight to a degree for both vehicles involved. The approaching vehicles would not be able to see vehicles in the other direction until they were close to the intersection. Therefore, it was concluded that the work zone reduced line of sight distance, decreasing available reaction time. This crash was categorized as Directly Related. The crash cause was categorized as "Limited sight distance due to work zone activities".

\subsubsection{LTCCS Directly Related Example}

The following is an example of a LTCCS Directly Related crash taken from the NASS LTCCS Case Viewer. Crash fields typically used to help diagnose Directly Related crashes are recorded below along with an exact quotation of the contents of the crash report's description. The crash diagram and the two most descriptive pictures in the crash 
report are also provided. Facility type and work zone type are not provided as a specific field. These are concluded from the crash description, diagram, and pictures. The reasoning for designating the crash as Directly Related and the crash cause are explained. Full definitions of the primary crash causes are displayed in Chapter 5.

Case Number: 2002-012-001

Case ID: 808005489

Date: $07 / 2002$

Day: Monday

Time: $12: 59$

Severity: A - Incapacitating Injury

Crash Type: Rear-end

Crash Description:

"V1, a Mack tractor pulling two dump trailers, drove into the back of V2, a Freightliner tractor pulling one van trailer that had slowed down due to traffic backed up on the road ahead. The slow traffic was the result of a work zone which required two lanes to merge into one. No adverse weather conditions were present at the time of the accident. The roadway was a divided highway with two lanes northbound and two lanes southbound, concrete, level, and a speed limit of $60 \mathrm{mph}$. The driver of the front truck observed V1 approaching at a high rate of speed (in his mirrors) and then saw smoke coming off the tires of V1 and made an unsuccessful attempt to pull ahead to avoid the collision. The impact caused extensive damage to the left side of the cab of V1, and also caused severe damage to the right rear corner of the V2 trailer. Both vehicles were towed as a result of 
damages sustained from the collision. The driver of V1 was admitted to the hospital in critical condition, the driver of V2 was not injured."

Figure 3.4: LTCCS Directly Related Crash Diagram

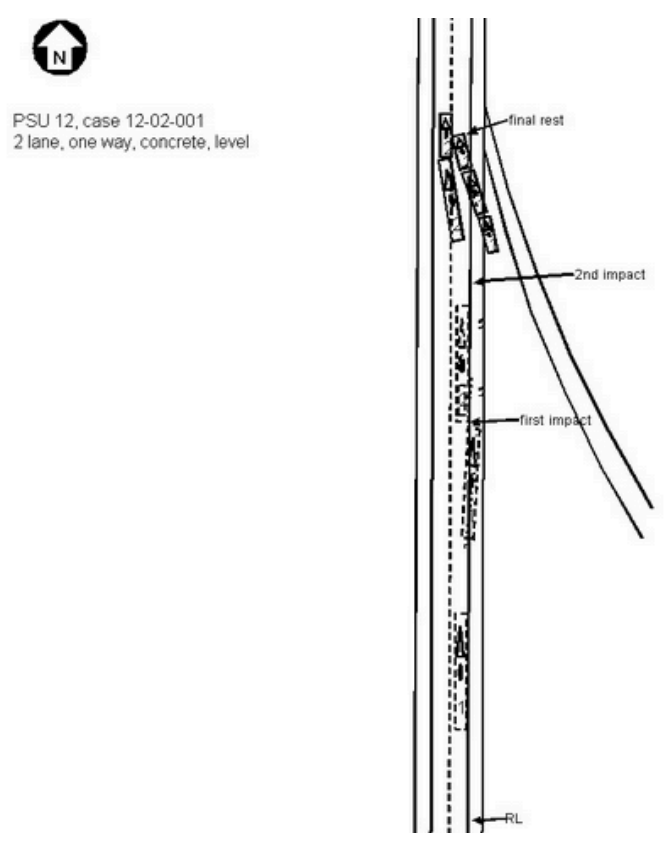

Figure 3.5: Location of Crash at a Congested Time

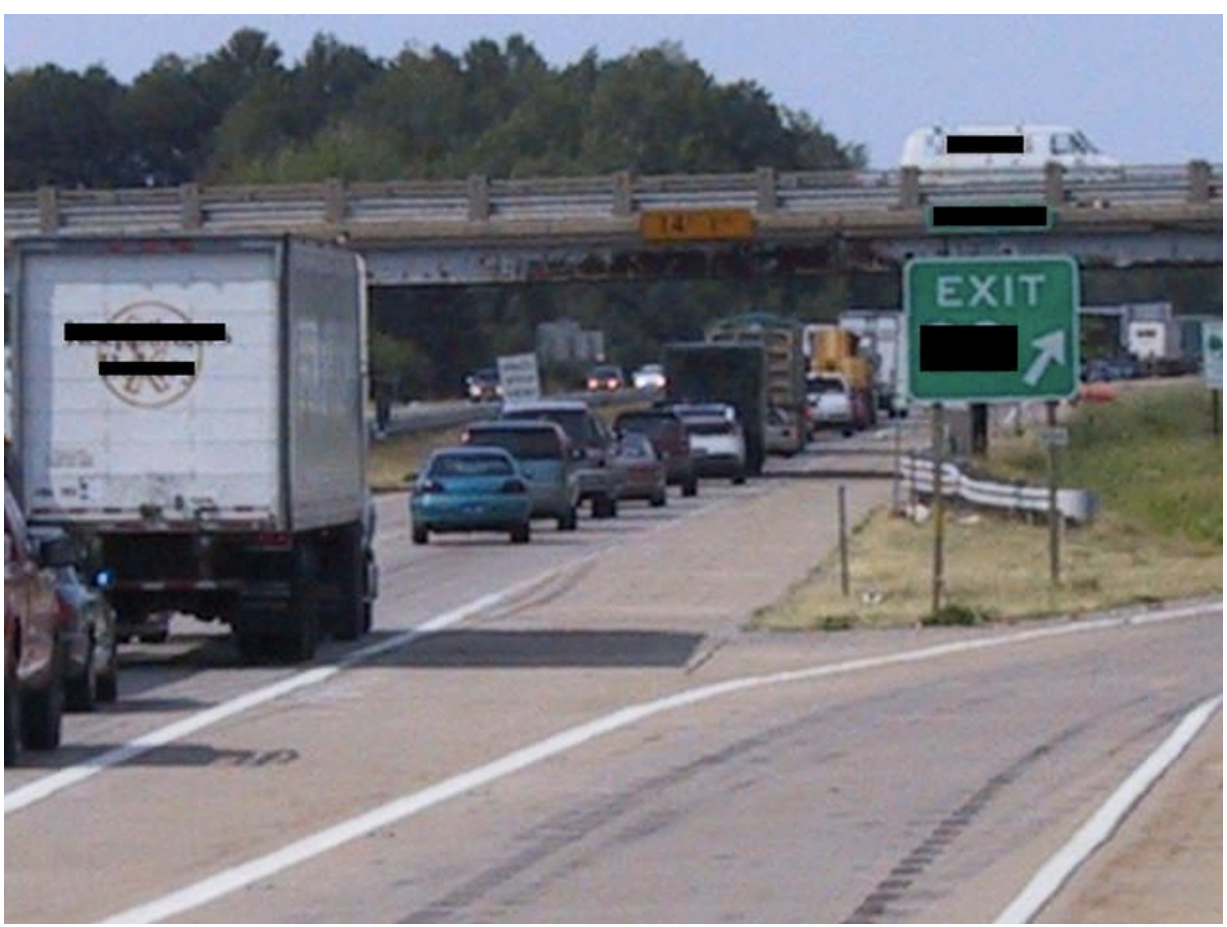


Figure 3.6: Location of Crash at Non-Congestion Time

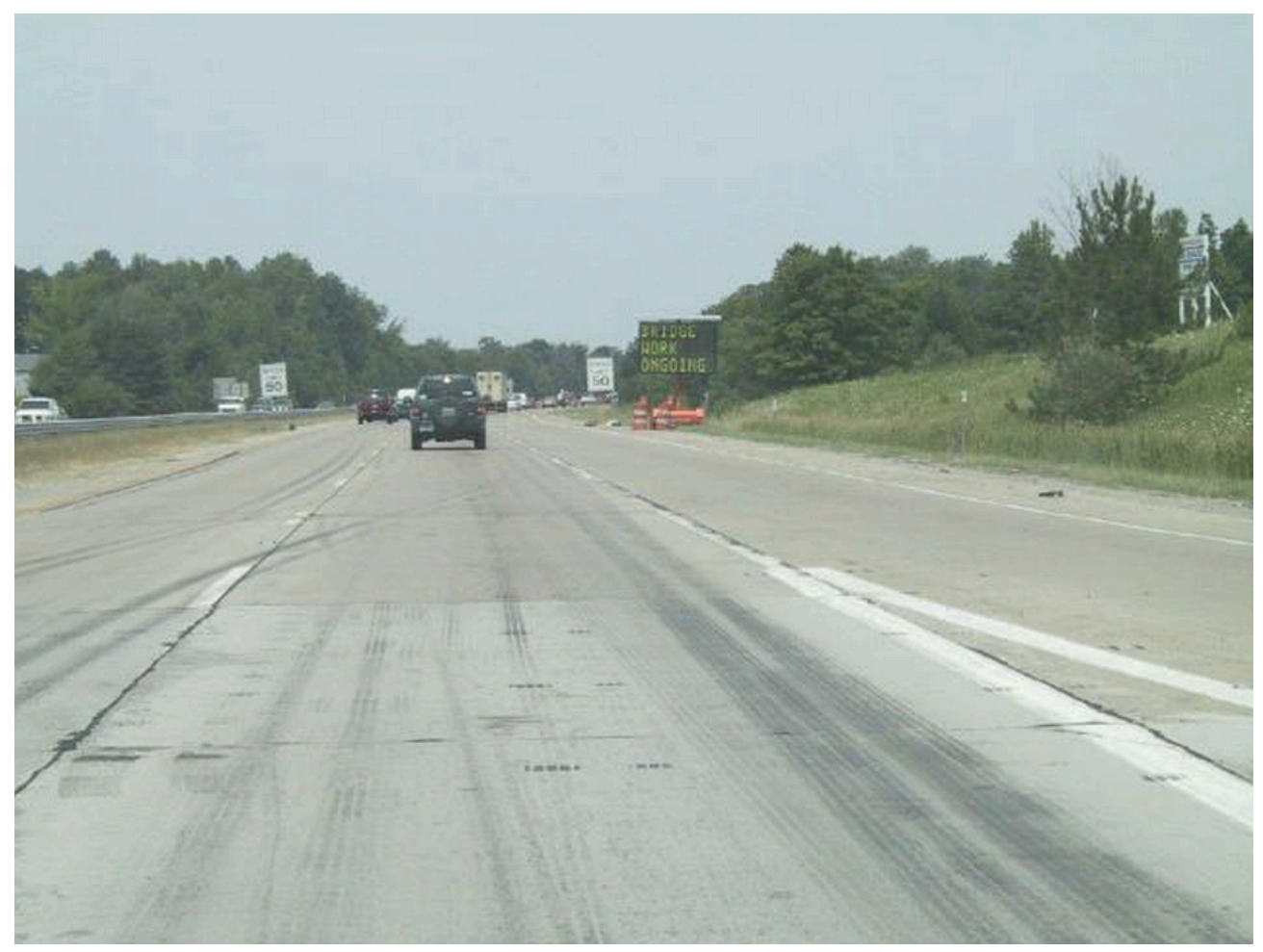

Additional Information: Facility type, and work zone type are not specific fields in the LTCCS crash reports like they were in the Virginia crash reports. Therefore, they were determined from the crash description, diagram, and pictures. The crash description, diagram and pictures indicate the crash occurred on a limited access highway. The crash description describes the roadway as "a divided highway with two lanes northbound and two lanes southbound, concrete, level, and a speed limit of $60 \mathrm{mph}$.” and the pictures show off-ramp and overpass, which are characteristic of a freeway. Therefore, the facility type is classified as "Freeway". The crash description describes the work zone layout as requiring "two lanes to merge into one". Therefore, the work zone type is classified as "Lane Closure".

Reasoning: The crash description mentions, "slowed down due to traffic backed up on the road ahead. The slow traffic was the result of a work zone which required two lanes 
to merge into one". By itself, this description describes an influential link between the work zone and the crash. If this were not enough, the crash pictures illustrate a long queue (Figures 3.5) backed up from a bridge closure work zone ahead (Figure 3.6). The crash diagram does not add much to this crash report, except to illustrate the exact location of the crash. The crash is categorized as a Directly Related crash because the slowing is connected to the lane closure. The crash is categorized into the broad crash category of "Stopping/slowing due to the work zone" and then into the subcategory "Stopping/slowing due to congestion" (discussed in the Chapter 5).

Compared to an earlier Virginia work zone congestion related crash (Virginia Example \#2), the LTCCS report provides more detail and is more thorough. The work zone's influence on the crash can be obtained both through pictures and the crash narrative. This makes diagnosing the crash cause easier and improves confidence in a correct diagnosis.

\subsubsection{NMVCCS Not Related Example}

The following is an example of a NMVCCS Not Related crash taken from the NASS NMVCCS Case Viewer. This crash was determined not to have been influenced by the work zone. Crash fields typically used to help diagnose Not Related crashes are recorded below along with an exact quotation of the contents of the crash report's description. The crash diagram and the two most descriptive pictures in the crash report are also provided, although additional pictures are also present in the crash report. Facility type, work zone type, and crash type are not provided as a specific field. These are concluded from the crash description, diagram, and pictures. The reasoning for designating the crash as Not Related and the crash cause are explained. 
Case Number: 2006-079-087

Case ID: 2006079624162

Date: $07 / 2006$

Day of Week: Thursday

Time: 19:24pm

Severity: B - Non-incapacitating injury

Crash Description:

"This two-vehicle collision occurred at the intersection of a seven-lane, north/south roadway and a two-lane, east/west roadway during afternoon daytime hours on a weekday. The intersection was controlled by a tri- light traffic signal. The speed limit for northbound traffic was $40 \mathrm{kmph}(25 \mathrm{mph}), 56 \mathrm{kmph}(35 \mathrm{mph})$ for southbound. At the time of the crash there were no adverse weather conditions. The roadway in the area of the crash was in poor condition; the travel lanes in both directions had undergone resurfacing preparation by a riding grinder, removing lane lines and leaving the road surface very rough.

Vehicle one (V1), a 1994 Ford Escort station wagon, was traveling northbound in the fourth lane and approaching the intersection with the intention of turning left. Vehicle two (V2), a 1985 Toyota Celica, was traveling southbound in the third lane of opposing traffic and approaching the intersection with the intention of passing straight through. As V1 executed the turn, the front of V1 impacted the front of V2. Both vehicles deflected southwest and came to rest in the southbound lanes.

The 81-year-old female driver of V1 stated that she saw V2's approach, but that V2 appeared to be very far away, and she believed she had adequate time to execute the 
turn. The driver was on her way to a poetry club, and was thinking about her poetry meeting at the time of the crash. The critical pre-crash event for V1 was: This vehicle traveling, turning left at intersection. The critical reason for the event was attributed to V1, and was coded as a driver related decision error, misjudgment of gap or other's speed.

The driver of V2, a 19-year-old male, was traveling with a 20-year-old male passenger. The driver was heading home from a fast food restaurant. The driver was talking to his passenger about social matters as he was traveling. The driver exercises every day by walking for 30 minutes. The driver has three years of driving experience. He does not have any formal driver training. The car belongs to a co-worker. He has been driving the car since the day before the crash, but has borrowed it in the past. His driver's license is currently suspended. The driver thought V1 would yield the right-of-way as he approached. He stated V1 turned in front of him, without warning, as he entered the intersection on a green light. The driver applied the brakes and swerved right, but could not avoid the impact. The critical precrash event for V2 was: Other vehicle encroaching into lane, from opposite direction over left lane line. The critical reason for the event was not attributed to V2." 
Figure 3.7: NMVCCS Not Related Crash Diagram

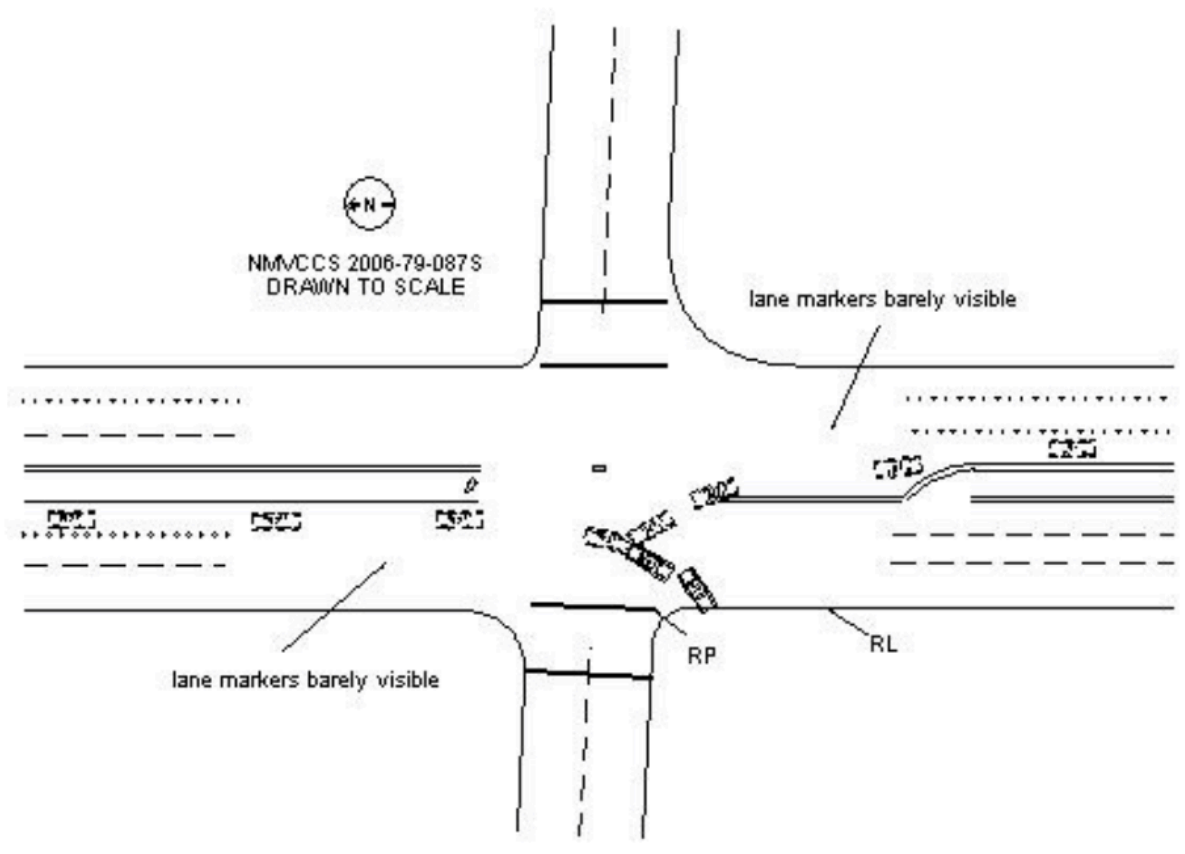

Figure 3.8: Picture of Intersection After Crash was Cleared

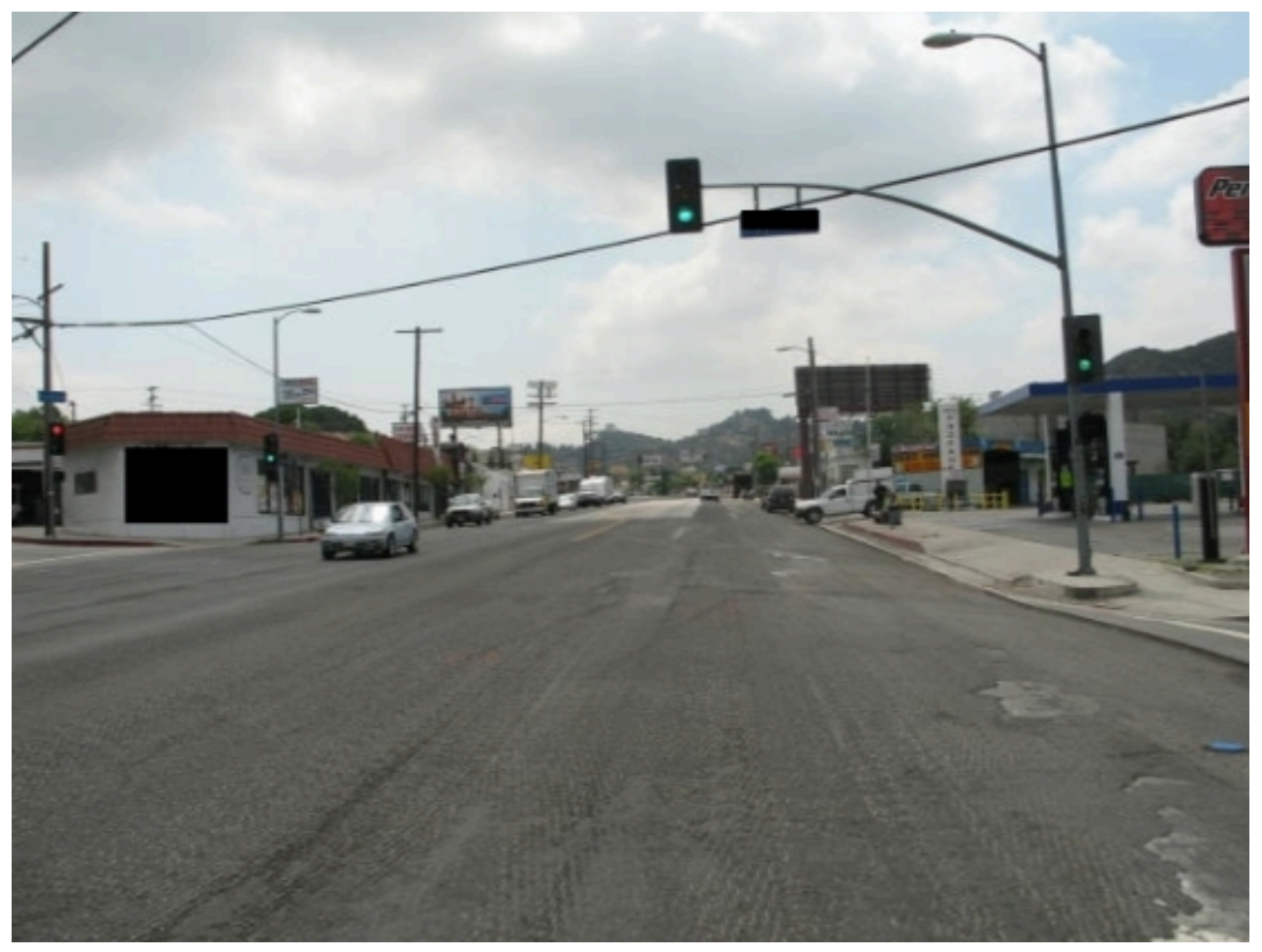




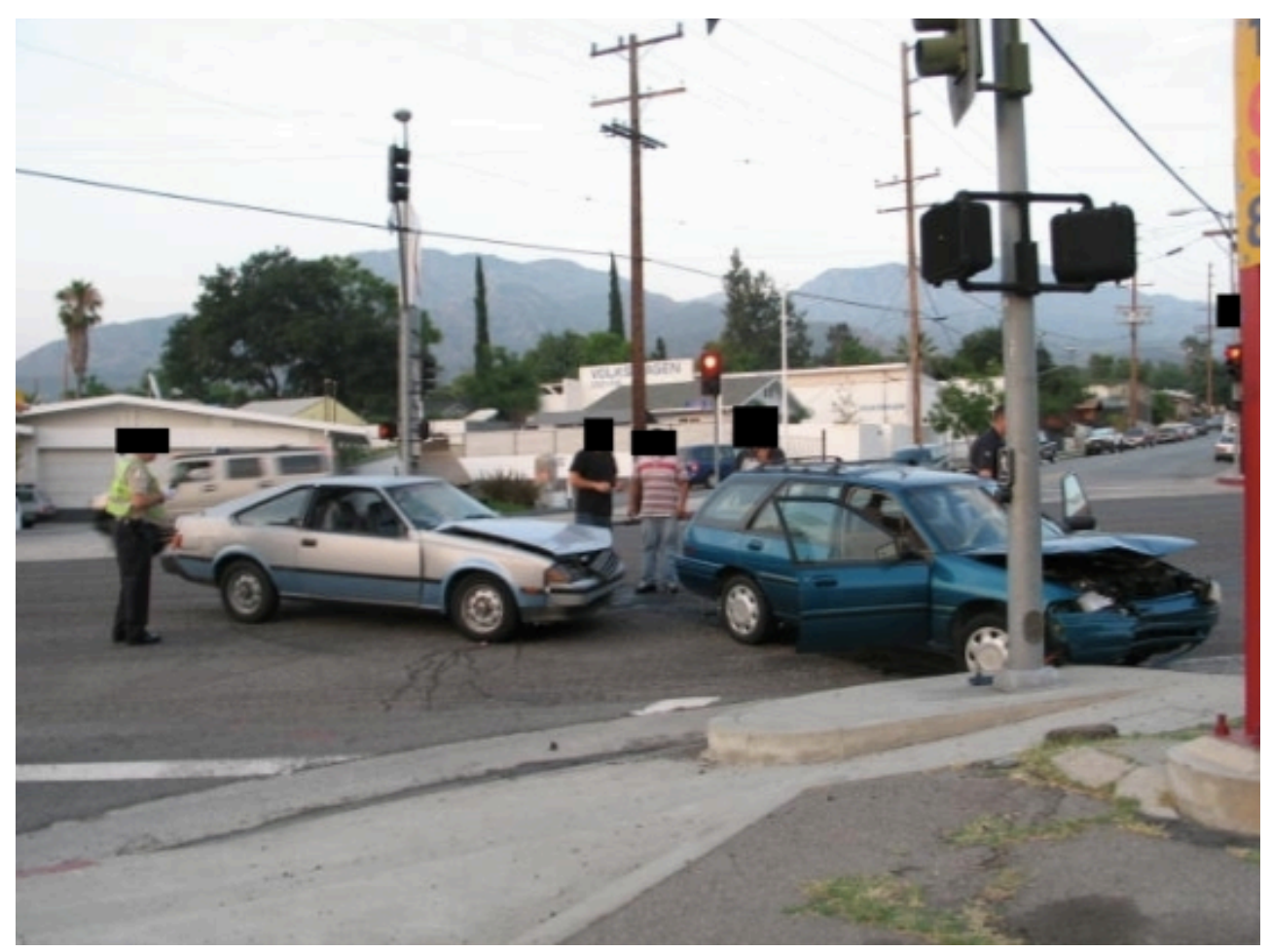

Additional Information: Facility type, crash type, and work zone type are not specific fields in the NMVCCS crash reports like they were in the Virginia crash reports. Therefore, they were determined from the crash description, diagram, and pictures. The crash diagram illustrates that this was an angle crash. The crash description, diagram, and pictures indicate the crash occurred at an intersection. Therefore, the facility type is classified as "Non-Freeway". The crash description describes the work zone as "the travel lanes in both directions had undergone resurfacing preparation by a riding grinder, removing lane lines and leaving the road surface very rough. The pictures show no active work zone in progress. The road must have been milled in preparation for resurfacing and then left as was until resurfacing was ready. Therefore, the work zone type is classified as "Other". 
Reasoning: The pictures do not show a work zone present in the intersection at the time of the crash. The crash description does not mention the work zone's presences, only that the road was very rough due to resurfacing preparations. From the crash description, it is clear that the crash resulted from the 81 -year old driver of vehicle 1 misjudging gap distance. This does not appear to be related to the unpaved roadway. Therefore, the crash is unrelated to a work zone and categorized as a Not Related crash. The crash is categorized into the broad crash category of "Misjudged Gap". 


\section{CHAPTER 4: VIRGINIA DATA ANALYSIS}

The analytical results of the Virginia dataset will be presented and discussed in this section. Of the 6,774 total Virginia Coded crashes identified as occurring within a work zone area, 6424 Coded crashes belonged to the four primary crash types (rear-end, angle, sideswipe - same direction, and fixed object - off road) analyzed in this paper. Of these, $23.0 \%$ were found to be influenced by the presence of a work zone (Directly Related crashes). It is still possible that the work zones may have contributed to some aspect of the remaining $77.0 \%$ of Coded crashes, but insufficient information was available to make a direct determination. Thus, the $23.0 \%$ of crashes attributable to the work zone should be viewed as a conservative (low) estimate. Interestingly, this finding falls between Ullman et al.'s (2008) CMFs for a non-active, no lane closure work zone and an active, no lane closure work zone.

This section begins with a high-level overview comparison between Total (work zone and non-work zone) crashes, Coded crashes, and Directly Related crashes within the Virginia datasets for the four primary crash types. Comparisons between crash type and work zone type are also examined. This is followed by identification and discussion of the most common crash causes for Directly Related crashes. Characteristics of Directly Related crashes are explored, including an investigation of objects hit and actions of any work zone vehicles involved in crashes. 


\subsection{Virginia High-Level Comparisons}

\subsubsection{Virginia Crashes by Roadway and Crash Type}

Certain roadway types may be overrepresented during work zone crash analysis. Approximately $23.4 \%$ of Total crashes were interstate crashes, but Coded and Directly Related crashes exhibited interstate proportions of about $56.5 \%$ and $56.7 \%$ respectively. Thus, overall work zone statistics may be skewed towards crash types that are more prevalent on the interstate system and understate crash types (like angle crashes) that are more common on primary and secondary routes. It is important to note that this study did not have access to the number, duration, length, or location of Virginia work zones. Currently, VDOT does not collect information on work zone exposure levels in a systematic manner. Thus, even though it is probable that the increased interstate crash proportions are due to a larger number of work zones on freeways, this cannot be concluded with certainty without work zone exposure information. Changes in facility type proportions are reflected in the crash count numbers displayed within parentheses in Table 4.1. Table 4.1 compares the Total, Coded, and Directly Related crash type

proportions by facility type (i.e., interstate, primary road, and secondary road). 
Table 4.1: Summary of Crashes by Roadway and Crash Type, 2011-2012

\begin{tabular}{|c|c|c|c|c|}
\hline Facility Type & Crash Type & $\begin{array}{l}\text { Total Crashes } \\
\text { (\%, Count) }\end{array}$ & $\begin{array}{l}\text { Coded Work } \\
\text { Zone Crashes (\%, } \\
\text { Count) }\end{array}$ & $\begin{array}{l}\text { Directly Related } \\
\text { Work Zone Crashes } \\
\text { (\%, Count) }\end{array}$ \\
\hline \multirow{4}{*}{ Interstate } & Rear-end & $\begin{array}{c}51.1 \% \\
(14,570) \\
\end{array}$ & $\begin{array}{l}60.5 \% \\
(2,195) \\
\end{array}$ & $\begin{array}{c}41.0 \% \\
(344) \\
\end{array}$ \\
\hline & Angle & $\begin{array}{c}8.0 \% \\
(2,272)\end{array}$ & $\begin{array}{l}8.8 \% \\
(319) \\
\end{array}$ & $\begin{array}{l}5.0 \% \\
(42)\end{array}$ \\
\hline & $\begin{array}{l}\text { Sideswipe - Same } \\
\text { Direction }\end{array}$ & $\begin{array}{l}13.4 \% \\
(3,815)\end{array}$ & $\begin{array}{l}17.0 \% \\
(618)\end{array}$ & $\begin{array}{l}9.4 \% \\
(79)\end{array}$ \\
\hline & $\begin{array}{l}\text { Fixed Object - Off } \\
\text { Road }\end{array}$ & $\begin{array}{l}27.6 \% \\
(7,883) \\
\end{array}$ & $\begin{array}{l}13.6 \% \\
(495) \\
\end{array}$ & $\begin{array}{c}44.6 \% \\
(374) \\
\end{array}$ \\
\hline \multirow{4}{*}{ Primary } & Rear-end & $\begin{array}{c}45.0 \% \\
(22,529) \\
\end{array}$ & $\begin{array}{l}60.4 \% \\
(1,163) \\
\end{array}$ & $\begin{array}{l}54.7 \% \\
(244) \\
\end{array}$ \\
\hline & Angle & $\begin{array}{c}26.9 \% \\
(13,450)\end{array}$ & $\begin{array}{c}22.6 \% \\
(435)\end{array}$ & $\begin{array}{l}15.9 \% \\
(71)\end{array}$ \\
\hline & $\begin{array}{l}\text { Sideswipe - Same } \\
\text { Direction }\end{array}$ & $\begin{array}{c}7.1 \% \\
(3,570) \\
\end{array}$ & $\begin{array}{l}10.5 \% \\
(202) \\
\end{array}$ & $\begin{array}{c}16.1 \% \\
(72)\end{array}$ \\
\hline & $\begin{array}{l}\text { Fixed Object - Off } \\
\text { Road }\end{array}$ & $\begin{array}{c}20.9 \% \\
(10,478)\end{array}$ & $\begin{array}{l}6.6 \% \\
(127) \\
\end{array}$ & $\begin{array}{c}13.2 \% \\
(59)\end{array}$ \\
\hline \multirow{4}{*}{ Secondary } & Rear-end & $\begin{array}{c}26.1 \% \\
(11,384)\end{array}$ & $\begin{array}{l}41.8 \% \\
(287) \\
\end{array}$ & $\begin{array}{c}48.8 \% \\
(78) \\
\end{array}$ \\
\hline & Angle & $\begin{array}{c}31.4 \% \\
(13,698) \\
\end{array}$ & $\begin{array}{c}38.3 \% \\
(263) \\
\end{array}$ & $\begin{array}{c}22.5 \% \\
(36) \\
\end{array}$ \\
\hline & $\begin{array}{l}\text { Sideswipe - Same } \\
\text { Direction }\end{array}$ & $\begin{array}{c}4.5 \% \\
(1952)\end{array}$ & $\begin{array}{c}9.9 \% \\
(68)\end{array}$ & $\begin{array}{c}10.0 \% \\
(16)\end{array}$ \\
\hline & $\begin{array}{l}\text { Fixed Object - Off } \\
\text { Road }\end{array}$ & $\begin{array}{c}38.0 \% \\
(16,603) \\
\end{array}$ & $\begin{array}{c}10.0 \% \\
(69) \\
\end{array}$ & $\begin{array}{c}18.8 \% \\
(30) \\
\end{array}$ \\
\hline \multirow{4}{*}{$\begin{array}{l}\text { All Facility } \\
\text { Types }\end{array}$} & Rear-end & $\begin{array}{c}39.7 \% \\
(48,483) \\
\end{array}$ & $\begin{array}{l}58.3 \% \\
(3,745) \\
\end{array}$ & $\begin{array}{l}45.9 \% \\
(679) \\
\end{array}$ \\
\hline & Angle & $\begin{array}{c}24.1 \% \\
(29,420) \\
\end{array}$ & $\begin{array}{l}16.5 \% \\
(1,062) \\
\end{array}$ & $\begin{array}{c}10.8 \% \\
(160) \\
\end{array}$ \\
\hline & $\begin{array}{l}\text { Sideswipe - Same } \\
\text { Direction }\end{array}$ & $\begin{array}{c}7.6 \% \\
(9,337)\end{array}$ & $\begin{array}{l}14.1 \% \\
(906)\end{array}$ & $\begin{array}{l}11.5 \% \\
(170)\end{array}$ \\
\hline & $\begin{array}{l}\text { Fixed Object - Off } \\
\text { Road }\end{array}$ & $\begin{array}{c}28.6 \% \\
(34,964) \\
\end{array}$ & $\begin{array}{l}11.1 \% \\
(711) \\
\end{array}$ & $\begin{array}{l}31.8 \% \\
(471)\end{array}$ \\
\hline
\end{tabular}

* Each facility types' crash type proportions sum vertically to $100 \%$. For example, $41.0 \%$ of Directly Related interstate crashes were rear-end crashes.

** Percentages are based on the summation of rear-end, angle, sideswipe-same direction, and fixed object - off road crashes. Other crash types are excluded for consistency.

When the crash type proportions are compared between the Total crashes and Coded work zone crashes, it appears that the likelihood of rear-end and sideswipe - same direction crashes increased, while the proportion of fixed object - off road crashes decreased. This trend was seen across all three facility types. Angle crashes increased for interstate and secondary roads, but decreased for primary routes. 
Trends differed when Coded crashes were compared with crashes determined to be influenced by the work zone. A chi-square test found Coded and Directly Related crash type distributions to be significantly different at an alpha $=0.05$ for interstates, primary roads, secondary roads, and all facilities. In all cases, the proportion of fixed object - off road crashes was higher in the Directly Related dataset than in the Coded dataset. This difference was most pronounced within the interstate dataset. Sideswipe same direction crash proportions were greater within the Directly Related dataset for primary roads, while rear-end crashes were greater for secondary roads.

It is possible that the Directly Related crash distribution is skewed due to an overrepresentation of fixed object - off road crashes. If a Virginia crash report listed a work zone object (i.e., jersey barrier, impact cushion, work zone maintenance equipment) under the field "First Harmful Event", then the crash was considered to be influenced by the work zone unless contradicted by the crash description. This definition resulted in a large number of fixed object - off road crashes being categorized as Directly Related crashes. An overrepresentation of fixed object - off road crashes would cause the proportion of other crash types to appear artificially low.

\subsubsection{Virginia Work Zone Types}

It is also possible that certain work zone types could be influencing changes in crash type proportions between Total, Coded, and Directly Related crashes. Table 4.2 displays Directly Related crash types by work zone type. While it would have been ideal to contrast these crash frequency numbers with measures of work zone exposure such as work zone VMT, that was not possible with existing DOT data systems. While the 
development of work zone exposure measures is an active area of work within VDOT, data systems that could quantify exposure were not available as of the date of this thesis.

Table 4.2: Crash Type vs. Work Zone Type (Directly Related Crashes)

\begin{tabular}{|c|c|c|c|c|c|c|c|}
\hline & Crash Type & $\begin{array}{c}\text { \# of } \\
\text { Crashes }\end{array}$ & $\begin{array}{c}\text { Lane } \\
\text { Closure }\end{array}$ & $\begin{array}{l}\text { Lane Shift/ } \\
\text { Crossover }\end{array}$ & $\begin{array}{c}\text { Work on } \\
\text { Shoulder or } \\
\text { Median }\end{array}$ & $\begin{array}{l}\text { Intermittent } \\
\text { or Moving } \\
\text { Work }\end{array}$ & Other \\
\hline \multirow{4}{*}{ 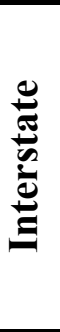 } & Rear End & 344 & $\begin{array}{l}73.0 \% \\
(251)\end{array}$ & $\begin{array}{c}5.2 \% \\
(18)\end{array}$ & $\begin{array}{c}12.5 \% \\
(43)\end{array}$ & $\begin{array}{l}7.3 \% \\
(25)\end{array}$ & $\begin{array}{c}2.0 \% \\
(7)\end{array}$ \\
\hline & Angle & 42 & $\begin{array}{c}57.1 \% \\
(24) \\
\end{array}$ & $\begin{array}{c}2.4 \% \\
(1)\end{array}$ & $\begin{array}{c}33.3 \% \\
(14)\end{array}$ & $\begin{array}{l}4.8 \% \\
(2)\end{array}$ & $\begin{array}{c}2.4 \% \\
(1) \\
\end{array}$ \\
\hline & $\begin{array}{l}\text { Sideswipe - } \\
\text { Same Direction }\end{array}$ & 79 & $\begin{array}{c}58.2 \% \\
(46) \\
\end{array}$ & $\begin{array}{l}8.9 \% \\
(7)\end{array}$ & $\begin{array}{c}24.1 \% \\
(19) \\
\end{array}$ & $\begin{array}{l}6.3 \% \\
(5)\end{array}$ & $\begin{array}{c}2.5 \% \\
(2) \\
\end{array}$ \\
\hline & $\begin{array}{l}\text { Fixed Object - } \\
\text { Off Road }\end{array}$ & 374 & $\begin{array}{c}10.7 \% \\
(40)\end{array}$ & $\begin{array}{c}3.7 \% \\
(14) \\
\end{array}$ & $\begin{array}{c}74.3 \% \\
(278) \\
\end{array}$ & $\begin{array}{c}2.4 \% \\
(9) \\
\end{array}$ & $\begin{array}{c}8.8 \% \\
(33) \\
\end{array}$ \\
\hline \multirow{4}{*}{ 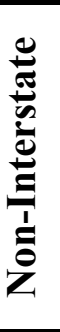 } & Rear End & 335 & $\begin{array}{l}53.7 \% \\
(180) \\
\end{array}$ & $\begin{array}{c}12.5 \% \\
(42) \\
\end{array}$ & $\begin{array}{c}14.6 \% \\
(49) \\
\end{array}$ & $\begin{array}{l}8.7 \% \\
(29) \\
\end{array}$ & $\begin{array}{c}10.4 \% \\
(35) \\
\end{array}$ \\
\hline & Angle & 118 & $\begin{array}{c}48.3 \% \\
(57)\end{array}$ & $\begin{array}{c}11.0 \% \\
(13)\end{array}$ & $\begin{array}{c}20.3 \% \\
(24)\end{array}$ & $\begin{array}{c}6.8 \% \\
(8)\end{array}$ & $\begin{array}{c}13.6 \% \\
(16)\end{array}$ \\
\hline & $\begin{array}{l}\text { Sideswipe - } \\
\text { Same Direction }\end{array}$ & 91 & $\begin{array}{c}52.7 \% \\
(48)\end{array}$ & $\begin{array}{c}13.2 \% \\
(12)\end{array}$ & $\begin{array}{c}17.6 \% \\
(16)\end{array}$ & $\begin{array}{c}12.1 \% \\
(11)\end{array}$ & $\begin{array}{c}4.4 \% \\
(4)\end{array}$ \\
\hline & $\begin{array}{l}\text { Fixed Object - } \\
\text { Off Road }\end{array}$ & 97 & $\begin{array}{c}17.5 \% \\
(17) \\
\end{array}$ & $\begin{array}{c}8.2 \% \\
(8) \\
\end{array}$ & $\begin{array}{c}55.7 \% \\
(54) \\
\end{array}$ & $\begin{array}{c}8.2 \% \\
(8) \\
\end{array}$ & $\begin{array}{c}10.3 \% \\
(10)\end{array}$ \\
\hline \multirow{4}{*}{ 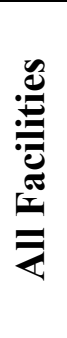 } & Rear End & 679 & $\begin{array}{c}63.5 \% \\
(431) \\
\end{array}$ & $\begin{array}{c}8.8 \% \\
(60) \\
\end{array}$ & $\begin{array}{c}13.5 \% \\
(92) \\
\end{array}$ & $\begin{array}{l}8.0 \% \\
(54) \\
\end{array}$ & $\begin{array}{c}6.2 \% \\
(42) \\
\end{array}$ \\
\hline & Angle & 160 & $\begin{array}{c}50.6 \% \\
(81) \\
\end{array}$ & $\begin{array}{c}8.8 \% \\
(14) \\
\end{array}$ & $\begin{array}{c}23.8 \% \\
(38) \\
\end{array}$ & $\begin{array}{c}6.3 \% \\
(10) \\
\end{array}$ & $\begin{array}{c}10.6 \% \\
(17) \\
\end{array}$ \\
\hline & $\begin{array}{l}\text { Sideswipe - } \\
\text { Same Direction }\end{array}$ & 170 & $\begin{array}{l}55.3 \% \\
(94) \\
\end{array}$ & $\begin{array}{c}11.2 \% \\
(19) \\
\end{array}$ & $\begin{array}{c}20.6 \% \\
(35) \\
\end{array}$ & $\begin{array}{c}9.4 \% \\
(16) \\
\end{array}$ & $\begin{array}{c}3.5 \% \\
(6) \\
\end{array}$ \\
\hline & $\begin{array}{l}\text { Fixed Object - } \\
\text { Off Road }\end{array}$ & 471 & $\begin{array}{c}12.1 \% \\
(57)\end{array}$ & $\begin{array}{c}4.7 \% \\
(22) \\
\end{array}$ & $\begin{array}{l}70.5 \% \\
(332)\end{array}$ & $\begin{array}{c}3.6 \% \\
(17)\end{array}$ & $\begin{array}{c}9.1 \% \\
(43) \\
\end{array}$ \\
\hline
\end{tabular}

* Each crash types' work zone type proportions sum horizontally to $100 \%$. For example, $73.0 \%$ of interstate rear-end crashes occurred in a lane closure work zone.

It is important to note that lane closure crashes comprise a large proportion (44.8\%) of all Directly Related work zone types. This reinforces Ullman et al.'s (2008) earlier findings that lane closure work zones had a higher CMF than other work zone types.

From Table 4.2, it appears that rear-end crashes occurring in a lane closure work zone are a large contributor to the increase in rear-end crash proportions seen in Table 4.1. Similarly, fixed object - off road crashes occurring on interstates in shoulder or 
median work zones are contributing to the increase in fixed object - off road crashes. Key contributing factors for these and other crash type increases are identified and discussed in the next section.

\subsection{Virginia Work Zone Causal Factors}

This section goes beyond the high-level overview of roadway and crash type distributions and identifies the major causes of work zone crashes. Only work zone crashes determined to be influenced by the work zone (i.e., Directly Related crashes) were used for this analysis. Practitioners often cite speeding as a contributing factor to work zone crashes, but only thirty (2.0\%) of all 1480 Directly Related crashes were coded as traveling too fast for conditions but did not exceed the posted speed limit. Seventeen (1.1\%) additional crashes were coded as traveling above the posted speed limit. The three most common crash cause categories for each crash type are displayed in Table 4.3.

Table 4.3: Summary of Crash Causes Directly Related to Work Zone Presence

\begin{tabular}{|c|c|c|c|c|c|}
\hline $\begin{array}{l}\text { Crash } \\
\text { Type }\end{array}$ & $\begin{array}{l}\text { \# of Directly } \\
\text { Related } \\
\text { Crashes } \\
\end{array}$ & $\begin{array}{l}\text { \% of Coded } \\
\text { Crash Type }\end{array}$ & $\begin{array}{l}1^{\text {st }} \text { Most Common } \\
\text { Cause }\end{array}$ & $\begin{array}{l}2^{\text {nd }} \text { Most Common } \\
\text { Cause }\end{array}$ & $\begin{array}{l}3^{\text {rd }} \text { Most Common } \\
\text { Cause }\end{array}$ \\
\hline Rear-end & 679 & $18.1 \%$ & $\begin{array}{l}\text { Stopping/ slowing } \\
\text { due to work zone } \\
(76.4 \%, 519 \\
\text { crashes) }\end{array}$ & $\begin{array}{l}\text { Changing lanes due } \\
\text { to work zone }(8.5 \% \text {, } \\
58 \text { crashes })\end{array}$ & $\begin{array}{l}\text { Work zone vehicle } \\
\text { entering/exiting } \\
\text { work zone }(1.9 \% \text {, } \\
13 \text { crashes) }\end{array}$ \\
\hline Angle & 160 & $15.1 \%$ & $\begin{array}{l}\text { Changing lanes due } \\
\text { to work zone } \\
(22.5 \%, 36 \text { crashes })\end{array}$ & $\begin{array}{l}\text { Confusion due to } \\
\text { work zone traffic } \\
\text { control }(21.3 \%, 34 \\
\text { crashes) }\end{array}$ & $\begin{array}{l}\text { Limited sight } \\
\text { distance due to } \\
\text { work zone ( } 11.9 \% \text {, } \\
19 \text { crashes) }\end{array}$ \\
\hline $\begin{array}{l}\text { Sideswipe } \\
\text { - Same } \\
\text { Direction }\end{array}$ & 170 & $18.8 \%$ & $\begin{array}{l}\text { Changing lanes due } \\
\text { to work zone } \\
(62.4 \%, 106 \\
\text { crashes) }\end{array}$ & $\begin{array}{l}\text { Work zone vehicle } \\
\text { entering/exiting } \\
\text { work zone }(5.3 \%, 9 \\
\text { crashes) }\end{array}$ & $\begin{array}{l}\text { Unauthorized work } \\
\text { zone entry }(4.1 \%, 7 \\
\text { crashes) }\end{array}$ \\
\hline $\begin{array}{l}\text { Fixed } \\
\text { Object - } \\
\text { Off Road }\end{array}$ & 471 & $66.2 \%$ & $\begin{array}{l}\text { Unknown, but work } \\
\text { zone device/ barrier } \\
\text { was struck ( } 37.4 \% \text {, } \\
176 \text { crashes) }\end{array}$ & $\begin{array}{l}\text { Lost control, struck } \\
\text { work zone device/ } \\
\text { barrier }(23.4 \%, 110 \\
\text { crashes) }\end{array}$ & $\begin{array}{l}\text { Avoiding crash with } \\
\text { another vehicle or } \\
\text { object }(14.6 \%, 69 \\
\text { crashes) }\end{array}$ \\
\hline
\end{tabular}




\subsubsection{Virginia Rear-end Crashes}

The most common crash cause categories for Directly Related rear-end crashes indicate a strong correlation between velocity and/or lane changes and rear-end crashes. Combining this finding with the large proportion of lane closure rear-end crashes seen in Table 4.2, suggests that congestion created by vehicles merging at a work zone lane closure is a large contributor to increased rear-end crashes. Definitions and further information about the most common rear-end crash cause categories displayed in Table 4.3 are given below.

Stopping/ slowing due to work zone. This category included 519 crashes resulting from vehicles stopping/slowing due to some aspect of the work zone. This does not include crashes caused by stopping or slowing due to a flagman, police officer, or work zone sign. Crash causes included in this category are:

$>$ Congestion. For rear-ends, 296 of the 519 crashes in this crash cause category were related to congestion at the work zone. Only crashes that were attributed to abnormal congestion were included in this category. Crashes attributed to recurring congestion, like congestion occurring during peak periods, were not included. The majority of these crashes $(73.0 \%)$ occurred during a lane closure work zone. Only six of these crashes were coded as traveling too fast for conditions but not exceeding the posted speed limit. One additional crash was coded as traveling above the posted speed limit.

Stopping/slowing for flagman, police officer, or work zone sign. Eighty of the 519 crashes in this category occurred when vehicles stopped at the direction of a flagman, police officer, or work zone traffic control. Traffic stopping for flaggers was responsible for 73 out of 80 crashes in this category. Only five of 
these crashes were coded as traveling too fast for conditions but not exceeding the posted speed limit.

Merging. Fifty of the 519 rear-end crashes in this category occurred while a vehicle was stopping/slowing due merging maneuvers. Vehicles involved in these crashes were not actively changes lanes. They were either waiting to change lanes or were waiting for other non-involved vehicles to change lanes. Only one of these crashes was coded as traveling too fast for conditions but not exceeding the posted speed limit. This included crashes involving either:

- Congestion caused by merging at a lane closure or crossover (27 crashes)

- A vehicle slowing to allow another vehicle to merge (12 crashes)

- A vehicle stopped in the closed lane waiting to merge (9 crashes)

- An existing highway acceleration lane shortened by the work zone (2 crashes).

Hazard. Twenty-six of the 519 rear-end crashes in this category were related to avoiding a work zone hazard in the travel lane. Typical hazards included avoiding equipment that had fallen into a travel lane, work zone channelizing devices, bumps, or roadway debris created by work zone activity.

$>$ Other. Ten of the 519 rear-end crashes in this category were related to confusion caused by the work zone traffic control. The remaining $57 \mathrm{crash}$ reports contained non-specific information about the reason for the deceleration (e.g., "Vehicle 1 slowed due to work zone. Vehicle 2 rear-ended Vehicle 1").

Changing lanes due to work zone. This category included crashes involving a vehicle actively in the process of, or just completing, changing lanes due to a work 
zone. About $58.6 \%$ of these crashes occurred in the advance warning area or transition area during a lane closure work zone. Only one of these crashes was coded as traveling too fast for conditions but not exceeding the posted speed limit. Two additional crashes were coded as traveling above the posted speed limit.

Work zone vehicle entering/exiting work zone. This category included crashes involving work vehicles that were entering or exiting a work zone. These crashes are discussed further within the Work Zone Vehicle section later in this paper. Five of these 13 rear-end crashes occurred on interstates. None of these crashes were coded as traveling too fast for conditions or exceeding the posted speed limit.

\subsubsection{Virginia Angle Crashes}

About $50.6 \%$ of Directly Related angle crashes occurred in a lane closure work zone, and another $15.0 \%$ occurred in a crossover or intermittent/moving work zone. This explains why changing lanes are the most common crash cause in Table 4.3. However, confusing work zone traffic control or limited sight distance also contributed to angle crashes, particularly at intersections. Definitions and further information about the most common angle crash cause categories displayed in Table 4.3 are given below.

Changing lanes due to work zone. This classification involved crashes where a vehicle was actively in the process of changing lanes due to a work zone. About $61.1 \%$ of these crashes occurred in the advance warning area or transition area during a lane closure work zone. Only one of these crashes was coded as traveling above the posted speed limit.

Confusion due to work zone traffic control. These crash reports' narrative noted driver confusion about some aspect of the work zone. All of these crashes occurred 
on non-interstate routes. Twelve of these crashes were attributed to confusion over unmarked lanes as a result of repaving or construction work. Eight crashes involved improper work zone instruction by either a flagman or a member of the work crew. Seven crashes involved a change in traffic patterns, causing the driver to be unaware that a lane or street was closed. In cases when a turn lane was closed, the driver was confused about how to properly execute the turn. Only one of these crashes was coded as traveling above the posted speed limit.

Limited sight distance due to work zone. This category included crashes attributed to a decrease in sight distance or visibility due to a work zone obstruction, including construction equipment, construction vehicles (both parked and not parked), and/or construction signs. Nine of these crashes occurred at a minor road stop-controlled intersection. In all of these cases, the stopped minor road vehicle could not see around work zone obstruction and was hit by a major road vehicle. Six of these crashes occurred at a 4-leg signalized intersection where both parties had a green ball, but the turning vehicle did not yield right-of-way because the driver's sight was obscured by a work zone obstruction.

\subsubsection{Virginia Sideswipe - Same Direction}

Similar to rear-end and angle crashes, about $55.3 \%$ of sideswipe - same direction crashes occurred at a lane closure work zone and another $20.6 \%$ occurred in a crossover or intermittent/moving work zone. This explains why changing lanes is the most common crash cause in Table 4.3. In addition, work zone entry and exit of both authorized work zone vehicles and unauthorized vehicles were two significant crash causes for this crash 
type. Definitions and further information about the most common sideswipe - same direction crash cause categories displayed in Table 4.3 are given below.

Changing lanes due to work zone. This category included crashes involving a vehicle actively in the process of changing lanes due to a work zone. About $53.9 \%$ of these crashes occurred in the advance warning area or transition area during a lane closure work zone. Only one of these crashes was coded as traveling above the posted speed limit.

Work zone vehicle entering/exiting work zone. This category included crashes involving work vehicles that were entering or exiting a work zone. These crashes are discussed further within the Work Zone Vehicle section later in this paper. Eight of these 9 sideswipe - same direction crashes occurred on interstates. While interstates crashes are overrepresented in the Virginia dataset, this result still suggests that work zone vehicles are finding it more difficult to merge into and out of interstate work zones than other facility types, possibly due to higher speeds. Only one of these crashes was coded as traveling too fast for conditions but not exceeding the posted speed limit.

Unauthorized work zone entry. This category included crashes involving vehicles entering a work zone in order to make an illegal maneuver, usually striking cones and/or barrels during the vehicle's entry or exit. Only one of these crashes was coded as traveling too fast for conditions but not exceeding the posted speed limit.

\subsubsection{Virginia Fixed Object Off Road Crashes}

This crash type exhibited the largest percentage of Coded crashes determined to be Directly Related crashes (about $66.2 \%$ in Table 4.3 ). This is likely due to how Directly 
Related work zone crashes were defined. Any crash where a vehicle hit a work zone object was designated as a Directly Related crash. The consequence of using this definition is that many of these crash reports contained vague crash descriptions. Therefore, the most common crash causes for fixed object - off road crashes were "Unknown" or "Lost Control (usually due to an unknown reason)".

About $74.3 \%$ of interstate (or $70.5 \%$ of all facility types) fixed object - off road crashes occurred during a shoulder or median work zone (Table 4.2). This is contrary to the other crash types which experienced the largest amount of crashes in lane closure work zones. Further, it is unusual that the proportion of fixed object - off road crashes in shoulder or median work zones is so large given that lane closure work zones are overrepresented. A likely explanation of this is that the work zones have installed concrete barriers to protect work activity during construction while trying to maintain the base number of lanes. Definitions and further information about the most common fixed object - off road crash cause categories displayed in Table 4.3 are given below.

Unknown, but work zone device/ barrier was struck. This category included crashes involving either a collision with a work zone object or crashes that were determined to have possible connections to the work zone. However, the crash cause was unable to be determined from the crash report's narrative. Only three of these crashes were coded as traveling too fast for conditions but not exceeding the posted speed limit. Three additional crashes were coded as traveling above the posted speed limit.

Lost control, struck work zone device/ barrier. This category included crashes attributed to the driver losing control of the vehicle. For 99 of the 110 crashes in this 
category, the reason for the driver's loss of control was not included in the crash report narrative. Only three of these crashes were coded as traveling too fast for conditions but not exceeding the posted speed limit. Two additional crashes were coded as traveling above the posted speed limit.

Avoiding crash with another vehicle or object. This category included crashes attributed to the driver swerving off-road in an effort to avoid a collision with another vehicle or object. Thirty-seven of these 69 crashes were caused by the vehicle trying to avoid what would have been a sideswipe - same direction crash, while 26 were caused by avoiding a rear-end collision.

\subsubsection{Virginia Fixed Object - Off Road First Object Hit}

The first object hit during a fixed object-off road crash was examined to determine the most common objects that were struck. This object was determined from a combined consideration of the "First Harmful Event" field and the crash narrative. If a crash report's narrative indicated that the crash involved a work zone vehicle or piece of work zone equipment, this information was used instead of the information provided by "First Harmful Event". The three most common objects hit within this crash type and their respective proportions of all Directly Related fixed object - off road crashes were:

- Work zone jersey barrier (58.2\%). These crashes involved a vehicle encountering a jersey wall as its first object hit.

- Impact cushioning device (26.5\%). These crashes involved hitting a stationary impact cushioning device (not mounted to a work zone vehicle).

- Traffic control equipment (5.9\%). These crashes involved a vehicle exiting the roadway and encountering a piece of traffic control equipment (i.e., channelizing devices, work zone signs). 


\subsubsection{Virginia Work Zone Vehicles}

Work zone vehicles were the second most common object hit for rear-end, angle, and sideswipe - same direction crashes (the first most common object hit was another vehicle in transport). They were the third most common object hit across all the crash types, causing them to be involved in $10.1 \%$ (149 crashes) of all Directly Related crashes. Because crashes involving work zone vehicles contribute significantly to the overall crash count, these crashes were further investigated. Table 4.4 displays categories, crash counts, and crash proportions for crashes involving work zone vehicles. These categories indicate the location or action of the work zone vehicle during the crash.

Crash trucks with traffic impact attenuators at lane closures or mobile work zones were the most common type of work vehicle struck. These 57 crashes $(38.3 \%$ of all work vehicle crashes) involved a vehicle fulfilling its function by protecting the work crews. The second most common situation where a work vehicle was struck was when a nonwork zone vehicle intruded into the workspace and struck a work vehicle. The third most common case involved work zone vehicles entering or leaving the work zone. 
Table 4.4 Location/Action of Work Zone Vehicles Involved in Crashes

\begin{tabular}{|l|c|c|}
\hline Location/Action of Work Zone Vehicle & $\begin{array}{l}\text { Number of Crashes } \\
\text { Involving a Work Zone } \\
\text { Vehicle }\end{array}$ & $\begin{array}{l}\text { Percentage of Crashes } \\
\text { Involving a Work Zone } \\
\text { Vehicle }\end{array}$ \\
\hline Vehicle stationary within work zone & 37 & $24.8 \%$ \\
\hline $\begin{array}{l}\text { Lane closure, stationary in lane at work } \\
\text { zone taper (crash protection vehicle) }\end{array}$ & 35 & $23.5 \%$ \\
\hline $\begin{array}{l}\text { Work zone vehicle entering/exiting work } \\
\text { zone }\end{array}$ & 27 & $18.1 \%$ \\
\hline $\begin{array}{l}\text { Mobile or intermittent work zone, } \\
\text { stationary or moving slowly in lane at } \\
\text { start of work zone (crash protection } \\
\text { vehicle) }\end{array}$ & 22 & $14.8 \%$ \\
\hline $\begin{array}{l}\text { Improper use/placement of vehicle or } \\
\text { equipment }\end{array}$ & 12 & $8.1 \%$ \\
\hline $\begin{array}{l}\text { Vehicle in transit within work zone, on } \\
\text { regular travel lane }\end{array}$ & 8 & $5.4 \%$ \\
\hline $\begin{array}{l}\text { Work zone vehicle hit another work zone } \\
\text { vehicle/pedestrian within work zone } \\
\text { activity area }\end{array}$ & 8 & $5.4 \%$ \\
\hline
\end{tabular}

\subsection{Virginia Data Summary}

This section showed that there are significant inconsistencies in the Virginia dataset between Coded crashes and Directly Related crashes. Therefore, Directly Related crashes need to be determined in order to develop reliable crash trend statistics, and help identify areas for future countermeasure deployment. Extracting Directly Related crashes and determining work zone crash causality is time-consuming and imprecise given current data limitations. Crash causal trends were sometimes difficult to identify in the Virginia dataset. Further, many Virginia Directly Related crash causes could not be identified due to insufficient information or a blank crash narrative. Stopping/slowing due to the work zone was the largest contributor to Directly Related rear-end crashes. Other prominent crash causes included changing lanes due to a lane merge, confusion related to work zone setup or layout, limited sight distance due to work zone, crashes involving a work zone 
vehicle entering/exiting work zone, and loss of control of the vehicle. Countermeasures for these crash causes will be recommended later in this thesis. 


\section{CHAPTER 5: NMVCCS AND LTCCS DATA ANALYSIS}

In contrast to the Virginia crash reports, the NMVCCS's and LTCCS's crash reports were very detailed and comprehensive. These datasets contained sufficient information to easily identify the crash cause in all Directly Related crashes. Therefore, analysis of the NMVCCS and LTCCS datasets will most likely provide more accurate information on the underlying causes of work zone crashes and yield different crash trends than those produced by the Virginia dataset.

The analysis results of both the NMVCCS and LTCCS datasets will be presented and discussed in this section. Due to the similarities between the two datasets, they will be discussed side-by-side. The NMVCCS dataset consists of 6949 crashes, of which 161 were identified as a work zone crash by a "1-Present" in the "Traffic Flow Interruption Factors: Construction Work Zone" field and/or the "Trafficway Flow Restriction: Work Zone" field. Of these 161 crashes, 143 belonged to the four primary crash types (rearend, angle, sideswipe - same direction, fixed object - off road) analyzed in this paper and are referred to as NMVCCS Coded crashes. Only 53.8\% (77 crashes) of the NMVCCS Coded crashes were determined to have been influenced by the presence of a work zone (i.e., NMVCCS Directly Related crashes). Another $21.0 \%$ of NMVCCS Coded crashes were determined to have no relationship to the work zone (i.e., Not Related crashes). The work zone's relationship to the remaining $25.2 \%$ of NMVCCS Coded crashes could not be determined due to insufficient information and are discussed later in this chapter in section 5.5 NMVCCS and LTCCS Possibly Related Crashes.

The LTCCS dataset consists of 1070 crashes, of which 70 were identified as work zone crashes by the presence of "Construction Work Zone" in the field "Traffic Flow 
Related Factors: Traffic Factor Element" and/or by the presence of "Work Zone" in the field "Trafficway relation to: Restrictions". Of these 70 crashes, 65 belonged to the four primary crash types analyzed in this paper and are referred to as LTCCS Coded crashes. Only $73.8 \%$ (48 crashes) of the LTCCS Coded crashes were determined to have been influenced by the presence of a work zone (i.e., LTCCS Directly Related crashes). Another $15.4 \%$ of LTCCS Coded crashes were determined to have no relationship to the work zone. The work zone's relationship to the remaining $10.8 \%$ of LTCCS Coded crashes could not be determined due to insufficient information. Thus, the $53.8 \%$ of NMVCC Coded crashes and the $73.8 \%$ of LTCCS Coded crashes directly attributable to the work zone should be viewed as conservative estimates.

This section begins with a high-level comparison between Coded crashes and Directly Related crashes within the NMVCCS and LTCCS datasets for the four primary crash types. Comparisons between crash type and work zone type are also examined. This is followed by identification and discussion of the most common crash causes for NMVCCS and LTCCS Directly Related crashes for the four primary crash types. Characteristics of Directly Related crashes are explored and actions of work zone vehicles involved in Directly Related crashes are discussed. This chapter concludes with an examination of NMVCCS Possibly Related crashes.

\subsection{NMVCCS \& LTCCS High-Level Comparisons}

\subsubsection{NMVCCS and LTCCS Crashes by Roadway and Crash Type}

Similar to the Virginia dataset, certain roadway types may be overrepresented during work zone crash analysis. Approximately $49.7 \%$ of NMVCCS Coded crashes were 
freeway crashes, while $56.6 \%$ of NMVCCS Directly Related crashes occurred on freeways. Therefore, Directly Related crash analysis may understate crash types (like angle crashes) that are more common on primary and secondary routes. One possible explanation for this is that 18 crashes of the NMVCCS intersection crashes fell into the NMVCCS Possibly Related crash category (18 is 50\% of the entire NMVCCS Possibly Related category and $23.4 \%$ of the NMVCCS Directly Related category). Determining a connection to the work zone for these crashes was difficult due to the complexity of intersection work zones and insufficient information about the work zone's relationship to the crash. This would result in a decrease in the proportion of non-freeway crashes. This shift in facility type proportions is reflected in the crash count numbers displayed within parentheses in Table 5.1. Table 5.1 compares both NMVCCS and LTCCS Coded and Directly Related crash type proportions. The NMVCCS dataset's results were broken down by facility type (freeway/non-freeway).

In the LTCCS dataset, approximately $87.7 \%$ of LTCCS Coded crashes were freeway crashes, as were $87.5 \%$ of LTCCS Directly Related crashes. This is understandable since this dataset is entirely composed of large truck crashes, which typically drive more often on freeways than non-freeways. As a result, non-freeway crash type proportions contain too few crashes to be meaningful. Thus, LTCCS results in Table 5.1 are not broken down by facility type. 
Table 5.1: NMVCCS \& LTCCS Summary of Crashes by Roadway and Crash Type, 2011-2012

\begin{tabular}{|c|c|c|c|}
\hline Facility Type & Crash Type & $\begin{array}{c}\text { Coded Work Zone Crashes } \\
\text { (\%, Count })\end{array}$ & $\begin{array}{l}\text { Directly Related Work Zone } \\
\text { Crashes (\%, Count) }\end{array}$ \\
\hline \multirow{4}{*}{$\begin{array}{l}\text { NMVCCS } \\
\text { Freeway }\end{array}$} & Rear-end & $\begin{array}{c}54.9 \% \\
(39)\end{array}$ & $\begin{array}{c}58.1 \% \\
(25)\end{array}$ \\
\hline & Angle & $\begin{array}{l}0 \% \\
(0)\end{array}$ & $\begin{array}{l}0 \% \\
(0)\end{array}$ \\
\hline & $\begin{array}{l}\text { Sideswipe - } \\
\text { Same Direction }\end{array}$ & $\begin{array}{c}14.1 \% \\
(10)\end{array}$ & $\begin{array}{c}16.3 \% \\
(7)\end{array}$ \\
\hline & $\begin{array}{l}\text { Fixed Object - } \\
\text { Off Road }\end{array}$ & $\begin{array}{c}31.0 \% \\
(22)\end{array}$ & $\begin{array}{c}25.6 \% \\
(11)\end{array}$ \\
\hline \multirow{4}{*}{$\begin{array}{l}\text { NMVCCS } \\
\text { Non-Freeway }\end{array}$} & Rear-end & $\begin{array}{c}29.2 \% \\
(21)\end{array}$ & $\begin{array}{c}41.2 \% \\
(14)\end{array}$ \\
\hline & Angle & $\begin{array}{c}58.3 \% \\
(42)\end{array}$ & $\begin{array}{c}44.1 \% \\
(15)\end{array}$ \\
\hline & $\begin{array}{l}\text { Sideswipe - } \\
\text { Same Direction }\end{array}$ & $\begin{array}{l}1.4 \% \\
(1)\end{array}$ & $\begin{array}{c}2.9 \% \\
(1)\end{array}$ \\
\hline & $\begin{array}{l}\text { Fixed Object - } \\
\text { Off Road }\end{array}$ & $\begin{array}{c}11.1 \% \\
(8)\end{array}$ & $\begin{array}{c}11.8 \% \\
(4)\end{array}$ \\
\hline \multirow{4}{*}{$\begin{array}{c}\text { NMVCCS } \\
\text { All Facility Types }\end{array}$} & Rear-end & $\begin{array}{c}42.0 \% \\
(60)\end{array}$ & $\begin{array}{c}50.6 \% \\
(39)\end{array}$ \\
\hline & Angle & $\begin{array}{c}29.4 \% \\
(42)\end{array}$ & $\begin{array}{c}19.5 \% \\
(15)\end{array}$ \\
\hline & $\begin{array}{l}\text { Sideswipe - } \\
\text { Same Direction }\end{array}$ & $\begin{array}{l}7.7 \% \\
(11)\end{array}$ & $\begin{array}{c}10.4 \% \\
(8)\end{array}$ \\
\hline & $\begin{array}{l}\text { Fixed Object - } \\
\text { Off Road }\end{array}$ & $\begin{array}{c}21.0 \% \\
(30)\end{array}$ & $\begin{array}{c}19.5 \% \\
(15)\end{array}$ \\
\hline \multirow{4}{*}{$\begin{array}{c}\text { LTCCS } \\
\text { All Facility Types }\end{array}$} & Rear-end & $\begin{array}{c}66.2 \% \\
(43)\end{array}$ & $\begin{array}{c}72.9 \% \\
(35)\end{array}$ \\
\hline & Angle & $\begin{array}{c}12.3 \% \\
(8)\end{array}$ & $\begin{array}{l}4.2 \% \\
(2)\end{array}$ \\
\hline & $\begin{array}{l}\text { Sideswipe - } \\
\text { Same Direction }\end{array}$ & $\begin{array}{c}12.3 \% \\
(8)\end{array}$ & $\begin{array}{c}12.5 \% \\
(6)\end{array}$ \\
\hline & $\begin{array}{l}\text { Fixed Object - } \\
\text { Off Road }\end{array}$ & $\begin{array}{l}9.2 \% \\
(6)\end{array}$ & $\begin{array}{c}10.4 \% \\
(5)\end{array}$ \\
\hline
\end{tabular}

* Each facility types' crash type proportions sum vertically to $100 \%$. For example, $58.1 \%$ of NMVCCS Directly Related freeway crashes were rear-end crashes.

** Percentages are based on the summation of rear-end, angle, sideswipe - same direction, and fixed object - off road crashes. Other crash types are excluded for consistency.

While there are small variations, there do not appear to be large differences in crash type proportions between the Coded and Directly Related crashes for either NMVCCS or LTCCS datasets, regardless of facility type. A chi-square test was used to examine whether there was a significant difference in the proportions of crashes in each 
crash type between the Directly Related and Coded crashes. The distributions were not significantly different at an alpha $=0.05$.

It is important to note that Table 5.1 displays NMVCCS and LTCCS crash proportions by roadway and crash type for all severity levels included in each dataset. As discussed in Chapter 3, the NMVCCS datasets contains KABCO crashes while the LTCCS dataset contains only KAB crashes. Therefore, results between the NMVCCS and LTCCS datasets are not directly comparable. However, even if similar severity levels were displayed in the Table 5.1 above, results might still not be directly comparable because each dataset focuses on different vehicle types.

\subsubsection{NMVCCS and LTCCS Work Zone Type}

Often the type of work zone influences increases or decreases in frequency of a particular crash type or crash cause. It is important to be aware of which work zone types are over/underrepresented in the NMVCCS and LTCCS datasets. In general, crashes involving a lane closure comprise a large proportion (58.4\%) of all NMVCCS Directly Related crashes and $64.0 \%$ of all LTCCS Directly Related crashes. Therefore, crashes occurring in lane closures may be over represented in this analysis. Table 5.2 compares work zone type crash proportions between Coded and Directly Related crashes for both NMVCCS and LTCCS datasets. 
Table 5.2: NMVCC \& LTCCS Work Zone Type (Directly Related Crashes)

\begin{tabular}{|c|c|c|c|c|}
\hline Work Zone Type & $\begin{array}{l}\text { NMVCCS Coded } \\
\text { Related Work Zone } \\
\text { Crashes (\%, } \\
\text { Count) }\end{array}$ & $\begin{array}{l}\text { NMVCCS } \\
\text { Directly Related } \\
\text { Work Zone } \\
\text { Crashes (\%, } \\
\text { Count) } \\
\end{array}$ & $\begin{array}{l}\text { LTCCS Coded } \\
\text { Related Work } \\
\text { Zone Crashes } \\
\text { (\%, Count) }\end{array}$ & $\begin{array}{l}\text { LTCCS Directly } \\
\text { Related Work } \\
\text { Zone Crashes } \\
\text { (\%, Count) }\end{array}$ \\
\hline Lane Closure & $\begin{array}{c}44.1 \% \\
(63)\end{array}$ & $\begin{array}{c}58.4 \% \\
(45)\end{array}$ & $\begin{array}{c}53.8 \% \\
(35) \\
\end{array}$ & $\begin{array}{c}64.6 \% \\
(31) \\
\end{array}$ \\
\hline Lane Shift/ Crossover & $\begin{array}{c}6.3 \% \\
(10) \\
\end{array}$ & $\begin{array}{c}7.8 \% \\
(7) \\
\end{array}$ & $\begin{array}{c}3.1 \% \\
(2)\end{array}$ & $\begin{array}{c}4.2 \% \\
(2)\end{array}$ \\
\hline Median/ Shoulder & $\begin{array}{c}21.7 \% \\
(32)\end{array}$ & $\begin{array}{c}23.4 \% \\
(19)\end{array}$ & $\begin{array}{c}21.5 \% \\
(14)\end{array}$ & $\begin{array}{c}12.5 \% \\
(6)\end{array}$ \\
\hline Intermittent/ Mobile & $\begin{array}{c}2.1 \% \\
(3)\end{array}$ & $\begin{array}{c}1.3 \% \\
(1)\end{array}$ & $\begin{array}{c}6.2 \% \\
(4)\end{array}$ & $\begin{array}{c}6.3 \% \\
(3)\end{array}$ \\
\hline Unknown & $\begin{array}{c}25.9 \% \\
(37) \\
\end{array}$ & $\begin{array}{c}9.1 \% \\
(7) \\
\end{array}$ & $\begin{array}{c}15.4 \% \\
(10) \\
\end{array}$ & $\begin{array}{c}12.5 \% \\
(6) \\
\end{array}$ \\
\hline
\end{tabular}

For NMVCCS Unknown work zone types, it was harder to determine if the work zone played a direct role in the crash. Consequently, there are a smaller proportion of this work zone type in the NMVCCS Directly Related crash subset. This causes other Directly Related work zone type proportions to increase, with the exception of Intermittent/ Mobile work zones. This is probably due to random variations in the small sample size. Therefore, changes in NMVCCS work zone type proportions are largely a consequence of lack of information rather than changes due to the work zone's presence.

Conversely, the LTCCS dataset did not exhibit the same trend in Unknown work zone types. LTCCS work zone type proportions increased for crashes occurring in lane closures work zones and decreased for crashes occurring in median/shoulder work zones. This is most likely related to the large number of rear-end crashes in the LTCCS dataset.

In order to better understand the effect different work zone types may have on crash distributions, Table 5.3 further breaks down NMVCC Directly Related work zone types by crash type. This was not done for the LTCCS dataset because its small sample size meant that some crash types did not occur in every work zone type. 
Table 5.3: NMVCCS Work Zone Type Distributions (Directly Related Crashes)

\begin{tabular}{|c|c|c|c|c|c|}
\hline $\begin{array}{c}\text { Dataset or } \\
\text { Crash Type }\end{array}$ & $\begin{array}{c}\text { Lane } \\
\text { Closure }\end{array}$ & $\begin{array}{c}\text { Lane Shift/ } \\
\text { Crossover }\end{array}$ & $\begin{array}{l}\text { Median/ } \\
\text { Shoulder }\end{array}$ & $\begin{array}{c}\text { Intermittent/ } \\
\text { Mobile }\end{array}$ & Unknown \\
\hline Rear-end & $\begin{array}{c}74.4 \% \\
(29)\end{array}$ & $\begin{array}{c}2.6 \% \\
(1)\end{array}$ & $\begin{array}{c}12.8 \% \\
(5)\end{array}$ & $\begin{array}{c}2.6 \% \\
(1)\end{array}$ & $\begin{array}{c}7.7 \% \\
(3)\end{array}$ \\
\hline Angle & $\begin{array}{c}46.7 \% \\
(7) \\
\end{array}$ & $\begin{array}{l}13.3 \% \\
(2) \\
\end{array}$ & $\begin{array}{c}26.7 \% \\
(4) \\
\end{array}$ & $\begin{array}{l}0 \% \\
(0) \\
\end{array}$ & $\begin{array}{c}13.3 \% \\
(2) \\
\end{array}$ \\
\hline $\begin{array}{l}\text { Sideswipe - } \\
\text { Same Direction }\end{array}$ & $\begin{array}{c}50.0 \% \\
(4)\end{array}$ & $\begin{array}{l}0 \% \\
(0)\end{array}$ & $\begin{array}{c}37.5 \% \\
(3)\end{array}$ & $\begin{array}{l}0 \% \\
(0) \\
\end{array}$ & $\begin{array}{c}12.5 \% \\
(1)\end{array}$ \\
\hline $\begin{array}{l}\text { Fixed Object - } \\
\text { Off Road }\end{array}$ & $\begin{array}{c}33.3 \% \\
(5)\end{array}$ & $\begin{array}{c}20.0 \% \\
(4)\end{array}$ & $\begin{array}{c}40.0 \% \\
(6)\end{array}$ & $\begin{array}{l}0 \% \\
(0) \\
\end{array}$ & $\begin{array}{c}6.7 \% \\
(1)\end{array}$ \\
\hline
\end{tabular}

* Each crash types' work zone type proportions sum horizontally to $100 \%$. For example, $74.4 \%$ of rearend crashes occurred in a lane closure work zone.

From Table 5.3, it appears the NMVCCS rear-end, angle, and sideswipe - same direction crashes occurred most often in a lane closure work zone (possibly due to an overrepresentation of lane closure work zones), while fixed object - off road crashes most often involved a shoulder or median work zone. Key contributing factors for these crashes are identified and discussed later in this chapter.

\subsubsection{NMVCCS and LTCCS Crash Severity}

Crash severity is often used as a performance measure when evaluating work zone safety.

Several studies have used Coded crash information to examine changes in crash severity within a work zone. Table 5.4 displays Coded and Directly Related crash severity level proportions for both NMVCCS and LTCCS datasets. Note, a pre-defined characteristic of the LTCCS dataset is that it does not contain crashes below a B - Non-Incapacitating Injury on the KABCO scale. 
Table 5.4: NMVCCS \& LTCCS Severity Level of Directly Related Crashes

\begin{tabular}{|c|c|c|c|c|}
\hline Severity Level & $\begin{array}{l}\text { NMVCCS } \\
\text { Coded Related } \\
\text { Work Zone } \\
\text { Crashes (\%, } \\
\text { Count) }\end{array}$ & $\begin{array}{l}\text { NMVCCS } \\
\text { Directly Related } \\
\text { Work Zone } \\
\text { Crashes (\%, } \\
\text { Count) }\end{array}$ & $\begin{array}{l}\text { LTCCS Coded } \\
\text { Related Work } \\
\text { Zone Crashes } \\
\text { (\%, Count) }\end{array}$ & $\begin{array}{l}\text { LTCCS } \\
\text { Directly Related } \\
\text { Work Zone } \\
\text { Crashes (\%, } \\
\text { Count) }\end{array}$ \\
\hline $\mathrm{K}-$ Killed & $\begin{array}{l}0 \% \\
(0)\end{array}$ & $\begin{array}{l}0 \% \\
(0)\end{array}$ & $\begin{array}{c}20.0 \% \\
(13)\end{array}$ & $\begin{array}{c}22.9 \% \\
(11)\end{array}$ \\
\hline $\begin{array}{l}\text { A - Incapacitating } \\
\text { Injury }\end{array}$ & $\begin{array}{c}11.2 \% \\
(16) \\
\end{array}$ & $\begin{array}{c}9.1 \% \\
(7)\end{array}$ & $\begin{array}{c}29.2 \% \\
(19) \\
\end{array}$ & $\begin{array}{c}27.1 \% \\
(13) \\
\end{array}$ \\
\hline $\begin{array}{l}\text { B - Non-Incapacitating } \\
\text { Injury }\end{array}$ & $\begin{array}{c}19.6 \% \\
(28) \\
\end{array}$ & $\begin{array}{c}19.5 \% \\
(15) \\
\end{array}$ & $\begin{array}{l}50.8 \% \\
(33) \\
\end{array}$ & $\begin{array}{l}50.0 \% \\
(24) \\
\end{array}$ \\
\hline $\mathrm{C}$ - Injury Possible & $\begin{array}{c}31.5 \% \\
(45)\end{array}$ & $\begin{array}{c}31.2 \% \\
(24)\end{array}$ & $\mathrm{n} / \mathrm{a}$ & $\mathrm{n} / \mathrm{a}$ \\
\hline $\mathrm{O}$ - No Injury & $\begin{array}{c}31.2 \% \\
(46) \\
\end{array}$ & $\begin{array}{c}35.1 \% \\
(27) \\
\end{array}$ & $\mathrm{n} / \mathrm{a}$ & $\mathrm{n} / \mathrm{a}$ \\
\hline $\begin{array}{l}\text { U - Injury, Severity } \\
\text { Unknown }\end{array}$ & $\begin{array}{l}0.7 \% \\
(1)\end{array}$ & $\begin{array}{l}1.3 \% \\
(1)\end{array}$ & $\mathrm{n} / \mathrm{a}$ & $\mathrm{n} / \mathrm{a}$ \\
\hline Unknown & $\begin{array}{l}4.9 \% \\
(7)\end{array}$ & $\begin{array}{c}3.9 \% \\
(3)\end{array}$ & $\mathrm{n} / \mathrm{a}$ & $\mathrm{n} / \mathrm{a}$ \\
\hline
\end{tabular}

Table 5.4 illustrates that Coded and Directly related crash proportions are very similar for both dataset. Therefore, the NMVCCS and LTCCS Directly Related datasets are not biased towards more or less severe crashes relative to the coded crash dataset.

\subsection{NMVCCS Work Zone Causal Factors}

This section goes beyond the high-level overview of roadway and crash type distributions and identifies the major causes of work zone crashes. Only work zone crashes determined to relate directly to the work zone (i.e., Directly Related crashes) were used for this analysis. Work zone causal factors for the NMVCCS dataset will be discussed first, followed by a discussion of the LTCCS dataset's causal factors. The three most common NMVCCS crash cause categories for each crash type are displayed in Table 5.5. 
Table 5.5: NMVCCS Summary of Crash Causes Directly Related to Work Zone Presence

\begin{tabular}{|c|c|c|l|l|l|}
\hline Crash Type & $\begin{array}{l}\text { \# of Directly } \\
\text { Related } \\
\text { Crashes }\end{array}$ & $\begin{array}{l}\text { Directly } \\
\text { Related as a } \\
\text { \%of Coded } \\
\text { Crash Type }\end{array}$ & $\begin{array}{l}\mathbf{1}^{\text {st }} \text { Most Common } \\
\text { Cause }\end{array}$ & $\begin{array}{l}\mathbf{2}^{\text {nd }} \text { Most } \\
\text { Common Cause }\end{array}$ & $\begin{array}{l}\mathbf{3}^{\text {Most }} \\
\text { Common } \\
\text { Cause }\end{array}$ \\
\hline Rear-end & 39 & $65.0 \%$ & $\begin{array}{l}\text { Stopped/slowed } \\
\text { due to work zone } \\
(61.5 \%, 24 \\
\text { crashes })\end{array}$ & $\begin{array}{l}\text { Changing lanes } \\
\text { due to work zone } \\
(10.3 \%, 4 \text { crashes })\end{array}$ & $\begin{array}{l}\text { Misjudged gap } \\
(7.7 \%, 3 \\
\text { crashes })\end{array}$ \\
\hline Angle & 15 & $35.7 \%$ & $\begin{array}{l}\text { Limited sight } \\
\text { distance due to } \\
\text { work zone }(40.0 \%, \\
\text { crashes })\end{array}$ & $\begin{array}{l}\text { Confusion or } \\
\text { distraction due to } \\
\text { work zone } \\
(33.3 \%, 5 \text { crashes })\end{array}$ & $\begin{array}{l}\text { Misjudged gap } \\
(20.0 \%, 3 \\
\text { crashes })\end{array}$ \\
\hline $\begin{array}{c}\text { Sideswipe - } \\
\text { Same }\end{array}$ & 8 & $72.7 \%$ & $\begin{array}{l}\text { Stopped/Slowed } \\
\text { due to work zone } \\
(37.5 \%, 3 \text { crashes })\end{array}$ & $\begin{array}{l}\text { Work zone } \\
\text { vehicle entering/ } \\
\text { exiting work zone } \\
(25.0 \%, 2 \text { crashes })\end{array}$ & $\begin{array}{l}\text { Lost control } \\
(25.0 \%, 2 \\
\text { crashes })\end{array}$ \\
\hline $\begin{array}{c}\text { Direction } \\
\text { Fixed Object } \\
\text { - Off Road }\end{array}$ & 17 & $50.0 \%$ & $\begin{array}{l}\text { Lost control, } \\
\text { struck work zone } \\
\text { device/ barrier } \\
(33.3 \%, 5 \text { crashes })\end{array}$ & $\begin{array}{l}\text { Inattention } \\
(26.7 \%, 4 \text { crashes })\end{array}$ & $\begin{array}{l}\text { Uneven } \\
\text { pavement } \\
(13.3 \%, 2 \\
\text { crashes })\end{array}$ \\
\hline
\end{tabular}

\subsubsection{NMVCCS Rear-end Crashes}

The most common crash cause categories for Directly Related rear-end crashes indicate a strong correlation between velocity and/or lane changes and rear-end crashes. Combining this finding with the large proportion of lane closure rear-end crashes seen in Table 5.3, suggests that the reduced capacity due to a lane closure is creating congestion. This congestion appears to be a large contributor to increased rear-end crashes, much like in the Virginia data. Definitions and further information about the most common rear-end crash cause categories displayed in Table 5.5 are given below.

Stopping/ slowing due to work zone. This category included 29 crashes resulting from vehicles stopping/slowing due to some aspect of the work zone. Twenty-three of these crashes were related to congestion at the work zone. Five involved stopping/slowing for flagman, police officer, or work zone sign. The final one 
occurred while a vehicle was stopping/slowing due to merging maneuvers. Three of these 29 rear-end crashes involved a speeding vehicle.

Changing lanes due to work zone. This category included crashes involving a vehicle actively in the process of, or just completing, changing lanes due to a work zone. One of these crashes involved a speeding vehicle.

Misjudged Gap - This category included crashes involving the driver misjudging gap distance while turning or merging.

\subsubsection{NMVCCS Angle Crashes}

Confusion or distraction due to work zone layout or setup and limited sight distance were the main contributors to angle crashes, particularly at intersections. None of these crashes involved speeding vehicles. Definitions and further information about the most common angle crash cause categories displayed in Table 5.5 are given below.

Limited sight distance due to work zone. This category included crashes attributed to a decrease in sight distance or visibility due to a work zone obstruction, including construction equipment, construction vehicles (both parked and not parked), and/or construction signs.

Confusion or distraction due to work zone. These crash reports' narrative noted driver confusion about some aspect of the work zone. All of these crashes occurred on non-interstate routes. Twelve of these crashes were attributed to confusion over unmarked lanes as a result of repaving or construction work.

Misjudged Gap - This category included crashes involving the driver misjudging gap distance while turning or merging. No sight distance obstructions were present in these cases. 


\subsubsection{NMVCCS Sideswipe - Same Direction}

The most significant crash causes for this crash type were stopping/slowing due to the work zone, a work zone vehicle entering/exiting the work zone, and loss of control of the vehicle. Definitions and further information about the most common sideswipe - same direction crash cause categories displayed in Table 5.5 are given below.

Stopping/ slowing due to work zone. This category included crashes resulting from vehicles stopping/slowing due to some aspect of the work zone. All of these crashes occurred while the driver trying to avoid a rear-end collision as a result of congestion related to the work zone.

Work zone vehicle entering/exiting work zone. This category included crashes involving work vehicles that were entering or exiting a work zone. In both cases the work zone vehicle was found to be at fault. This crash cause will be discussed in more detail later in the NMVCCS and LTCCS Work Vehicles Crash Involvement section.

Lost control. This category involved crashes attributed to the driver losing control of the vehicle due to falling asleep or a medical condition. One of these crashes involved a speeding vehicle.

\subsubsection{NMVCCS Fixed Object Off Road Crashes}

The most significant crash causes for this crash type were loss of control of the vehicle, loss of control due to uneven pavement, and driver inattention. Definitions and further information about the most common fixed object - off road crash cause categories displayed in Table 5.5 are given below. Per Table 5.3, fixed object - off road crashes 
occurred more often in median and shoulder work zones than any other work zone type. Lane closure, lane shift/crossover, and mobile/intermediate work zone have a side effect of forcing surrounding traffic to slow down because they take up at least one lane. Conversely, three of the four fixed object - off road crashes involving a speeding vehicle occurred in a median/shoulder work zone. Thus additional efforts to reduce speeds around median/shoulder work zones may merit consideration.

Lost control. This category involved crashes attributed to the driver losing control of the vehicle. For these crashes, loss of control was unrelated to the work zone. The driver either had a medical condition (2), experienced a tire blowout (1), was speeding (1), or swerved to avoid an object in the roadway (1). These crashes were categorized as related to the work zone because the vehicle hit a work zone object (i.e., jersey wall) when it ran of the road.

Inattention. This category included crashes involving the drivers day dreaming, falling asleep, or looking down inside the car. These crashes were categorized as related to the work zone because the vehicle hit a work zone object (i.e., jersey wall) when it ran off the road. One of these crashes involved a speeding vehicle.

Uneven Pavement. This category included crashes attributed to the driver losing control of the vehicle due to uneven pavement as the result of road repaving/milling. Two out of these four crashes involved a speeding vehicle.

\subsubsection{NMVCCS Fixed Object - Off Road First Object Hit}

The most common first object hit during NMVCCS Directly Related fixed object-off road crashes was a concrete work zone jersey barrier. Ten of these 17 crashes (or 58.8\% of the entire NMVCCS Directly Related dataset) struck a work zone jersey barrier as 
their first object hit. Another 8 Directly Related crashes (with crash types of rear-end, angle, or sideswipe - same direction) involved a vehicle striking a work zone jersey barrier as their second object hit after another motor vehicle in transit. In these crashes, the jersey barrier may have increased the severity of the crash. Other first objects hit during NMVCCS Directly Related fixed object - off road crashes include arrow panels, embankments, ditches, curbs, fences, and utility poles.

\subsection{LTCCS Work Zone Causal Factors}

This section goes beyond the high-level overview of work zone type, severity level, and crash type distributions and identifies the major causes of work zone crashes. Only work zone crashes determined to relate directly to the work zone (i.e., Directly Related crashes) were used for this analysis. The most common crash cause categories for each crash type are discussed in the four crash type sections below.

\subsubsection{LTCCS Rear-end Crashes}

The most common rear-end crash cause for the LTCCS dataset was Stopping/Slowing due to Congestion Caused by Work Zone. Of the 35 Directly Related rear-end crashes, 24 (68.6\%) were attributed to this crash cause. This indicates a strong correlation between velocity and/or lane changes and rear-end crashes, although none of these crashes were coded as exceeding the recommended speed limit. Combining this finding with the large proportion of lane closure crashes within the LTCCS dataset, suggests that (similar to the Virginia Crash Analysis) congestion created by the reduction in capacity at a work zone 
lane closure is a large contributor to increased rear-end crashes. Other crash causes contained 1-3 crashes and included:

- Improper Work Zone Setup or Conduct (3 crashes),

- Work Zone vehicle Entering/Exiting from Work Zone (2 crashes),

- Changing Lanes due to WZ (2 crashes),

- Lost Control (2 crashes),

- Inattention (1 crash),

- Reckless Driving (1 crash).

\subsubsection{LTCCS Angle Crashes}

This crash type's sample size was very small, largely because most crashes occurred on interstates where angle crashes are rare. The crash causes of the 2 crashes in this crash type are:

- Lost Control due to Uneven Pavement (1 crash), and

- Work Zone vehicle Entering/Exiting from Work Zone (1 crash).

\subsubsection{LTCCS Sideswipe - Same Direction}

This crash type did not demonstrate a dominant crash cause due to the small sample size. The crash causes of the 6 crashes in this crash type include:

- Changing Lanes due to WZ (3 crashes),

- Stopping/Slowing due to Congestion caused by Work Zone (2 crashes),

- Inattention (1 crash). 


\subsubsection{LTCCS Fixed Object Off Road Crashes}

This crash type did not demonstrate a dominant crash cause due to the small sample size. The crash causes of the 5 crashes in this crash type include:

- Lost Control (2 crashes),

- Lost Control due to Uneven Pavement (1 crash),

- Stopping/Slowing due to Congestion caused by Work Zone (1 crash),

- Changing Lanes due to WZ (1 crash).

\subsection{NMVCCS and LTCCS Work Zone Vehicles Crash Involvement}

While not a large part of the dataset, work zone vehicles were involved in $19(15.2 \%)$ of the NMVCCS and LTCCS Directly Related crashes. For this reason, their involvement in the crash is further broken down in this section. Table 5.6 displays categories, crash counts, and crash proportions for crashes involving work zone vehicles. These categories indicate the location or action of the work zone vehicle during the crash. 
Table 5.6: NMVCCS \& LTCCS Location/Action of Work Zone Vehicles Involved in Crashes

\begin{tabular}{|c|c|c|}
\hline Location/Action of Work Zone Vehicle & $\begin{array}{l}\text { NMVCCS Directly } \\
\text { Related Work Zone } \\
\text { Crashes Involving a } \\
\text { Work Zone Vehicle (\%, } \\
\text { Count) }\end{array}$ & $\begin{array}{l}\text { LTCCS Directly } \\
\text { Related Work Zone } \\
\text { Crashes Involving a } \\
\text { Work Zone Vehicle (\%, } \\
\text { Count) }\end{array}$ \\
\hline $\begin{array}{l}\text { Work zone vehicle entering/exiting work } \\
\text { zone }\end{array}$ & $\begin{array}{l}5.2 \% \\
(4)\end{array}$ & $\begin{array}{c}6.3 \% \\
(3)\end{array}$ \\
\hline $\begin{array}{l}\text { Stationary or moving slowly in lane at } \\
\text { start of work zone (crash protection } \\
\text { vehicle) }\end{array}$ & $\begin{array}{l}5.2 \% \\
(4)\end{array}$ & $\begin{array}{l}2.1 \% \\
(1)\end{array}$ \\
\hline $\begin{array}{l}\text { Work zone vehicle hit another work zone } \\
\text { vehicle/pedestrian within work zone } \\
\text { activity area }\end{array}$ & $\begin{array}{c}1.3 \% \\
(1)\end{array}$ & $\begin{array}{l}4.2 \% \\
(2)\end{array}$ \\
\hline $\begin{array}{l}\text { Vehicle in transit within work zone, on } \\
\text { regular travel lane }\end{array}$ & $\begin{array}{l}1.3 \% \\
(1)\end{array}$ & $\begin{array}{l}4.2 \% \\
(2)\end{array}$ \\
\hline $\begin{array}{l}\text { Parked on shoulder or in Work Zone } \\
\text { blocking sight distance }\end{array}$ & $\begin{array}{c}1.3 \% \\
(1)\end{array}$ & $\begin{array}{l}0 \% \\
(0)\end{array}$ \\
\hline
\end{tabular}

* Percentages represent the crashes proportion of all NMVCCS or LTCCS direction related crashes within the four primary crash types. For example, 4 of the 77 (i.e., 5.1\%) Directly Related NMVCCS crashes involved a work zone vehicle entering/exiting work zone.

Between the two datasets, work zone vehicles entering/exiting a work zone was the most common category. Four NMVCCS crashes and three LTCCS crashes fell into this category. Two involved a construction truck entering a divided freeway from the median/lane closure work zone without an acceleration area. One involved a work zone vehicle slowing to almost a near stop in the travel lane of a 4 lane divided rural roadway in order to turn into the work zone area. One involved a work zone dump truck slowing down on an eight lane divided freeway in order to enter a lane closure work zone. It had its flashing hazard lights on but was rear-ended by a truck changing lanes behind it. Another involved a work zone vehicle beginning to accelerate within the lane closure in order to move into the travel lane. The work zone vehicle only accelerated to approximately $5 \mathrm{mph}$ before he started to merge into the travel lane. The other vehicle was traveling at much higher speed and could not avoid the collision. The last two involved a work zone vehicle parked on the shoulder/in a work zone, which then 
attempted to cross 3-4 travel lanes in order to reach the work zone/the other shoulder. Of the seven NMVCCS and LTCCS work zone vehicle crashes involving a work zone vehicle entering/exiting the work zone, three crash narratives $(42.9 \%$ of crashes in this category) found the work zone vehicle driver at fault, while the other four found the work zone vehicle partially at fault.

Of all 19 NMVCCS and LTCCS work zone vehicle crashes, six crash narratives $(31.6 \%)$ found the work zone vehicle at fault. Other than the three crashes related to the a work vehicle entering/exiting work zone, two crash narratives that found the work zone vehicle at fault involved the vehicle backing up in the work zone's activity area. The last one involved a distracted work zone vehicle driver in transit to/from the work zone. Overall, another seven crash narratives found the work zone vehicle partially at fault. In the remaining six crashes, the work zone vehicle was not found at fault.

\subsection{NMVCCS Possibly Related Crashes}

The work zone's relationship to $25.2 \%$ of NMVCCS Coded crashes (36 crashes) could not be determined due to insufficient information. These crashes were largely comprised of intersection and congestion related crashes, the reports of which did not provide enough information to confirm the work zone's relationship to the crash.

Thirteen (36.1\%) of these NMVCCS crashes were angle intersection crashes attributed to driver inattention. These crashes typically involved a high degree of construction occurring in and around the intersection, including many barrels, cones, work zone vehicles and lane closures. These anomalies could have contributed to distraction, sight impairment, or confusion. Even though the crash report's pictures 
suggested that these conclusions are plausible, the work zone's influence on the crashes could not be confirmed in the crash narratives.

An image of one of these crashes is shown below in Figure 5.1. During this crash, the driver (in the travel lane the image was taken from) collided with a left turning vehicle in the opposite direction. The image depicts a work zone sign blocking visibility of left turning vehicles in the opposite direction. While it is plausible that this may have influenced the crash, the crash narrative did not refer to the impairment.

Figure 5.1: May Be Directly Related Angle Crash

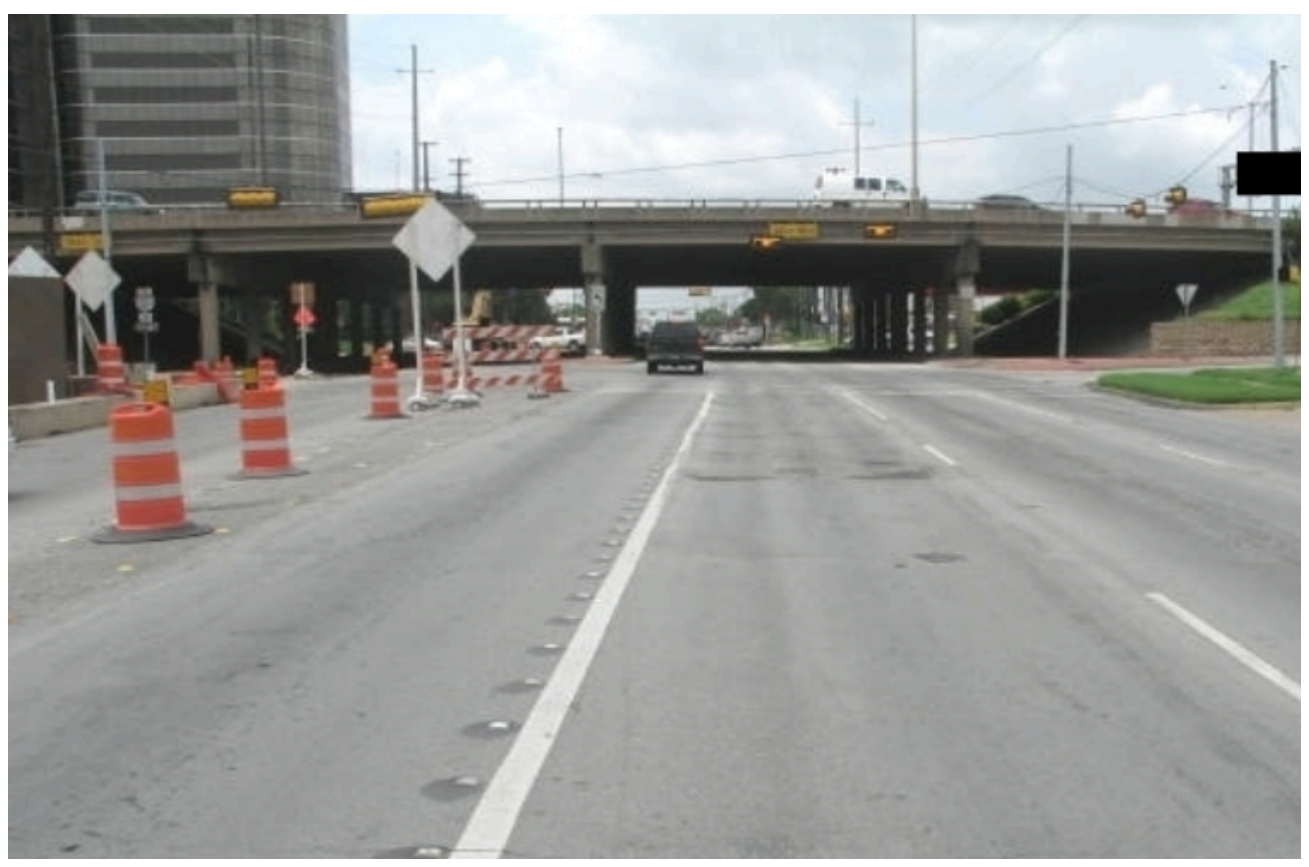

Ten $(27.8 \%)$ of the NMVCCS Possibly Related crashes and three $(42.9 \%)$ of the LTCCS Possibly Related crashes were rear-end crashes related to congestion. These reports did not provide any information about the work zone's layout, placement relative to the crash, or influence on the crash. However, "Construction" was listed in report as a 
possible traffic flow factor (aka. there was a work zone somewhere in the area). Pictures were inconclusive and typically showed a large amount of traffic.

The remaining NMVCCS Possibly Related crashes and LTCCS Possibly Related crashes fall into several crash categories, with only 1-3 crashes in each. Due to the small sample size, they were left out of the discussion. 


\section{CHAPTER 6: COMPARISON OF FINDINGS BETWEEN VIRGINIA DATA AND NMVCCS/LTCCS DATASETS}

In the previous two chapters, it was shown that Coded crash trends often do not align with Directly Related crash trends. This section compares findings from the Virginia dataset to the NMVCCS/LTCCS datasets. It is theorized that NMVCCS's and LTCCS's more detailed Directly Related crash datasets will yield different trends than those produced by the Virginia dataset and provide more accurate information on the underlying causes of work zone crashes. If findings from all three datasets are similar, then this may imply that current DOT crash reports provide a sufficient level of detail to determine crash causality. If findings from the Virginia dataset and the NMVCCS and LTCCS datasets differ, then this may suggest that Virginia's crash reports need to be improved in order to capture more accurate information. In such a case, characteristics of the NMVCCS and LTCCS crash reports may help to recommend potential improvements to the Virginia's crash reports, thereby improving VDOT's ability to identify and address specific observed safety concerns.

Differences between the Virginia and NMVCCS/LTCCS distributions are likely due to the much smaller amount of information in the Virginia crash reports. The relationship of most Virginia crashes to the work zone could not be determined due to a lack of information. The Virginia crash narrative length averaged 30-40 words and was often too vague to determine what role the work zone played in the crash. In fact, 527 Virginia Coded crashes (8.2\% of all Virginia Coded crashes) contained a blank crash narrative. 
Conversely, all crashes in the NMVCCS and LTCCS datasets could be categorized as Directly Related, Possibly Related, or Not Related crashes due to each crash report's detailed information. These differences suggest that the current method of collecting Virginia work zone crash data may be insufficient. This chapter's comparison analysis will provide insight into the Virginia dataset's insufficiencies and their effects on crash trend statistical results which are needed for effect performance measurements and countermeasure development.

\subsection{High-Level Comparison of Findings}

High-level comparison analysis of crash trend distributions was performed first. Distributions of Coded crashes and Directly Related crashes between datasets were considered, then the percentage of Coded crashes identified as Directly Related crashes within each dataset were compared.

Since severity level distributions between each dataset differed greatly, crash severity data was standardized across the datasets for this section's comparison analysis. The LTCCS included only large truck crashes that experienced a severity level of K Kill, A - Incapacitating Injury, or B - Non-Incapacitating Injury. The NMVCCS includes crashes involving at least one light passenger vehicle that was towed due to damage (which resulted in the exclusion of many PDO crashes). The Virginia crash dataset does not exclude any crash severity levels. Therefore, it contains a larger proportion of PDO crashes than the NMVCCS or LTCCS datasets. For consistency, PDO crashes were removed from the Virginia and NMVCCS datasets before being compared against the LTCCS dataset for the high-level analysis. Further, only rear-end, angle, sideswipe - 
same direction, and fixed object - off road crashes in each dataset were considered for consistency.

\subsubsection{Distribution of Crash Types within KABC Coded Crashes}

Coded crash data collection methods vary between datasets. The Virginia crash reports target all crashes occurring in the work zone, but the reporting police officer is not asked to make a connection between the crash and work zone presence. NMVCCS and LTCCS crash reports flag a work zone crash when the researcher believes that the work zone impacted traffic. As shown in the Chapter 5, the NMVCCS and LTCCS Coded and Directly Related crash type distributions were not found to be significantly different using a chi-square tests. The Virginia Coded and Directly Related crash type distributions were found to be significantly different at an alpha $=0.05$. This suggests that the NMVCCS and LTCCS researcher's method of identifying a work zone related crash was more closely tied to the causal factors of the crash than Virginia's current method. Therefore, the Virginia and NMVCCS/LTCCS Coded crash type distributions are mostly likely fundamentally different from each other.

To confirm this, Coded crash type distributions (percentage of rear-end, angle, sideswipe - same direction, and fixed object - off road) were compared between datasets using a chi-square distribution test. Chi-square results are displayed in Table 6.1. The Virginia and NMVCCS as well as the NMVCCS and LTCCS Coded crash type distributions were found to be significantly different at an alpha $=0.05$. 
Table 6.1: Chi-Square Distribution Tests for KABC Crashes

\begin{tabular}{|l|c|c|c|}
\hline Comparison Type/ Datasets & $\begin{array}{c}\text { Virginia - NMVCCS } \\
\boldsymbol{X}^{\mathbf{2}} \text { Value }\end{array}$ & $\begin{array}{c}\text { Virginia - LTCCS } \\
\boldsymbol{X}^{\mathbf{2}} \text { Value }\end{array}$ & $\begin{array}{c}\text { NMVCCS - LTCCS } \\
\boldsymbol{X}^{2} \text { Value }\end{array}$ \\
\hline $\begin{array}{l}\text { Coded Crash Type } \\
\left(\text { Critical } X^{2}=7.81 \text { ) }\right.\end{array}$ & 18.28 & $\mathbf{3 . 3 5}$ & 18.15 \\
\hline $\begin{array}{l}\text { Directly Related Crash Type } \\
\left(\text { Critical } X^{2}=7.81 \text { ) }\right.\end{array}$ & $\begin{array}{c}6.74 \\
\text { (sig. at alpha=0.10) }\end{array}$ & 16.63 & 10.44 \\
\hline $\begin{array}{l}\text { \% Directly Related Crash Type } \\
\left(\text { Critical } X^{2}=7.81\right)\end{array}$ & 55.59 & 102.28 & $\mathbf{3 . 3 6}$ \\
\hline $\begin{array}{l}\text { Cause of Crash } \\
\left(\text { Critical } X^{2}=23.68\right)\end{array}$ & 78.04 & 47.95 & 26.50 \\
\hline
\end{tabular}

Coded crash type proportions for each dataset are displayed in Table 6.2. The NMVCCS data exhibits a smaller proportion of rear-end crashes and a larger proportion of angle crashes than either the Virginia or LTCCS dataset. The difference between NMVCCS and LTCCS crash type distributions may be related to the differences in vehicle types targeted in each study. The NMVCCS dataset is composed of mainly light passenger vehicle crashes while all of the LTCCS datasets included a large truck over 10,000 pounds. 
Table 6.2: Coded and Directly Related KABC Crash Type Distributions (Number of crashes shown in parentheses)

\begin{tabular}{|l|l|c|c|c|}
\hline & Crash Type & $\begin{array}{c}\text { Virginia } \\
\text { Dataset }\end{array}$ & $\begin{array}{c}\text { NMVCCS } \\
\text { Dataset }\end{array}$ & $\begin{array}{c}\text { LTCCS } \\
\text { Dataset }\end{array}$ \\
\hline \multirow{4}{*}{$\begin{array}{l}\text { KABC Coded } \\
\text { Crashes }\end{array}$} & Rear-Ends & $\begin{array}{c}64.3 \% \\
(1442)\end{array}$ & $\begin{array}{c}44.4 \% \\
(40)\end{array}$ & $\begin{array}{c}66.2 \% \\
(43)\end{array}$ \\
\cline { 2 - 5 } & Angle & $\begin{array}{c}17.0 \% \\
(376)\end{array}$ & $\begin{array}{c}31.1 \% \\
(28)\end{array}$ & $\begin{array}{c}12.3 \% \\
(43)\end{array}$ \\
\cline { 2 - 5 } & Sideswipe- Same Direction & $\begin{array}{c}7.3 \% \\
(162)\end{array}$ & $\begin{array}{c}7.8 \% \\
(7)\end{array}$ & $\begin{array}{c}12.3 \% \\
(8)\end{array}$ \\
\cline { 2 - 5 } & Fixed Object Off Road & $\begin{array}{c}11.4 \% \\
(252)\end{array}$ & $\begin{array}{c}16.7 \% \\
(15)\end{array}$ & $\begin{array}{c}9.2 \% \\
(6)\end{array}$ \\
\hline \multirow{4}{*}{$\begin{array}{l}\text { KABC Directly } \\
\text { Related Crashes }\end{array}$} & Rear-Ends & $\begin{array}{c}51.9 \% \\
(271)\end{array}$ & $\begin{array}{c}55.3 \% \\
(26)\end{array}$ & $\begin{array}{c}72.9 \% \\
(35)\end{array}$ \\
\cline { 2 - 5 } & Angle & $\begin{array}{c}10.9 \% \\
(57)\end{array}$ & $\begin{array}{c}19.1 \% \\
(9)\end{array}$ & $\begin{array}{c}4.2 \% \\
(2)\end{array}$ \\
\cline { 2 - 5 } & Sideswipe - Same Direction & $\begin{array}{c}5.7 \% \\
(30)\end{array}$ & $\begin{array}{c}8.5 \% \\
(4)\end{array}$ & $\begin{array}{c}12.5 \% \\
(6)\end{array}$ \\
\cline { 2 - 5 } & Fixed Object Off Road & $\begin{array}{c}31.4 \% \\
(164)\end{array}$ & $\begin{array}{c}17.0 \% \\
(8)\end{array}$ & $\begin{array}{c}10.4 \% \\
(5)\end{array}$ \\
\hline \multirow{4}{*}{$\begin{array}{l}\text { Percent of KABC } \\
\text { Coded Crashes } \\
\text { Found to be } \\
\text { KABC Directly } \\
\text { Related Crashes }\end{array}$} & Rear-Ends & $\begin{array}{c}19.1 \% \\
(271)\end{array}$ & $\begin{array}{c}65.0 \% \\
(26)\end{array}$ & $\begin{array}{c}81.4 \% \\
(35)\end{array}$ \\
\cline { 2 - 5 } & Angle & $\begin{array}{c}15.2 \% \\
(57)\end{array}$ & $\begin{array}{c}32.1 \% \\
(9)\end{array}$ & $\begin{array}{c}25.0 \% \\
(2)\end{array}$ \\
\cline { 2 - 5 } & Sideswipe - Same Direction & $\begin{array}{c}18.5 \% \\
(30)\end{array}$ & $\begin{array}{c}57.1 \% \\
(4)\end{array}$ & $\begin{array}{c}75.0 \% \\
(6)\end{array}$ \\
\cline { 2 - 5 } & Fixed Object Off Road & $\begin{array}{c}65.1 \% \\
(164)\end{array}$ & $\begin{array}{c}53.3 \% \\
(8)\end{array}$ & $\begin{array}{c}83.3 \% \\
(5)\end{array}$ \\
\hline
\end{tabular}

The Virginia and LTCCS Coded crash type proportions were not found to be significantly different. It is counterintuitive that the crash type proportions of a large truck dataset would be similar to the entire Virginia dataset while a light passenger car dataset's crash type proportions are significantly different. This could be a byproduct of the LTCCS dataset's small sample size.

\subsubsection{Distribution of Crash Types within KABC Directly Related Crashes}

Next, Directly Related crash type distributions were compared between datasets using a chi-square distribution test (Table 6.1). The Virginia and LTCCS as well as the NMVCCS and LTCCS Directly Related crash type distributions were found to be 
significantly different at an alpha $=0.05$. The Virginia and NMVCCS datasets were found to be significantly different at an alpha $=0.10$. This suggests that Directly Related crash type distributions drawn from Virginia data are not interchangeable with the NMVCCS and LTCCS data. Directly Related crash type proportions for each dataset are displayed in Table 6.2. NMVCCS and LTCCS crash reports' greater level of detail allowed for a more accurate capturing of Directly Related crashes. Many Virginia crash reports provided an insufficient amount of information, limiting the number and type of crashes categorized as Directly Related crashes.

\subsubsection{Distribution of KABC Coded Crashes Identified as KABC Directly Related Crashes}

The percentage of KABC Coded crashes found to be KABC Directly Related to the work zone for the Virginia, NMVCCS and LTCCS datasets was $21.3 \%, 52.2 \%$, and $73.8 \%$, respectively. These Virginia and NMVCCS numbers differ slightly from those listed in Chapters 4 and 5 because these percentages represent KABC crash severities in order to be comparable to the LTCCS dataset. A chi-square distribution test was performed between the proportions of Coded crashes identified to be Directly Related crashes, by crash type (Table 6.1). The Virginia and NMVCCS as well as the Virginia and LTCCS crash type distributions were found to be significantly different at an alpha $=0.05$. The NMVCCS and LTCCS datasets were not found to be significantly different.

The NMVCCS and LTCCS datasets demonstrated higher percentages of Coded rear-end, angle, and sideswipe - same direction crashes determined to be Directly Related crashes than the Virginia dataset. These proportions for each dataset are displayed in Table 6.2. The larger percentages in the NMVCCS and LTCCS datasets suggest that 
some of the Directly Related rear-end, angle, and sideswipe - same direction crashes were not identified in the Virginia dataset due to the crash reports' lack of information.

Conversely, the NMVCCS and LTCCS datasets demonstrate lower percentages of Coded fixed object - off road crashes determined to be Directly Related crashes than the Virginia dataset. This reinforces the theory mentioned in Chapter 4 that a surplus of Virginia fixed object - off road crashes may have been labeled as Directly Related crashes.

\subsubsection{Distribution of KABC Cause of Crash}

Lastly, the crash cause distributions for $\mathrm{KABC}$ crashes within the four primary crash types were compared. Crashes in all dataset were grouped into these broad categories. The groups are displayed in Table 6.3 along with percentages and crash counts for each dataset. 
Table 6.3: Cause of Crash Distributions (number of crashes shown in parentheses)

\begin{tabular}{|c|c|c|c|}
\hline $\begin{array}{l}\text { Work Zone Related Cause } \\
\text { of Crash }\end{array}$ & $\begin{array}{l}\text { Virginia Directly } \\
\text { Related Crashes }\end{array}$ & $\begin{array}{l}\text { NMVCCS Directly } \\
\text { Related Crashes }\end{array}$ & $\begin{array}{l}\text { LTCCS Directly } \\
\text { Related Crashes }\end{array}$ \\
\hline $\begin{array}{l}\text { Stopped/Slowed due to Work } \\
\text { Zone }\end{array}$ & $\begin{array}{l}39.1 \% \\
(204)\end{array}$ & $\begin{array}{c}36.2 \% \\
(17)\end{array}$ & $\begin{array}{l}56.3 \% \\
(27)\end{array}$ \\
\hline $\begin{array}{l}\text { Changing Lanes due to Work } \\
\text { Zone }\end{array}$ & $\begin{array}{c}9.0 \% \\
(47)\end{array}$ & $\begin{array}{c}6.4 \% \\
(3)\end{array}$ & $\begin{array}{l}12.5 \% \\
(6)\end{array}$ \\
\hline $\begin{array}{l}\text { Avoiding Crash with Another } \\
\text { Vehicle or Animal }\end{array}$ & $\begin{array}{l}4.4 \% \\
(23)\end{array}$ & $\begin{array}{c}0.0 \% \\
(0)\end{array}$ & $\begin{array}{c}0.0 \% \\
(0)\end{array}$ \\
\hline $\begin{array}{l}\text { Entering/Exiting Work Zone } \\
\text { Vehicle from Work Zone }\end{array}$ & $\begin{array}{c}1.7 \% \\
(9)\end{array}$ & $\begin{array}{c}6.4 \% \\
(3)\end{array}$ & $\begin{array}{l}6.3 \% \\
(3)\end{array}$ \\
\hline $\begin{array}{l}\text { Limited Sight Distance due to } \\
\text { Work Zone }\end{array}$ & $\begin{array}{c}1.1 \% \\
(6)\end{array}$ & $\begin{array}{c}8.5 \% \\
(4)\end{array}$ & $\begin{array}{c}0.0 \% \\
(0)\end{array}$ \\
\hline Confused due to Work Zone & $\begin{array}{c}3.4 \% \\
(18) \\
\end{array}$ & $\begin{array}{l}4.3 \% \\
(2)\end{array}$ & $\begin{array}{l}0.0 \% \\
(0)\end{array}$ \\
\hline $\begin{array}{l}\text { Improper Work Zone Setup } \\
\text { or Conduct }\end{array}$ & $\begin{array}{l}1.9 \% \\
(10)\end{array}$ & $\begin{array}{c}2.1 \% \\
(1)\end{array}$ & $\begin{array}{c}6.3 \% \\
(3)\end{array}$ \\
\hline Inattention & $\begin{array}{c}4.2 \% \\
(22) \\
\end{array}$ & $\begin{array}{c}8.5 \% \\
(4)\end{array}$ & $\begin{array}{c}4.2 \% \\
(2)\end{array}$ \\
\hline Distracted by Work Zone & $\begin{array}{l}1.0 \% \\
(5)\end{array}$ & $\begin{array}{c}6.4 \% \\
(3)\end{array}$ & $\begin{array}{c}0.0 \% \\
(0)\end{array}$ \\
\hline $\begin{array}{l}\text { Disabled Vehicle Without } \\
\text { Shoulders }\end{array}$ & $\begin{array}{l}0.4 \% \\
(2)\end{array}$ & $\begin{array}{l}4.3 \% \\
(2)\end{array}$ & $\begin{array}{c}0.0 \% \\
(0)\end{array}$ \\
\hline Uneven Pavement & $\begin{array}{l}0.4 \% \\
(2)\end{array}$ & $\begin{array}{c}2.1 \% \\
(1)\end{array}$ & $\begin{array}{c}4.2 \% \\
(2)\end{array}$ \\
\hline Lost Control & $\begin{array}{c}13.0 \% \\
(68)\end{array}$ & $\begin{array}{c}10.6 \% \\
(5)\end{array}$ & $\begin{array}{l}8.3 \% \\
(4)\end{array}$ \\
\hline $\begin{array}{l}\text { Unauthorized Entry/Exit } \\
\text { Work Zone }\end{array}$ & $\begin{array}{c}1.9 \% \\
(10)\end{array}$ & $\begin{array}{l}2.1 \% \\
(1)\end{array}$ & $\begin{array}{c}0.0 \% \\
(0)\end{array}$ \\
\hline Reckless Driving & $\begin{array}{c}1.1 \% \\
(6)\end{array}$ & $\begin{array}{c}2.1 \% \\
(1)\end{array}$ & $\begin{array}{c}2.1 \% \\
(1)\end{array}$ \\
\hline Unknown & $\begin{array}{c}17.2 \% \\
(90)\end{array}$ & $\begin{array}{c}0.0 \% \\
(0)\end{array}$ & $\begin{array}{c}0.0 \% \\
(0)\end{array}$ \\
\hline
\end{tabular}

Chi-square tests performed between each dataset's crash cause distribution found that all three datasets had crash cause distributions that were significantly different from each other at an alpha $=0.05$ (Table 6.1). The chi-square value between the NMVCCS and LTCCS datasets was the lowest out of the three combinations. This suggests that either the more detailed datasets are revealing different causal trends than the more aggregate Virginia data, or perhaps the crash characteristics of Virginia work zone crashes differ from those in other states. 


\subsection{Similarities Among Datasets}

It is apparent that differences in data collection and recording are causing unique trends to emerge within each dataset's analysis. The next sections will discuss specific similarities and differences between specific trends within the datasets. Unlike the previous comparisons in this chapter, the following sections consider all severity levels for each dataset. This is done because 1) the LTCCS dataset is frequently omitted from the more detailed comparison analysis due to its small sample size and 2) removing NMVCCS PDO crashes from the dataset causes the NMVCCS dataset to be too small to produce useful comparisons with the Virginia dataset.

\subsubsection{Work Zone Crash Causes for All Severity Levels}

In all three datasets, stopping/slowing due to a work zone was the primary cause of rearend collisions. Nearly all of the stopping/slowing in this category was the result of congestion caused by the work zone. Reduced capacity due to lane closures, mobile/intermittent work zones, or lane shifts/crossovers is a likely contributor.

Beyond this crash cause, LTCCS crashes have too small a sample size to be meaningful. Therefore, only crash causes between the Virginia and NMVCCS dataset are discussed further. Changing lanes due to the work zone is another main crash cause of rear-end crashes in both the Virginia and NMVCCS dataset. This crash cause is also heavily influenced by congestion related to the work zone. Limited sight distance and confusion due to work zone are two main causes of angle crashes in both the Virginia and NMVCCS dataset. 
A noteworthy sideswipe - same direction crash cause in both datasets was a work zone vehicle entering/exiting the work zone. This is discussed later in the "Work Zone Vehicles" section. Finally, loss of control in fixed object - off road crashes was a primary crash cause between both dataset. While all of these crash causes ranked in the top three crash causes by crash type, each crash causes' percentage of Directly Related crashes varies. If the goal is to only identify the major crash causes in work zones, then the Virginia dataset provides some of the same results as the NMVCCS and LTCCS datasets. However, if accurate proportions or information about more minor crash causes are desired, the "Difference" section will illustrate that Virginia dataset and analysis does not provide equivalent results to NMVCCS's and LTCCS's more detailed datasets and rigorous analyses.

\subsubsection{First Object Hit: Jersey Barriers for All Severity Levels}

Work zone jersey barriers were the primary first object hit during fixed object - off road crashes in all three datasets. 58.2\% (274 crashes) of all Virginia fixed object - road crashes and $66.7 \%$ (10 crashes) of all NMVCCS fixed object - off road crashes struck a jersey wall as their first object hit. Only 20\% (1 crash) of all LTCCS fixed object - off road crashes struck a jersey wall first, but this finding is not meaningful due to the small sample size.

\subsubsection{Work Zone Vehicles for All Severity Levels}

A noteworthy percent of crashes in each dataset involved a work zone vehicle. Virginia, NMVCCS, and LTCCS crashes involving a work zone vehicle comprised 10.1\%, 14.3\%, and $16.7 \%$ of each datasets' Directly Related crashes, respectively (for all severity 
levels). Of these, vehicles entering/exiting a work zone was a primary issue in all three datasets. Of the seven NMVCCS and LTCCS work zone vehicle crashes involving a work zone vehicle entering/exiting the work zone, three crash narratives $(42.9 \%$ of crashes in this category) found the work zone vehicle driver at fault, while the other four found the work zone vehicle partially at fault. For the most part, fault could not be assigned in the Virginia dataset due to a lack of information.

\subsection{Differences Among Datasets}

\subsubsection{Work Zone Crash Causes for All Severity Levels}

While some of the same crash causes ranked in the top three in both the Virginia and NMVCCS datasets (discussed previously), their proportions differ from each other. Table 6.6 lists proportional statistics and crash counts for work zone crash causes from the Virginia and NMVCCS datasets by crash type for all severity levels. Proportions are given as percentages of all Directly Related crashes within a crash type. Only the most common crash causes per work zone type are listed below. LTCCS crash causes were not included because they have too small a sample size to be reasonably comparable.

The most prominent rear-end crash cause, stopping/slowing due to a work zone, comprised $76.4 \%$, and $61.5 \%$ of Virginia and NMVCCS Directly Related rear-end crashes, respectively (for all severity levels). This crash cause was also the LTCCS's most prominent rear-end crash cause. Approximately $68.6 \%$ (24 crashes) of LTCCS rearend crashes were the result of stopping/slowing due to the work zone. This is the only LTCCS crash cause containing a large enough sample size to merit mention. 
These and other crash cause proportional variations seen in Table 6.4 reinforce the chi-square crash cause distribution test results discussed earlier. The datasets' proportional differences could be due to NMVCCS's small sample size, less detailed information in the Virginia crash reports, or fundamental differences between work zone crash causes in Virginia and those in other states.

Table 6.4: Virginia and NMVCCS Crash Cause Distributions for All Severity levels

\begin{tabular}{|c|c|c|c|}
\hline Crash Type & Crash Cause & $\begin{array}{l}\text { Virginia Dataset } \\
(\%, \text { Count })\end{array}$ & $\begin{array}{l}\text { NMVCCS Dataset } \\
(\%, \text { Count })\end{array}$ \\
\hline \multirow{2}{*}{ Rear-end } & $\begin{array}{l}\text { Stopping/Slowing } \\
\text { due to the Work } \\
\text { Zone }\end{array}$ & $\begin{array}{l}76.4 \% \\
(519)\end{array}$ & $\begin{array}{l}61.5 \% \\
(24)\end{array}$ \\
\hline & $\begin{array}{l}\text { Changing lanes } \\
\text { due to the work } \\
\text { zone }\end{array}$ & $\begin{array}{c}22.5 \% \\
(58)\end{array}$ & $\begin{array}{l}10.3 \% \\
(4)\end{array}$ \\
\hline \multirow{2}{*}{ Angle } & $\begin{array}{l}\text { Limited sight } \\
\text { distance due to } \\
\text { work zone }\end{array}$ & $\begin{array}{l}11.9 \% \\
(19)\end{array}$ & $\begin{array}{l}40.0 \% \\
\quad(6)\end{array}$ \\
\hline & $\begin{array}{l}\text { Confusion or } \\
\text { distraction due to } \\
\text { work zone }\end{array}$ & $\begin{array}{c}21.3 \% \\
(34)\end{array}$ & $\begin{array}{l}33.3 \% \\
\quad(5)\end{array}$ \\
\hline $\begin{array}{c}\text { Sideswipe - Same } \\
\text { Direction }\end{array}$ & $\begin{array}{l}\text { Work zone vehicle } \\
\text { entering/ exiting } \\
\text { work zone }\end{array}$ & $\begin{array}{l}5.3 \% \\
(9)\end{array}$ & $\begin{array}{l}25.0 \% \\
(8)\end{array}$ \\
\hline \multirow{3}{*}{$\begin{array}{c}\text { Fixed Object }- \text { Off } \\
\text { Road }\end{array}$} & $\begin{array}{l}\text { Unknown, but } \\
\text { work zone device/ } \\
\text { barrier was struck }\end{array}$ & $\begin{array}{c}37.4 \% \\
(176)\end{array}$ & $\begin{array}{l}0 \% \\
(0)\end{array}$ \\
\hline & $\begin{array}{l}\text { Lost control, } \\
\text { struck work zone } \\
\text { device/ barrier }\end{array}$ & $\begin{array}{c}23.4 \% \\
(110)\end{array}$ & $\begin{array}{l}33.3 \% \\
(5)\end{array}$ \\
\hline & Uneven Pavement & $\begin{array}{c}1.9 \% \\
(9)\end{array}$ & $\begin{array}{l}11.8 \% \\
\text { (2) }\end{array}$ \\
\hline
\end{tabular}

Further, some crash causes ranked in the top three for one dataset and not for the others. The Virginia dataset contains a large number of Directly Related crashes with an “Unknown”, causality, particularly for fixed object - off road crashes. Conversely, the NMVCCS and LTCCS datasets contain zero crashes with an "Unknown" causality, meaning that all Directly Related crash causalities in these two datasets could be 
identified. This is attributed to the long detailed narrative that accompanied each NMVCCS/LTCCS crash report.

Lost control due to uneven pavement was a noteworthy crash causality in the NMVCCS and LTCCS datasets, but not in the Virginia dataset. It is possible that other states leave uneven pavement exposed more often. Alternatively, it could be that this crash cause category is not being effectively captured in the Virginia dataset. All 9 of the Virginia Directly Related uneven pavement crashes were identified using the crash narrative. Many Virginia crash narratives cited lost control as the crash cause but did not cite the reason the driver lost control. It is possible that some of these crashes could have been related to uneven pavement, causing the proportion of Virginia uneven pavement crashes to be misrepresented.

Thus, the Virginia dataset and analysis does not provide equivalent results to NMVCCS's and LTCCS's more detailed datasets and rigorous analyses. If the goal is to estimate accurate crash cause proportions either for cost benefit analysis, performance measurement, or for comparison against other datasets, then more detailed Virginia crash data will be required in order to produce more accurate results.

\subsection{Summary of Differences}

Proportional distributions between each dataset's Coded crashes, Directly Related crashes, Coded crashes identified as Directly Related crashes, work zone types, and crash causes are not similar for the most part. If only identification of major work zone crash causes is desired, then the Virginia dataset provides some of the same results as the NMVCCS and LTCCS datasets. However, if accurate proportions or information about 
more minor crash causes are desired, the Virginia dataset and analysis does not provide equivalent results to NMVCCS's and LTCCS's more detailed datasets and rigorous analyses.

Factors that may have contributed to these differences include NMVCCS and LTCCS datasets' small sample size or fundamental differences between work zone crash causes in Virginia and those in other states. However, most likely these disparities indicate inaccuracies within the Virginia dataset's due to its insufficient level of information. This could hinder proactive performance measure and countermeasure selection. Accurate work zone crash causal statistics are needed in order to effectively utilize performance measures and direct DOTs towards countermeasures that deserve priority and immediate attention. 


\section{CHAPTER 7: CONCLUSIONS AND RECOMMENDATIONS}

\subsection{Conclusions}

The analysis of work zone crashes from the Virginia database, the NMVCCS, and the LTCCS produced several major conclusions related to work zone crash causality.

1. Past research on work zone crash causality has primarily used coded crashes, and only examined high level trends in the data using pre-coded crash report data fields. Limited studies have attempted to determine crash causality or define precipitating events that led to the crash. This information is needed to define targeted safety countermeasures, and develop action plans that a DOT could execute to impact performance measures.

2. There are significant inconsistencies in the Virginia dataset between the number of crashes that occurred within the work zone (Coded crashes) and those that appear to have been actually influenced by the work zone (Directly Related crashes). Only $23.0 \%$ of Virginia Coded crashes were determined to be Directly Related crashes, meaning that the relationship between the work zone and crash cause was uncertain for the other $77 \%$. . Further, Virginia Coded and Directly Related crash type distributions were found to be significantly different for alpha $=0.05$. As a result, it is likely that some of the true crash trends in work zones have been masked in prior studies. Therefore, Directly Related crashes 
need to be determined in order to select the most effective countermeasures to deal with observed safety problems.

3. As previously mentioned, FHWA produced a primer (Ullman et al., 2011A) that suggested several work zone safety performance measures. A number of these performance measures rely on work zone crash data. This study has shown that use of Coded crashes could produce very different results from the use of Directly Related crashes. Without using Directly Related crashes, the following performance measures may false identify safety problem areas and/or misguide priorities for safety improvements.

- Number of fatal crashes per year or per project broken down by fatal, injury, and property damage only (PDO) crashes.

- Percent crashes of certain types, such as manner of collision (e.g., rear-end crashes) and/or contributing factors (e.g., DUI crashes, speeding).

- Percent change in crash rate or absolute change from the expected nonwork zone crash rate; possibly stratified by roadway, work zone type, or severity.

- Percent of projects that exceed an acceptable (pre-defined) crash rate in the work zone.

- Percent change in work zone crash costs from the expected no-work zone crash costs, using monetized crashes based on severity level 
4. Several Directly Related work zone crash causes in each of the four primary crash types (rear-end, angle, sideswipe - same direction, and fixed object - off road) were common across all datasets. Consistently observed rear-end crash causes included: stopping/ slowing due to the work zone and changing lanes due to the work zone. Prominent angle crash causes in each dataset included: confusion related to work zone setup or layout and limited sight distance due to work zone. Sideswipe - same direction crashes involving a work zone vehicle entering/exiting work zone were notable in all datasets. The most prominent fixed object - off road crash cause was loss of control of the vehicle.

5. Extracting Directly Related crashes and determining work zone crash causality from typical DOT databases is time-consuming and imprecise. Crash causal trends were sometimes difficult to identify in the Virginia dataset. Further, many Virginia Directly Related crash causes could not be identified due to insufficient information or a blank crash description. Conversely, the NMVCCS/LTCCS datasets contained sufficient information to identify the crash cause in all Directly Related crashes. However, these more detailed reports take about 15 times longer to extract information than the Virginia reports.

6. Crash type and crash cause proportions significantly varied between datasets. These differences are most likely the result of different levels of crash detail within the Virginia dataset and the NMVCCS/LTCCS datasets. 


\subsection{Recommendations}

Several recommendations are presented based on the analysis of the three datasets. The first series of recommendations focuses on countermeasure selection based on several common work zone crash causations identified across all three datasets.

Recommendations for Virginia work zone safety emphasis areas are also discussed.

Afterwards, recommendations on how VDOT can improve Virginia crash reports and work zone data collection are presented. These changes will increase the DOT's ability to identify and diagnose crash causes efficiently and accurately.

\subsubsection{Major Work Zone Crash Causes and Possible VDOT Corrective Actions}

Table 7.1 highlights several reoccurring crash causal trends that were prominent in the analysis of the Virginia, NMVCCS, and LTCCS datasets. The crash causes in Table 7.1 are directly related to DOT actions, so they merit further investigation since they would be logical issues for a DOT to address. 
Table 7.1: Summary of Significant Crash Causes Across Crash Types

\begin{tabular}{|c|c|c|c|}
\hline Crash Cause & $\begin{array}{l}\text { Virginia Crashes } \\
\text { Directly Related to } \\
\text { Work Zone }\end{array}$ & $\begin{array}{l}\text { NMVCCS } \\
\text { Crashes Directly } \\
\text { Related to Work } \\
\text { Zone } \\
\end{array}$ & $\begin{array}{l}\text { LTCCS Crashes } \\
\text { Directly Related } \\
\text { to Work Zone }\end{array}$ \\
\hline $\begin{array}{l}\text { Stop/Slowing due to work zone related } \\
\text { congestion }\end{array}$ & $\begin{array}{c}24.1 \% \\
(356)\end{array}$ & $\begin{array}{l}29.9 \% \\
(23)\end{array}$ & $\begin{array}{l}56.3 \% \\
(27)\end{array}$ \\
\hline Changing lanes due to work zone & $\begin{array}{l}15.5 \% \\
(229)\end{array}$ & $\begin{array}{c}6.5 \% \\
(5)\end{array}$ & $\begin{array}{c}12.5 \% \\
(5)\end{array}$ \\
\hline Involved work zone vehicle & $\begin{array}{c}10.1 \% \\
(149)\end{array}$ & $\begin{array}{c}14.3 \% \\
(11)\end{array}$ & $\begin{array}{c}16.7 \% \\
(8)\end{array}$ \\
\hline $\begin{array}{ll}- & \text { Work zone vehicle } \\
& \text { entering/exiting work zone }\end{array}$ & $\begin{array}{c}2.2 \% \\
(33)\end{array}$ & $\begin{array}{l}5.2 \% \\
(4)\end{array}$ & $\begin{array}{c}6.3 \% \\
(3)\end{array}$ \\
\hline Involved a flagman & $\begin{array}{c}4.9 \% \\
(73)\end{array}$ & $\begin{array}{c}5.2 \% \\
(4)\end{array}$ & $\begin{array}{l}10.4 \% \\
(5)\end{array}$ \\
\hline $\begin{array}{l}\text { Involved exceeding posted speed limit or } \\
\text { driving too fast for conditions }\end{array}$ & $\begin{array}{c}3.2 \% \\
(47)\end{array}$ & $\begin{array}{c}14.3 \% \\
(11)\end{array}$ & $\begin{array}{c}8.3 \% \\
(4)\end{array}$ \\
\hline Occurred at an Intersection & $\begin{array}{c}11.8 \% \\
(175)\end{array}$ & $\begin{array}{c}24.7 \% \\
(19) \\
\end{array}$ & $\begin{array}{l}0 \% \\
(0)\end{array}$ \\
\hline $\begin{array}{ll}- & \text { Limited sight distance due to } \\
\text { work zone }\end{array}$ & $\begin{array}{c}1.3 \% \\
(19) \\
\end{array}$ & $\begin{array}{c}7.8 \% \\
(6) \\
\end{array}$ & $\begin{array}{l}0 \% \\
(0) \\
\end{array}$ \\
\hline $\begin{array}{l}\text { - } \quad \text { Confusion due to work zone } \\
\text { setup or layout }\end{array}$ & $\begin{array}{l}3.0 \% \\
(44)\end{array}$ & $\begin{array}{l}3.9 \% \\
(3)\end{array}$ & $\begin{array}{l}0 \% \\
(0)\end{array}$ \\
\hline $\begin{array}{l}\text { Fixed Object - Off Road, First Object Hit: } \\
\text { Jersey Wall }\end{array}$ & $\begin{array}{l}18.5 \% \\
(274)\end{array}$ & $\begin{array}{c}13.0 \% \\
(10)\end{array}$ & $\begin{array}{l}2.1 \% \\
(1)\end{array}$ \\
\hline
\end{tabular}

By concentrating on these crash causes, a DOT has an opportunity to take corrective actions that could influence safety performance measures. Corrective actions to address this crash causes could likely show much more rapid improvements in crash performance measures than other measures that would rely on long-term changes to driver behavior, such as distracted driving campaigns. It is recommended that the VDOT Traffic Engineering Division review the findings of this study, and develop a strategic plan for addressing notable work zone crash causes. Examples of crash causes and possible corrective actions are discussed below:

- A large proportion of Directly Related crashes occurred during work zone related congestion. About $73.3 \%$ of the Virginia Directly Related crashes attributed to 
work zone related congestion (261 crashes) occurred on an interstate, and 57.0\% (203 crashes) during an interstate lane closure. This indicates that DOTs should continue to place a high priority on analysis and countermeasures to mitigate work zone congestion, particularly on interstates. Improved transportation management plan design would help address this issue. Other recommended countermeasures include: increased use of night work, improved incident management in the work zone to reduce the likelihood of secondary crashes, increased use of work zone intelligent transportation systems, use of queue warning systems, and driver education to reduce distracted driving.

- Approximately $15.5 \%, 6.5 \%, 12.5 \%$ of all Virginia, NMVCCS, and LTCCS Directly Related crashes, respectively, were attributed to changing lanes at a work zone. Logically, lane change and congestion related crashes are closely linked. Less congestion results in a greater number of gaps large enough to effectively merge. VDOT should consider additional advance warning mechanisms for lane closures (like additional changeable message signs), particularly in congested areas. Other mechanisms to improve merging operations near a work zone taper (like the late merge or early merge) are also valuable in targeting these crashes.

- About $4.9 \%, 5.2 \%, 10.4 \%$ of all Virginia, NMVCCS, and LTCCS Directly Related crashes, respectively, were related to flagger control. This implies a greater need to examine traffic control placement so that drivers are aware that they are approaching a flagger and a possible unexpected stop. Likewise, Virginia 
should re-visit flagger training and certification procedures and audit contractors that have an abnormally high number of flagger crashes.

- Work vehicles entering/exiting the work zone were also an issue. This points to a need to re-examine work zone access points and internal traffic control plan design. About 57.6\% (19 crashes) of these crashes in the Virginia dataset involved a shoulder or median work zone. In these cases, the work vehicle may be merging or diverging from a high-speed roadway, and additional attention should be paid to developing traffic control plans for ingress and egress from these sites. Work zone traffic management plans should be designed to consider work zone vehicle acceleration/deceleration space as well as work zone sight distance.

- Approximately $3.2 \%, 14.3 \%$, and $8.3 \%$ of all Virginia, NMVCCS, and LTCCS Directly Related crashes, respectively, were coded as either exceeding the posted speed limit or driving too fast for conditions. This points to a need to increase speed enforcement in work zones. Additional reduced speed signs, speed feedback signs, and police presence could all help to reduce vehicle speeds in work zones.

- Work zone confusion on primary/secondary roads was an issue. This indicates the need to improve marking/signing/delineation, especially on these facilities. These facilities have more access points than freeways, and navigation demands on 
drivers are often more difficult. Design of work zone traffic control on complex urban roads can be difficult, and more work zone training is recommended.

- Limited sight distance due to poor placement of work vehicles and equipment at intersections was noted as an issue for angle crashes. This should be a point of emphasis for work zone traffic control training.

- Work zone jersey barriers were the primary first object hit during fixed object off road crashes in all three datasets. Approximately $58.2 \%$ (274 crashes) of all Virginia fixed object - road crashes and 66.7\% (10 crashes) of all NMVCCS fixed object - off road crashes struck a jersey wall as their first object hit. In most cases, the jersey wall serves to either protect the workers from traffic or prevent a vehicle from entering the opposite flowing traffic lanes. Since jersey barriers are an effective and necessary form of preventing an even more severe crash, it is recommended to investigate methods for increasing clear zone spaces between the traffic and the jersey wall in order to mitigate the current number of crashes.

\subsubsection{Recommended Changes to the Virginia FR-300 Crash Report to Improve Work Zone Crash Analysis and Reporting}

As previously stated, there are limitations using the Virginia data. The NMVCCS and LTCCS provide a greater level of detail and increase the ease and accuracy of identifying crash causes. However, the level of detail in the NMVCCS and LTCCS is not practical to obtain on a large scale from a time or cost perspective. A higher degree of granularity in 
capturing work zone causal relationships is needed in the Virginia data, but improvements should not place an undue burden on the responding officer. Improvements in work zone crash data will prove valuable for Virginia's work zone safety countermeasure development and performance measurement programs.

A common concern within DOTs is that performance measures may reflect certain trends that are beyond a DOT's ability to control. By distinguishing between crashes that simply occurred within the work zone area from crashes influenced by the work zone, the DOT will have a performance measure that directly indicates items that could be impacted by improved DOT work zone safety programs. This finer grained data would need to be collected in a consistent and easy to use way in order to support the performance management program.

Minor changes to the current Virginia crash report will make this information readily available, reduce processing time required to obtain Directly Related crash data, and improve the precision and accuracy of work zone causal factor diagnosis. It is recommended that individual fields establishing the relationship of a crash to the work zone as well as the crash's primary cause be either added to the Virginia crash report or modified from current fields. These small changes do not requiring the time and effort investments of the NMVCCS and LTCCS and should not prove too onerous for responding police officers. Each field is described in more detail below and multiplechoice options for each field are recommended.

\subsubsection{Work Zone's Influence Field}

Currently, determining the level of influence a work zone had on a crash is time consuming and not straightforward. A simple change could be made to Virginia crash reports that would cause the Directly Related crashes to be readily available. This change 
involves empowering the responding police officer to judge and record a crash's relationship to the work zone. This would likely be more accurate than retrospective assessment based solely on the crash report information provided by the responding police officer. Further, this will most likely produce more accurate work zone analysis results then using all crashes that occurred in the work zone area (i.e., Coded crashes in this report).

The recommended adjustment to the crash report would involve changing the crash field titled: "Work Zone Related" to "Work Zone's Influence". The field would have four options/levels of influence for the officer to choose from:

1. Crash did not occur in a work zone area.

2. Crash occurred in a work zone area but was not influenced by the work zone.

3. Crash occurred in a work zone area and may have been influenced by some aspect of the work zone.

4. Crash occurred in a work zone area and was definitely influenced by some aspect of the work zone.

This change would allow Directly Related crashes to be easily separated from all other crashes occurring in a work zone. Further, crashes that were determined by the officer to have a definite relationship to the work zone could be given higher priority for effective countermeasure development. The field should also prompt the officer to include information in the narrative about the role of the work zone in the crash for all crashes receiving a \#3 or \#4 entry. Definitions of each multiple choice option which 
could be directly incorporated in the Virginia FR-300 crash report manual are given below.

Option \#1: This option should be selected for all crashes that did not occur in the MUTCD (2003) defined work zone area or in a work zone related queue (i.e., a queue caused by reduced roadway capacity related to the work zone, which extends past the MUTCD (2003) roadwork ahead sign). This will be the primary option selected for most crashes in Virginia.

Option \#2: These crashes occurring within the MUTCD (2003) defined work zone area but were not influenced by the work zone to any degree. Essentially, the crash cause was completely independent from the work zone. Examples of this are:

- A deer enters the travel lanes of a work zone. A vehicle strikes the deer, runs off road, and does not hit any work zone devices or barriers.

- The work zone is located on the shoulder of a roadway that routinely experiences peak hour congestion. A rear-end crash occurs related to vehicles stopping and slowing due to congestion. The current congestion is not influenced or increased by the work zone to any determinable degree.

- A work zone recently milled an intersection in preparation for resurfacing. Vehicle 1 failed to yield to oncoming traffic due to inattention and turned left into an oncoming vehicle. Signs of work zone activity were not present at the time of the crash and thus sight distance was not impaired and the drivers were not distracted by work zone activity. 
Option \#3: This option is for crashes that may have been influenced by the work zone to some degree but the level of influence is small or unknown. However, it is apparent that the work zone's presence has caused a change in the severity, outcome, or chain of events that led up to the crash. Examples of this are:

- A work zone removes a lane or reduced lane widths, which caused congestion to increase on the roadway. The crash is related to the presence of the congestion.

- A vehicle ran off road due to driver error and struck a traffic control device or temporary barrier that would not have been present if the work zone was not present. In this case the work zone may have affected the severity of the crash.

- A work zone required the removal of one or more permanent roadside devices, such as pavement striping, overhead lighting, or similar features that might have slightly altered the chain of event of a crash.

Option \#4: This option is for crashes that were definitely influenced by the work zone and its influence is obvious. For example, a direct influence would be if the traffic control plan was improperly laid out, a key traffic control device was missing, or if the traffic control was misleading to drivers, work zone vehicle was involved.

\subsubsection{Identify "Work Zone Crash Causality"}

Currently, work zone crash causality in Virginia can only be determined by manually reading through crash reports. This is a very time consuming processes and conclusions may not be able to be reached if insufficient information is provided. If crashes directly related to a work zone are determined by using the field "Influenced by Work Zone", 
discussed previously, then the number of crashes to sift through will be greatly reduced. However, this task may still require too much manpower.

In order to expedite collection of crash causality trends, it is recommended that a “Work Zone Crash Causality" field be added to states' crash reports. This field would have the most common crash causes as multiple-choice options. It is important that the number of choices in this field remain concise (no more than 15 options). Too many options in this field may overwhelm the responding officer who will most likely select from the first few in the list when filling out a crash report. This will lead to large errors in analysis results and cause the information generated from this field to be inaccurate and biased. Recommendations for multiple-choice options within this field are:

1. Stopping/ slowing due to work zone

2. Changing lanes due to work zone

3. Confusion related to work zone setup or layout

4. Distraction caused by work zone

5. Limited sight distance due to work zone

6. Work zone vehicle entering/exiting work zone

7. Avoiding crash with another vehicle or object

8. Backing Up

9. Inattention

10. Lost Control (elaborate in crash narrative)

11. Reckless Driving

12. Speeding

13. Other (elaborate in crash narrative) 


\section{Unknown}

This list focuses on broad crash categories. Information about more subtle crash causes (e.g. lost control due to uneven pavement) is still desired. Therefore, this field should instruct the responding police officer to select the high-level crash cause in this field but provide specific details in the crash narrative description.

\subsubsection{Recommendations for Future Research}

Several possible future research problems flow from the findings of this project. First, one limitation of using the NMVCCS and LTCCS is that the data from those efforts was collected in other states. Thus, the comparisons of these datasets to Virginia data are influenced by different underlying source data. It would be ideal to conduct a study similar to the NMVCCS and LTCCS, but focused on Virginia crashes to have a consistent comparison base. Even though the sample size would be smaller, the study would yield more detailed crash reports, capture subtler crash causes, and be directly comparable to the results in Chapter 4: Virginia Data Analysis. Such a study would 1) more accurately highlight Virginia crash data collection problems and inconsistencies and 2) provide more accurate and reliable statistics to use for countermeasure cost/benefit analysis and before/after study analysis.

It is also recommended that multiple long-term work zones be exclusively studied in Virginia. This would entail thorough documentation of work zone layout, duration, activity periods, and crashes occurring while the work zone is present. This information would provide exposure levels for work zone type, time of day, and facility type as well 
as capture the work zone's level of influence on the crash and detailed information about the crash cause. This information could be compared to crashes occurring before and after the work zone was erected as well as to general work zone trends found across the state.

Currently, work zone exposure levels are mostly unknown. Better information about the number of work zones, work zone vehicle miles traveled (VMT), and work zone duration is needed in order to effectively normalize the analysis presented in this thesis, most notably work zone type and facility type proportions. Additionally, this research would allow crash cause trends to be examined by work zone durations. It is possible that long-term work zones exhibit different crash trends than short-term work zones.

It is recommended that VDOT examine the impact of enacting targeted safety programs to address specific work zone causal factors identified in the study. Assessing the impacts of safety treatments and changes in crash trend proportions will indicate successful countermeasures, which can be extended to other states.

Further, it is recommended that a study be conducted utilizing the Naturalistic Driving Study data collected by Virginia Tech to examine crash and near crash behavior at work zones. Although this dataset would be small, the video and vehicle trajectory data could be mined to better understand causality. This data source could provide even greater levels of detail beyond those seen in the NMVCCS's and LTCCS's crash reports.

Lastly, DOTs should consider how work zone crash data collection could be integrated with and enhanced by connected vehicle technology. Obtaining information from vehicle on board equipment could enhance the amount of work zone crash data 
available and reduce the role of the police officer in the recording process. In order for connected vehicle technology to be effective, DOTs will need detailed work zone exposure data. Work zone location as well as the start and end points of each work zone area (i.e., transition, buffer, activity, termination areas) need to be electronically available to cross-reference against the connected vehicle information. If such information was available and connected vehicle technology was installed in every vehicle, then work zone crash data collection would be more accurate than if it was captured by a police officer or researcher. It could also reduce the amount of manpower needed to record and analyze the crash. DOTs should begin to consider the work required to ensure that systems are set up in manner to support future connected vehicle work zone applications. 


\section{REFERENCES}

Akepati, S., and S. Dissanayake. Characteristics of Work Zone Crashes. Presented at $1^{\text {st }}$ T\&DI Congress, Chicago, Illinois, 2011, pp. 1286-1295.

American Association of State Highway and Transportation Officials (AASHTO). A Policy on Geometric Design of Highways and Streets, $6^{\text {th }}$ Edition. American Association of State Highway and Transportation Officials, 444 N Capitol St. NW - Suite 249 Washington, DC 20001, 2011.

American Association of State Highway and Transportation Officials (AASHTO). Highway Safety Manual (HSM). Pub Code: HSM-1. American Association of State Highway and Transportation Officials, 444 N Capitol St. NW - Suite 249 - Washington, DC 20001, 2010.

Antonucci, N. D., Hardy, K. K., Bryden, J. E., Neuman, T. R., Pfefer, R., and Slack, K. Guidance for Implementation of the AASHTO Strategic Highway Safety Plan, Volume 17: A Guide for Reducing Work Zone Collisions. NCHRP Report 500. Transportation Research Board, National Research Council, Washington, D.C., 2005.

Arditi, D., D. Lee, and G. Polat. Fatal Accidents in Nighttime vs. Daytime Highway Construction Work Zones. Journal of Safety Re- search, Vol. 38, Issue 4, 2007, pp. 399 405.

Bai, Y. and Y. Li. Determining Major Causes of Highway Work Zone Accidents in Kansas. Final Report No. K-TRAN: KU-05-01, the University of Kansas, Lawrence, Kansas, 2006.

Bai, Y. and Y. Li. Determining Major Causes of Highway Work Zone Accidents in Kansas (Phase 2). Final Report No. K-TRAN: KU-06-01, the University of Kansas, Lawrence, Kansas, 2007.

Bellis, E. and J. Page. National Motor Vehicle Crash Causation Survey (NMVCCS): SAS Analytical Users Manual. Report No. DOT HS 811 053. US Department of Transportation, National Highway Traffic Safety Administration, 1200 New Jersey Avenue SE, Washington, DC 20590. December 2008. Accessible at: http://wwwnrd.nhtsa.dot.gov/Pubs/811053.pdf

Bourne, J. S., C. Eng, G. L. Ullman, D. Gomez, T. A. Scriba, R. D. Lipps, D. L. Markow, K. C. Matthews, D. L. Holstein, and R. Stargell. Best Practices in Work Zone Assessment, Data Collection, and Performance Evaluation. NCHRP Project 20-68A, Scan 08-04. Transportation Research Board, National Research Council, Washington, DC, 2010. Accessible at http://onlinepubs.trb.org/onlinepubs/nchrp/docs/NCHRP2068A_08-04.pdf.

Daniel, J., K. Dixon, and D. Jared. Analysis of Fatal Crashes in Georgia Work zones. In 
Transportation Research Record: Journal of the Transportation Research Board, No. 1715, Transportation Research Board of the National Academies, Washington, D.C., 2000, pp. 18-23.

Department of Motor Vehicles (DMV). Virginia State Crash Report Training Manual. FR300M. 2014. Accessible at:

http://www.dmv.state.va.us/safety/pdf/crash_report_instruction.pdf

Fatality Analysis Reporting System (FARS), NHTSA (2014). http://wwwfars.nhtsa.dot.gov/Main/index.aspx. Accessed November 17, 2014.

Federal Highway Administration (FHWA). Facts and Statistics - Work Zone Activity. U.S. Department of Transportation, Federal Highway Administration, Work Zone Safety and Mobility Program. September 2013. Accessible at:

http://www.ops.fhwa.dot.gov/wz/resources/facts_stats/activity.htm

Federal Highway Administration (FHWA). Selecting Useful Work Zone Performance Measures. U.S. Department of Transportation, Federal Highway Administration, Work Zone Safety and Mobility Program. December 2013. Accessible at: http://www.ops.fhwa.dot.gov/wz/resources/publications/fhwahop11033/select_measures. htm

Federal Highway Administration. Manual on Uniform Traffic Control Devices (MUTCD): 2003 Edition. U.S. Department of Transportation, Government Printing Office, Superintendent of Documents, P.O. Box 371954, Pittsburgh, PA 15250, 2003.

Garber, N. J. and Zhao, M. Crash Characteristics at Work Zones. Research Report VTRC 02-R12, Virginia Transportation Research Council, Charlottesville, Virginia, 2002.

Harb, H., Radwan, E., Xuedong, Y., Pande, A., Abdel-Aty, M. Freeway Work-Zone Crash Analysis and Risk Identification Using Multiple and Conditional Logistic Regression. Journal of Transportation Engineering, 2008, pp. 203-214.

Hughes, R.G., Stewart, R., Rodgman, E., Martel, C., Pein, W., and Lewis, L. Large Trucks Involved in Fatal Crashes: The North Carolina Data 1993-1997. Submitted to: The North Carolina Governor's Highway Safety Program. The University of North Carolina Highway Safety Research Center, Chapel Hill, NC, 1999.

Khattak, A. J., A.J. Khattak, and F. M. Council. Effects of Work Zone Presence on Injury and Non-injury Crashes. Accident Analysis and Prevention, Vol. 34, No. 1, 2002, pp. 1929.

Khattak, A., and F. Targa. Injury Severity and Total Harm in Truck-Involved Work Zone Crashes. Submitted for Publication to: Journal of the Transportation Research Board, Transportation Research Board of the National Academies, Washington, D.C., 2004. 
Lindly, J., J. McFadden, J. Chambless, A. Ghadiali. Development of a Short Course for Enhancements to the Design of Work Zones. UTCA Report No. 00107, University of Alabama, Tuscaloosa, Alabama, 2000.

Lindly, J., S. Noorjahan, and S. Hill. Identification of Potential Enhancements for Work Zone Safety in Alabama. UTCA Report Number 00465, University Transportation Center for Alabama, Tuscaloosa, Alabama, 2002.

Maze, T., A. Kamyab, and S. Schrock. Evaluation of Work Zone Speed Reduction Measures. CTRE Management Project Number 99-44, Center for Transportation Research and Education, Iowa State University, IA, 2000.

National Automotive Sampling System (NASS). National Motor Vehicle Crash Causation Study (NMVCCS) Case Viewer. NHTSA. US Department of Transportation, National Highway Traffic Safety Administration, 1200 New Jersey Avenue SE, Washington, DC 20590, 2014. Accessible at: http://wwwnass.nhtsa.dot.gov/nass/nmvccs/SearchForm.aspx

National Automotive Sampling System (NASS). Large Truck Crash Causation Study (LTCCS) Case Viewer. US Department of Transportation, National Highway Traffic Safety Administration, 1200 New Jersey Avenue SE, Washington, DC 20590, 2014. Accessible at: http://www-nass.nhtsa.dot.gov/nass/ltccs/SearchForm.aspx

National Highway Traffic Safety Administration (NHTSA). National Motor Vehicle Crash Causation Survey Report to Congress. Report No. DOT HS 811 059. US Department of Transportation, National Highway Traffic Safety Administration, 1200 New Jersey Avenue SE, Washington, DC 20590. July 2008. Accessible at: http://www.thenewspaper.com/rlc/docs/2008/us-crashcause.pdf

NHTSA's National Center for Statistics and Analysis. The National Motor Vehicle Crash Causation Survey: Traffic Safety Facts, Research Note. Report No. DOT HS 811 057. US Department of Transportation, National Highway Traffic Safety Administration, 1200 New Jersey Avenue SE, Washington, DC 20590. December 2008. Accessible at: http://www-nrd.nhtsa.dot.gov/Pubs/811057.pdf

Pigman, J. G., and K. R. Agent. Analysis of Accidents in Construction and Maintenance Work Zones. Transportation Research Record 1270, Transportation Research Board, National Research Council, Washington, D.C., 1990, pp. 12-21.

Qin, X., Y. Chen, and D. Noyce. Anatomy of Wisconsin Work Zone Crashes. Presented at ITE Annual Meeting and Exhibit, Pittsburgh PA, 2007, pp. 1-19.

Rouphail, N. M., Z. S. Yang, and J. Frazio. Comparative Study of Short- and Long-Term Urban Freeway Work Zones. Transportation Research Record, Journal of the 
Transportation Research Board, No. 1163, Transportation Research Board, Washington, D.C., 1988, pp. 4-14.

Schrock, D. S., Ullman, G. L., Cothron, A. S., Kraus, E., and Voigt, A. P. An Analysis of Fatal Work Zone Crashes in Texas. Report FHWA/TX-05/0-4028-1, FHWA, U.S.

Department of Transportation, 2004.

Starnes, M., Large-Truck Crash Causation Study: An Initial Overview. Report No. DOT HS 810 646. US Department of Transportation, National Highway Traffic Safety Administration, 1200 New Jersey Avenue SE, Washington, DC 20590. August 2006. Accessible at: http://www-nrd.nhtsa.dot.gov/Pubs/810646.pdf

Swansen, E., M. Knodler, and J. Kennedy. An Analysis of Linked Crash and Citation Data for use in Determining Causation for Work Zone Crashes. Presented at 91st Annual Meeting of the Transportation Research Board, Washington, D.C., 2012.

Toth, G. R., G. A. Radja, K. K. Thiriez, and J. S. Carra. Large Truck Crash Causation Study in the United States. National Highway Traffic Safety Administration United States of America, 2003, Paper Number 252.

Ullman, G. L. and R.A. Krammes. (1991). Analysis of Crashes at Long-Term Construction Projects in Texas. Report FHWA/TX-90/1108-2, FHWA, U.S. Department of Transportation. 1990.

Ullman, G. L. and A. J. Holick, T. A. Scriba, and S. M. Turner. Estimates of Work Zone Exposure on the National Highway System in 2001. Transportation Research Record: Journal of the Transportation Research Board, No. 1877, Transportation Research Board of the National Academies, Washington, D.C., 2004, pp. 62-68.

Ullman, G., M. Finley, J. Bryden, R. Srinivasan, and F. Council. Traffic Safety Evaluation of Daytime and Nighttime Work Zones. Final Report on NCHRP Project, 1730, Transportation Research Board of the National Academies, Washington, D.C., 2008.

Ullman, G. L., T.J. Lomax, and T. Scriba. A Primer on Work Zone Safety and Mobility Performance Measurements. FHWA-HOP-11-033. FHWA, U.S. Department of Transportation, 2011.

Ullman, G., T. Lomax, and F. Ye. Work Zone Performance Measures Pilot Test. Publication FHWA-HOP-11-022. FHWA, U.S. Department of Transportation, 2011.

U.S. Department of Transportation Federal Motor Carrier Safety Administration (U.S. DOT FMCSA). Report to Congress on the Large Truck Crash Causation Study. National Technical Information Service, Springfield, Virginia 22161. November 2005. Accessible at:

http://www.dallasnews.com/sharedcontent/dws/spe/2006/roadhazards/pdfs/day1/fmcsa_st udy.pdf 
Walker, V., and J. Upchurch. Effective Countermeasures to Reduce Accidents in Work Zones. Report FHWA-AZ99-467, Department of Civil and Environmental Engineering, Tempe, AZ, 1999. 